
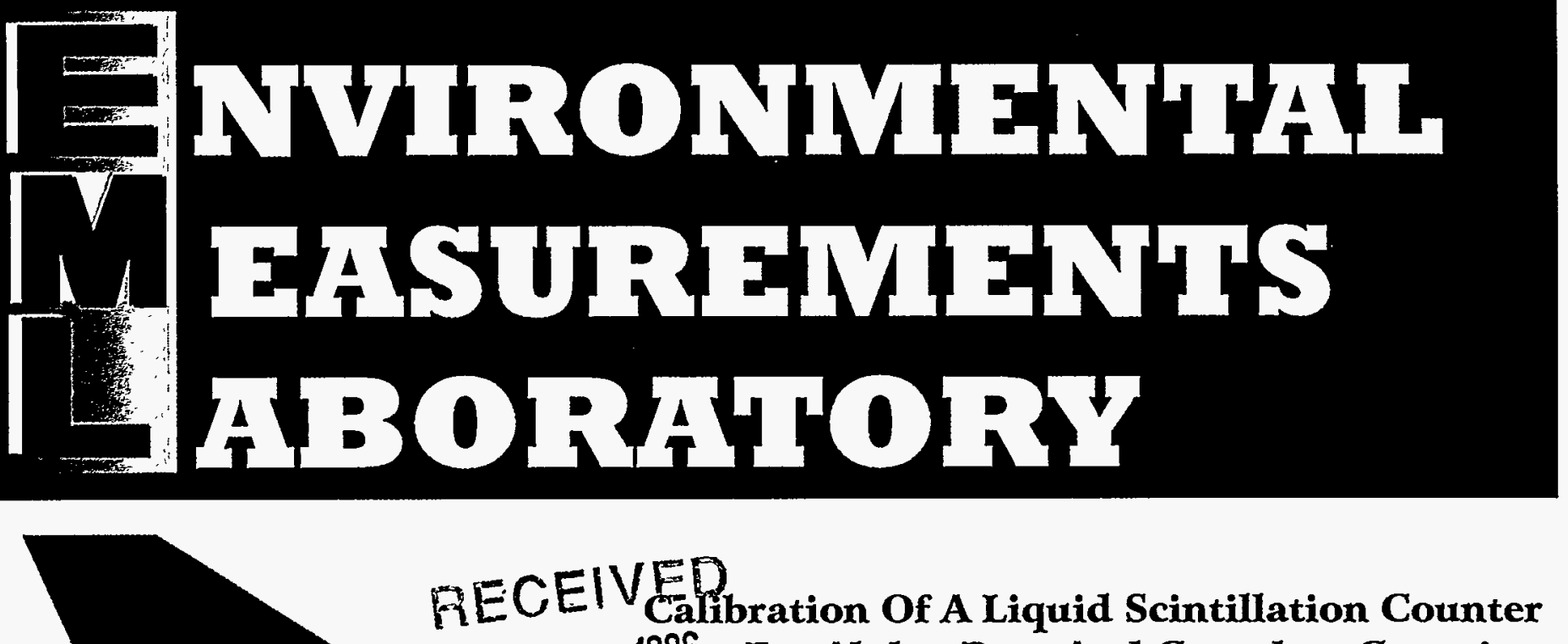
SEP 101996 For Alpha, Beta And Cerenkov Counting
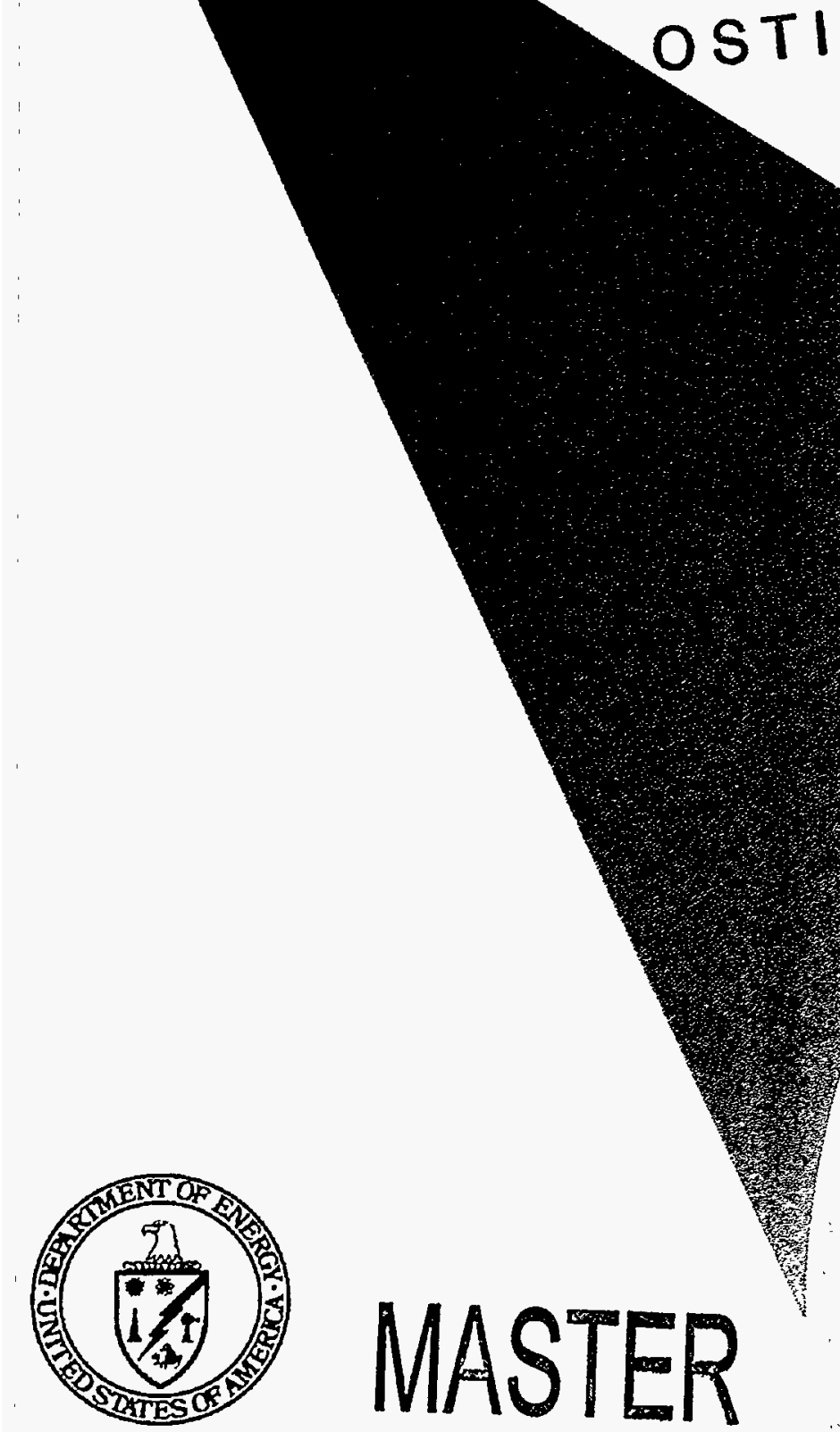

Salvatore C. Scarpitta \& Isabel M. Fisenne 
EML-583

\title{
CALIBRATION OF A LIQUID SCINTILLATION COUNTER FOR ALPHA, BETA AND CERENKOV COUNTING
}

\author{
Salvatore C. Scarpitta \\ and \\ Isabel M. Fisenne

\section{Environmental Measurements Laboratory \\ U.S. Department of Energy \\ New York, NY 10014-4811}

July 1996

\section{DISCLAMMER}

"This report was prepared as an account of work sponsored by an agency of the United States Government. Neither the United States Government nor ang agency thereof, nor any of their employees, makes any warranty, express or implied, or assumes any legal liability or responsibility for the accuracy, completeness, or usefulness of ang information, apparatus, product, or process disclosed, or represents that its use would not infringe privately owned rights. Reference herein to any specific commercial product, process, or service by trade name, trademark, manufacturer, or otherwise, does not necessarily constitute or imply its endorsement, recommendation, or favoring by the United States Government or any agency thereof. The views and opinions of authors expressed hercin do not necessarily state or reflect those of the United States Government or any agency thereof."

This report has been reproduced directly from the best available copy.

Available from the National Technical Information Service, U.S. Department of Commerce, 5285 Port Royal Road, Springfield, Virginia 22161.

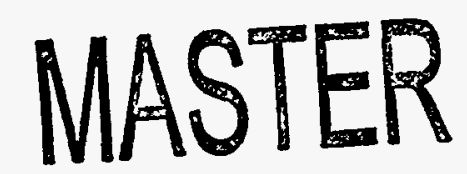




\section{DISCLAIMER}

Portions of this document may be illegible in electronic image products. Images are produced from the best available original document. 


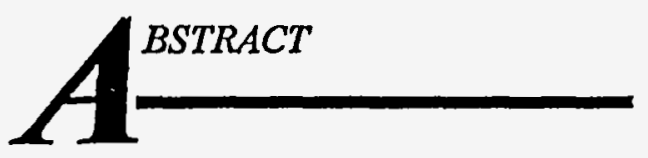

Calibration data are presented for 25 radionuclides that were individually measured in a Packard TriCarb 2250CA liquid scintillation (LS) counter by both conventional and Cerenkov detection techniques. The relationships and regression data between the quench indicating parameters and the LS counting efficiencies were determined using microliter amounts of tracer added to low ${ }^{40} \mathrm{~K}$ borosilicate glass vials containing $15 \mathrm{~mL}$ of Insta-Gel XF scintillation cocktail. Using ${ }^{40} \mathrm{~K}$, the detection efficiencies were linear over a three order of magnitude range $(10-10,000 \mathrm{mBq})$ in beta activity for both LS and Cerenkov counting. The Cerenkov counting efficiency (CCE) increased linearly ( $42 \%$ per MeV) from 0.30 to $2.0 \mathrm{MeV}$, whereas the LS efficiency was $>90 \%$ for betas with energy in excess of $0.30 \mathrm{MeV}$. The CCE was $20-50 \%$ less than the LS counting efficiency for beta particles with maximum energies in excess of $1 \mathrm{MeV}$. Based on replicate background measurements, the lower limit of detection (LLD) for a 1-h count at the $95 \%$ confidence level, using water as a solvent, was 0.024 counts $\mathrm{sec}^{-1}$ and 0.028 counts sec $\mathrm{s}^{-1}$ for plastic and glass vials, respectively. The LLD for a 1-h-count ranged from 46 to $56 \mathrm{mBq}(2.8-3.4 \mathrm{dpm})$ for both Cerenkov and conventional LS counting. This assumes: 1) a 100\% counting efficiency, 2) a $50 \%$ yield of the nuclide of interest, 3) a 1-h measurement time using low background plastic vials, and 4) a $0-50 \mathrm{keV}$ region of interest. The LLD is reduced an order of magnitude when the yield recovery exceeds $90 \%$ and a lower background region is used (i.e., $100-500 \mathrm{keV}$ alpha region of interest). Examples and applications of both Cerenkov and LS counting techniques are given in the text and appendices. 


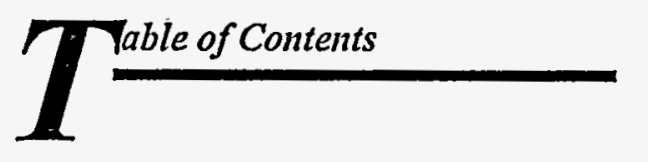

Pages

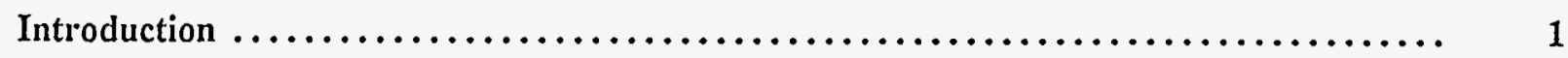

The Liquid Scintillation Process $\quad \ldots \ldots \ldots \ldots \ldots \ldots \ldots \ldots \ldots \ldots \ldots \ldots \ldots \ldots \ldots \ldots$

Description of the Liquid Scintillation System $\ldots \ldots \ldots \ldots \ldots \ldots \ldots \ldots \ldots \ldots \ldots \ldots \ldots$

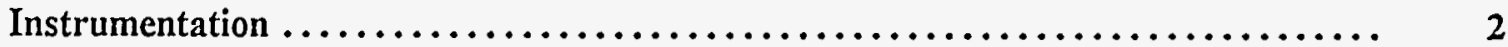

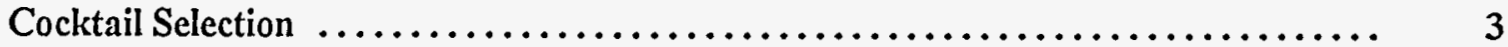

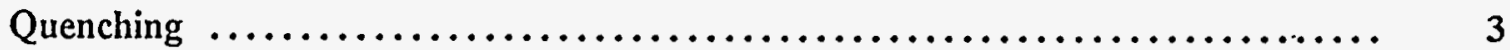

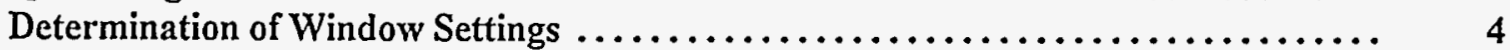

Instrument Background and Lower Limit of Detection $\ldots \ldots \ldots \ldots \ldots \ldots \ldots \ldots \ldots . . \ldots$

Unquenched Detection Efficiencies for Alpha and Beta Emitters $\ldots \ldots \ldots \ldots \ldots \ldots \ldots \ldots$

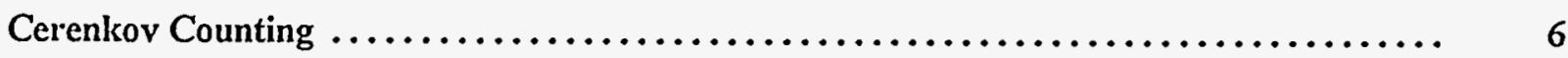

Energy Calibration Curves for Cerenkov Counting $\ldots \ldots \ldots \ldots \ldots \ldots \ldots \ldots \ldots \ldots$

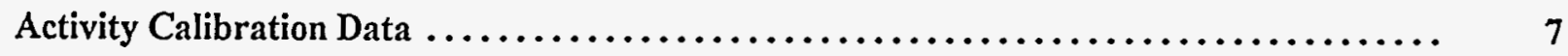

Beta and Gamma Emitting Nuclides $\ldots \ldots \ldots \ldots \ldots \ldots \ldots \ldots \ldots \ldots \ldots \ldots \ldots \ldots \ldots$

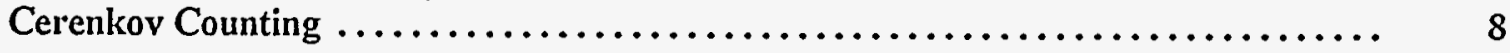

Calibration of Liquid Scintillation for Quenching $\ldots \ldots \ldots \ldots \ldots \ldots \ldots \ldots \ldots \ldots$

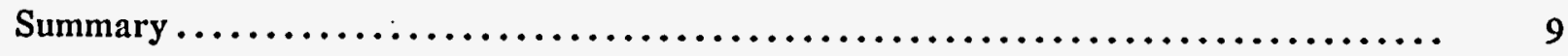

References $\ldots \ldots \ldots \ldots \ldots \ldots \ldots \ldots \ldots \ldots \ldots \ldots \ldots \ldots \ldots \ldots \ldots \ldots \ldots \ldots \ldots \ldots \ldots \ldots$

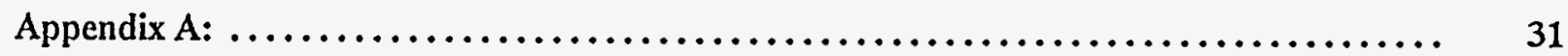

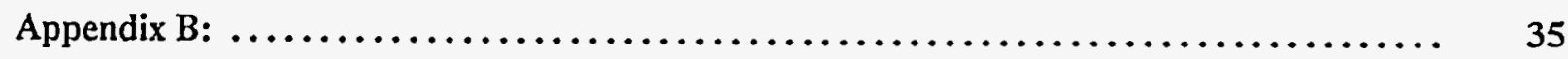

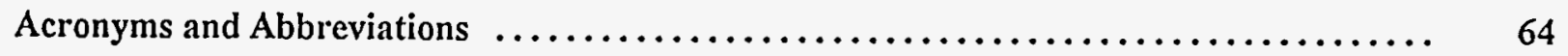




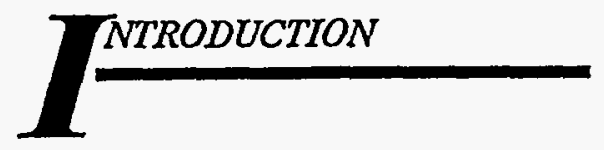

Liquid scintillation (LS) counting systems are designed to detect low energy (e.g., ${ }^{3} \mathrm{H},{ }^{14} \mathrm{C}$ ) to high energy beta particles (i.c., ${ }^{90} \mathrm{Y},{ }^{106} \mathrm{Rh}$ ), and alpha particles. Samples containing mixtures of radionuclides that emit alpha and beta particles, conversion electrons or Auger electrons can be detected and quantified using variations of the LS counting technique. Depending on the LS cocktail (i.e., scintillator-solvent mixture), the alpha detection efficiency is generally $>95 \%$, whereas the beta detection efficiency is dependent on energy, spectral shape and cocktail. Typically, beta particles with maximum energies $\left(E_{\max }\right)>0.250 \mathrm{MeV}$ are detected with $>90 \%$ counting efficiency.

Õne variation of the LS counting technique is Cerenkov counting, an adjunct to LS counting, which does not require a LS cocktail. Cerenkov counting in aqueous samples is applicable to beta particles with endpoint energies $>0.263 \mathrm{MeV}$. The Cerenkov counting efficiency (CCE) is typically $40 \%$ per MeV for beta particles with endpoint energies above the Cerenkov threshold. Alpha particles are not detected in pure aqueous solutions unless an additive is used to enhance the detection counting efficiency.

Studies were conducted at the Environmental Measurements Laboratory (EML) to determine which radionuclides could be measured by Cerenkov counting with a commercially available Packard Tri-Carb CA-2250 spectrometer. The primary objectives of this study were: 1) to compare the CCEs to those obtained using conventional LS counting technique; 2) Establish efficiency versus $\beta$ energy calibration curves for both LS and Cerenkov counting; and 3) determine the lower limit of detection (LLD) of the spectrometer for Cerenkov counting using both glass and plastic vials.

Twenty five nuclides were included in this study to establish a data base that could be used to quickly determine the expected $\mathrm{CCE}$ of other nuclides using Cerenkov counting techniques. Examples and applications of these techniques are given in the text and appendices of this report.

\section{MHE LIQULD SCINTILLATION PROCESS}

Liquid scintillation counting is one of several detection methods that may be utilized to quantitate alpha or beta emitting radionuclides in a liquid medium. The liquid medium consists of a solvent and organic scintillators that convert the energy absorbed by charged particles into light that is detectable by the LS analyzer. Alpha decay results in the emission of a charged helium nucleus ${ }^{4} \mathrm{He}_{2}$ (composed of two neutrons and two protons). Most alpha emitters are in the range of $3-9 \mathrm{MeV}$, but appear in the LS spectra at about $100-600 \mathrm{keV}$ because of their reduced photon yield, as compared to beta particles. For alpha particles in a scintillating cocktail, one photon of light is produced per keV of decay energy.

$$
{ }^{A} X_{Z} \Longrightarrow{ }^{A-4} Y_{Z-2}+{ }^{4} \mathrm{He}_{2}^{+2}+\text { Decay Energy }
$$

where $\mathrm{A}$ is the atomic number and $\mathrm{Z}$ is the number of protons.

Beta decay is characterized by electrons with either a positive (positron) or negative (negatron) charge that are emitted with a continuum of energy ranging from $0-2500 \mathrm{keV}$. The energy continuum 
results from the sharing of energy by both beta particle and the anti-neutrino (v). For beta particles (or positrons) in a LS cocktail, 10 photons of light are produced per keV of beta decay energy.

$$
\begin{aligned}
& \text { Negatron: } \quad{ }^{\mathrm{A}} \mathrm{X}_{\mathrm{Z}} \Longrightarrow{ }^{\mathrm{A}} \mathrm{Y}_{\mathrm{Z}+1}+\mathrm{B}^{-}+\mathrm{y}+\text { Decay Energy } \\
& \text { Positron: } \quad{ }^{\mathrm{A}} \mathrm{X}_{\mathrm{z}} \Longrightarrow{ }^{\mathrm{A}} \mathrm{Y}_{\mathrm{Z}-1}+\mathrm{B}^{+}+\mathrm{v}+\text { Decay Energy }
\end{aligned}
$$

Gamma radiation, which is electromagnetic radiation, originates from the nucleus. In some modes of alpha, beta and electron capture (EC), a daughter nucleus in an excited state may liberate its energy over a 0.5 to $2.0 \mathrm{MeV}$ range. Examples of spectra from each of the above decay processes are shown in. Figure 1 for ${ }^{222} \mathrm{Rn},{ }^{14} \mathrm{C}$ and ${ }^{125} \mathrm{I}$.

Typically, a radionuclide is introduced into a scintillation cocktail that is composed of: 1) a solvent, 2) organic scintillators, and 3) an emulsifier. The solvent can be water or an organic liquid. The organic scintillators in the cocktail (see Figure 2) convert the decay energy into fluorescent light of $350-400 \mathrm{~nm}$ and $450 \mathrm{~nm}$, respectively.' The sensitive region of the photomultiplier tube (PMT) is about $450-500 \mathrm{~nm}$. The light intensity (photons of light per $\mathrm{keV}$ ) depends on the type of radiation and the energy of the nuclear decay. The number of light pulses, recorded as counts per minute (cpm), is proportional to activity (dpm).

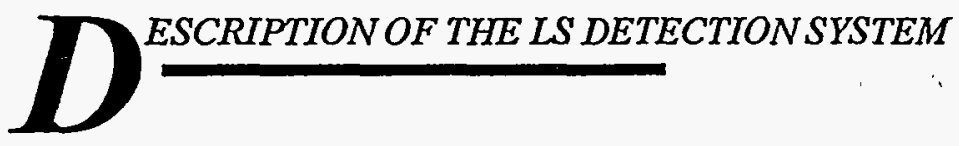

\section{INSTRUMENTATION}

EML's Packard Tri-Carb-2250CA LS instrument is a multitasker unit for quantitative detection of alpha, beta, positron, and conversion electron radiation. The system may be preprogrammed to select any of 15 unique programs stored on computer disk. The instrument can be operated in one of three counting modes. The first and most often used is conventional LS counting, where the user presets a window or region of interest (ROI) where counts per unit time (cpm) are obtained. Two alternative counting modes are dual-dpm and full spectrum analysis (FSA) (Fujii and Takiue, 1988). Both dual-dpm and FSA modes are for samples that contain two emitters of different energy (i.e., ${ }^{55} \mathrm{Fe} /{ }^{59} \mathrm{Fe},{ }^{95 \mathrm{~m}} \mathrm{Tc} /{ }^{99} \mathrm{Tc}$, and ${ }^{85} \mathrm{Sr} /{ }^{90} \mathrm{Sr}$. Counts are obtained and converted automatically to dpm. The system provides computer controlled data reduc-tion of counting results after each sample or after every batch of samples identified by the user. When using either the dual-dpm or FSA mode, calculations are performed internally by the LS software and require two separate calibration (i.e., quench) curves, one for each of the two emitting components.

The scintillation detector well is located underneath the sample changer. Samples are automatically lowered into the detector well. The detector assembly consists of two facing bi-alkali high performance PMTs, operated in a coincidence counting mode. The shielding assembly consists of a light-tight detection chamber, magnetic shielding and $5 \mathrm{~cm}$ of lead to reduce external radiation.

Spectral analysis is the basis of the Packard LS system. Typically, a beta particle will take a few nanoseconds to dissipate all its energy in the scintillation solution, whereas energy dissipation for an alpha particle is considerably longer. The scintillation process, resulting from energy dissipation and photon production, results in an analog pulse rising to its maximum amplitude and falling to zero. The 
amplitude of the analog pulse is converted to a digital value. The conversion is achieved in a high speed analog-to-digital converter (ADC), and the digital value, which represents the beta particle energy, is an address on the memory slot of a $0-2000 \mathrm{keV}$ spectrum analyzer. The conversion by the ADC is linear over the full-energy window so that during the measurement of a sample, the spectrum analyzer will accumulate counts representing the complete energy spectrum of the radionuclide. The spectrum analyzer is calibrated in units of $\mathrm{keV}$ and the user can select three ROI's over a range of $0-2000 \mathrm{keV}$.

\section{COCKTAIL SELECTION}

Standard scintillator cocktails for alpha and beta counting applications employ solvents such as xylene, pseudocumene, toluene, benzene, alkylbenzenes or DIN (di-isopropyl naphthalene) (see Figure $2 a$ ). Additives (see Figures $2 b$ and $2 c$ ) such as bis-MSB, PPO, POPOP, PPD, and naphthalene are added to increase the efficiency of the transfer of energy from the solvent to the fluor or to offer better alpha/beta spectral separation in a sample. The selection of a suitable cocktail for a specific radionuclide is based on several factors that may include: 1) optimum counting efficiency, 2) minimum background, 3) load volume (ratio of sample volume to scintillator volume), 4) biodegradability of the cocktail, and 5) ability to separate alpha from beta energy regions.

For most applications, EML utilizes a commercially available xylene free (XF) scintillant, Insta-GelXF (psuedocumene + PPO and bis MSB) or equivalent, that can accept $50 \%$ of its volume as water. According to the manufacturer, the cocktail is biodegradable. The data presented in this report are for Insta-Gel-XF only, and are not representative of other commercially available cocktails (Klein and Gershey, 1990).

\section{QUENCHING}

Quenching refers to interferences with any of the steps of energy transfer from the solvent (where most of the energy from the ionizing radiation is initially deposited) to the scintillant and subsequent light transmission to the PMT. When a sample is quenched, the spectrum is usually shifted toward the lower energy regions resulting in an increase in counts (i.e., apparent increase in counting efficiency) in any low energy preset ROI. Efficiency is defined as the ratio of the observed count rate (cpm) to the actual activity (dpm) in a sample. If a sample differs in chemical composition from the nuclide standard used to calibrate the instrument, a quench-efficiency curve must be established. A series of quenched samples containing a known activity of the nuclide of interest are prepared with a measured volume of scintillation cocktail. These samples, containing increasing amounts of a chemical quenching agent, are then measured for spectrum analysis.

The quench index parameter (QIP) of the Packard LS counter utilizes a gamma source $\left({ }^{133} \mathrm{Ba}\right)$ positioned near the scintillation vial. The quench value is obtained from the energy distribution and the attenuation of the ${ }^{133} \mathrm{Ba}$ gamma rays within the scintillation medium. The QIP can range from zero (for a totally quenched sample) to 1000 for an unquenched sample. The QIP is also known as the automatic external standardization (AES) number or the transformed spectral index of the external standard (tSIE).

If a sample contains two or three radionuclides that emit alpha, beta or conversion electrons, then quench-efficiency curves are prepared separately for each component after which the sample can be analyzed in the dual-dpm mode. This option is suitable, provided that the cross-talk (spectral overlap) 
from one nuclide's energy spectra into another's preset ROI is minimal (i.e., there is sufficient energy separation in any two ROI's). The activity in each ROI is then ascribed to a particular nuclide.

An additional feature of the Packard Tri-Carb LS counter is the ability to produce a second quench parameter, the spectral index of the sample (SIS), which is a value assigned by the instrument based on the sample spectrum and the nuclide endpoint energy. At a given level of quenching, each radionuclide's spectral shape has a definite mean pulse height distribution and hence a unique SIS value. The SIS values are utilized, in conjunction with the QIP values, to deconvolute the composite spectrum of a dual-tracer (i.e., two different nuclides) sample into two components, yielding the activity concentrations of each component. This forms the basis upon which a FSA is performed, as described in Appendix A of this report. Figure 3 shows both the QIP (tSIE) and SIS versus efficiency relationships for both ${ }^{14} \mathrm{C}$ and ${ }^{3} \mathrm{H}$.

Although not investigated in this report, an alternative method to correct for color or chemical quenching is the channels ratio method (Stubbs, 1967; Moir, 1971; Randolph, 1975; Bem et al., 1980; Kessler, 1986). This method accounts for spectral shifting which may occur when other chemicals are present in a sample.

\section{DETERMINATION OF WINDOW SETTINGS}

For most LS counting applications, the energy windows are set for three ROIs (i.e., ${ }^{3} \mathrm{H}$, beta, and alpha) by measuring unquenched standards. Using guidance found in the LS operating manual, the energy regions are optimized based on the figure of merit (FOM). The FOM, derived from statistical considerations, is the ratio of the squared efficiency to the background, $E^{2} / \mathrm{bkg}$., and relates to the signalto-noise ratio of the instrument.

For the data presented in this report, three ROIs were selected: Region A for low energy emitters $(0$ to $50 \mathrm{keV})$, Region B for alpha emitters (100 to $600 \mathrm{keV}$ ) and for high energy beta emitters, and Region C (601 to $2000 \mathrm{keV}$ ). As previously mentioned, the energy to light conversion for alpha particles is one tenth that of beta particles, so that energy spectra appears in a 100-600 keV region (Passo and Cook, 1994). Using $\mathrm{a}^{3} \mathrm{H}$ reference standard, a spectrum analysis is performed, and the energy range of Region A ( 0 to $\left.20 \mathrm{keV},{ }^{3} \mathrm{H}\right)$ is visually adjusted to maximize the count rate and minimize the energy range. A properly adjusted ${ }^{3} \mathrm{H}$ ROI should not contain any interference from alpha particles. However, there will be interference from low energy beta particles with energies similar to ${ }^{3} \mathrm{H}$, as well as the beta continuum from higher energy beta particles. A spectrum is collected using a suitable alpha standard, and the Region $\mathrm{B}$ ( 100 to $600 \mathrm{keV}$ ) energy range is visually adjusted to maximize the count rate and minimize the energy range. A properly adjusted alpha range should not interfere with low energy or the beta region. However, beta's with middle-to-high energies will interfere with Regions A and B. A spectrum is recorded using a suitable beta reference standard, with Region $C$ set at 650 to $2000 \mathrm{keV}$. The lower level energy cutoff is adjusted such that the beginning of the range is about 25 to $50 \mathrm{keV}$ above the end of the alpha energy range. The end value cutoff should be the highest energy of the spectrum ( $2000 \mathrm{keV})$.

With the appropriate window settings, sealed ${ }^{3} \mathrm{H}$ and ${ }^{14} \mathrm{C}$ standards are counted at least weekly to determine the instrument's performance, using both background and counting efficiency as indicators. These measured values are stored and later retrieved to produce the chart shown in Figure 4. 


\section{INSTRUMENT BACKGROUND AND LOWER LIMIT OF DETECTION .}

Figure 5 shows the instrument background for four ROIs (1-50,51-500,501-2000 keV and $0-2000 \mathrm{keV}$ ) using $15 \mathrm{~mL}$ of neat (no water) Insta-Gel-XF cocktail in glass vials, as well as at two different quench values (i.e., 520,310$)$. The data show that the largest percentage of background ( $54 \%$ of total background) is in the lower energy ROI. For each ROI shown above, the background increases $<4 \%$ with an increasing degree of quench. In this case, water was added as a quenching agent in $5 \mathrm{~mL}$ increments.

For Cerenkov counting, water, having a refractive index of 1.33 , is typically used as the solvent. The average instrument background, using $20-\mathrm{mL}$ plastic vials containing 3-18 $\mathrm{mL}$ of ultra-pure water was $0.225 \pm 0.018$ counts per second (cps) for the $0.50 \mathrm{keV}$ Cerenkov ROI. The average background count rate for glass vials $(0.346 \pm 0.010 \mathrm{cps})$ is about $30 \%$ higher than that obtained using plastic vials (see Figure 6) because of ${ }^{40} \mathrm{~K}$ contained in the glass (Kellogg, 1983; Pacer, 1980). Based on replicate background data (water), the lower limit of detection (LLD) for a 60 -min count at the $95 \%$ confidence level is $0.023 \mathrm{cps}$ for plastic, and $0.028 \mathrm{cps}$ for glass using the following relationship (Pasternack and Harley, 1971):

$$
L L D=3.29 S_{0} \text { and } S_{o}=S q r t\left(R_{b} / T_{s}+S_{b}{ }^{2} / n\right)
$$

where, $R_{b}=$ the background count rate $(\mathrm{cpm}), T_{s}=$ the sample count time (min), $S_{b}=$ the standard deviation of replicate background measurements $(0.018 \mathrm{cps}$ for plastic and $0.10 \mathrm{cps}$

for glass), and $\mathbf{n}=$ the number of replicate measurements.

Assuming a CCE of $50 \%$ and a radiochemical yield of $100 \%$, then the minimum detectable activity (MDA) range for a $60-\mathrm{min}$ count, based on LLDs of 0.023 and $0.028 \mathrm{cps}$ for plastic and glass vials containing $10 \mathrm{~mL}$ of water is estimated to be:

$$
\mathrm{MDA}_{60 \min }(0-50 \mathrm{keV})=\frac{\mathrm{LLD}}{0.50 \mathrm{cps} / \mathrm{dps}}=0.046 \text { to } 0.056 \mathrm{~Bq}(2.8 \text { to } 3.4 \mathrm{dpm})
$$

\section{TNQUENCHED DETECTIONEFFICENCIES: ALPHA AND BETA}

EML's LS counter was calibrated for efficiency and quench effects using 25 individual nuclides that emit either alpha, beta, gamma, Auger and internal conversion electrons using carrier free aqueous solutions of ${ }^{3} \mathrm{H},{ }^{14} \mathrm{C},{ }^{40} \mathrm{~K},{ }^{45} \mathrm{Ca},{ }^{54} \mathrm{Mn},{ }^{55} \mathrm{Fe},{ }^{59} \mathrm{Fe},{ }^{99} \mathrm{Tc},{ }^{95 \mathrm{~m}} \mathrm{Tc},{ }^{85} \mathrm{Sr},{ }^{89} \mathrm{Sr},{ }^{90} \mathrm{Sr} /{ }^{90} \mathrm{Y},{ }^{133} \mathrm{Ba},{ }^{137} \mathrm{Cs} /{ }^{137} \mathrm{Ba},{ }^{106} \mathrm{Ru} /$ ${ }^{106} \mathrm{Rh},{ }^{207} \mathrm{Bi},{ }^{210} \mathrm{Bi} /{ }^{210} \mathrm{Po},{ }^{226} \mathrm{Ra},{ }^{232} \mathrm{U}$, natural $\mathrm{U},{ }^{237} \mathrm{~Np},{ }^{241} \mathrm{Am},{ }^{243} \mathrm{Am},{ }^{242} \mathrm{Pu}$, and ${ }^{244} \mathrm{Cm}$. The decay properties for the nuclides used are shown in Tables 1 and 2. All radionuclides were obtained from the USDC National Institute of Standards and Technology (NIST) or Amersham International, many as certified standard solutions. Most of the nuclide solutions, as received at EML, were calibrated by $2 \pi$ or $4 \pi$ gas proportional counting (Fisenne, 1992).

Figure 7 shows the unquenched LS counting efficiencies as a function of increasing beta energy that were obtained using weighed amounts of standard solution added to $10{ }^{40} \mathrm{~K}$ borosilicate glass vials containing $15 \mathrm{~mL}$ of neat Insta-Gel-XF scintillation cocktail. Alpha emitting nuclides (not shown) are usually detected with $>99 \%$ in organic based scintillants, depending on the decay scheme of the nuclide. With the exception of ${ }^{137} \mathrm{Cs}$, the LS counting efficiency increased sharply and achieved a maximum value 
of $98 \%$ when beta energies exceeded $0.252 \mathrm{MeV}$ (i.e.. ${ }^{45} \mathrm{Ca}$ ). The average LS detection efficiency for ${ }^{137} \mathrm{Cs}$ was $112 \%$ due to the contributions from both betas [i.e., $0.514 \mathrm{MeV}(94 \%)$ and $1.176 \mathrm{MeV}(6 \%)$ ] and ${ }^{137 \mathrm{~m}} \mathrm{Ba}$ internal conversion electrons $(9.7 \%)$. EC nuclides that emit K-L3 Auger electrons (see Table 1 and 2) are plotted separately in Figure 7. The data show that these nuclides, which are principally used as gamma yield tracers in some radiochemical procedures, are detectable by conventional LS analysis with counting efficiencies approaching $90 \%$. The same gamma emitting nuclides were found to be undetectable by Cerenkov counting.

Figure 8 shows a "spectral map" indicating the unquenched LS counting efficiencies in Insta-Gel-XF for selected alpha and beta emitters using three preset energy windows (i.e., $0-50 \mathrm{keV}, 50-500 \mathrm{keV}$, and $0-2000 \mathrm{keV}$ ). The detection efficiency for some alpha emitters exceeded $100 \%$ because of progeny activity that contributed to the count rate.

The spectral peak for unquenched alpha emitters typically appears in the 200-600 keV energy window (see Figure 9a). The unquenched alpha peak is about a factor of 10 less than the actual alpha energy $(\mathrm{MeV})$ because of the reduced alpha photon yield. Quenching occurs when water or another chemical agent is present in the sample. As with beta emitters, the effect of increased quenching is to shift the alpha spectral peak to a lower energy region. Figure $9 \mathrm{~b}$ illustrates that the location of the spectral peak (keV) is directly dependent on the alpha energy and degree of quench. For any alpha emitter, this quenching effect (i.e., shifting of the alpha peak) is linear over the range of the instrument's QIP (Figure 9b) or SIS values (Figure 10).

\section{YERENKOV COUNTING}

Cerenkov radiation occurs when charged particles pass through a dielectric medium (liquid) where there is an exchange of energy from the charged particle to the molecules of the medium (Haberer, 1966). The exchange energy produces local electronic polarizations in the medium if the charged particle is moving at velocities greater than the velocity of light in the medium. When these polarized molecules return to their normal state, the excess energy is released as electromagnetic radiation known as Cerenkov radiation.

A threshold energy exists for the production of Cerenkov radiation and is a function of the refractive index, $n$, of the medium. For water $(n=1.33)$ the lowest electron energy that will produce Cerenkov radiation is $0.263 \mathrm{MeV}$ (Berger and King, 1985). With beta emitters, the maximum energy, $\mathrm{E}_{\max }$, must substantially exceed this value because of the broad beta energy spectrum. Photoelectrons and Compton electrons from gamma emitting nuclides, having energies in excess of the threshold energy, can also be measured by Cerenkov counting. The lowest gamma energy ray which produces a $0.263 \mathrm{MeV}$ Compton electron is $0.430 \mathrm{MeV}$. Alpha particles, in water, do not produce Cerenkov radiation. Some nuclides that can be measured by Cerenkov counting are:
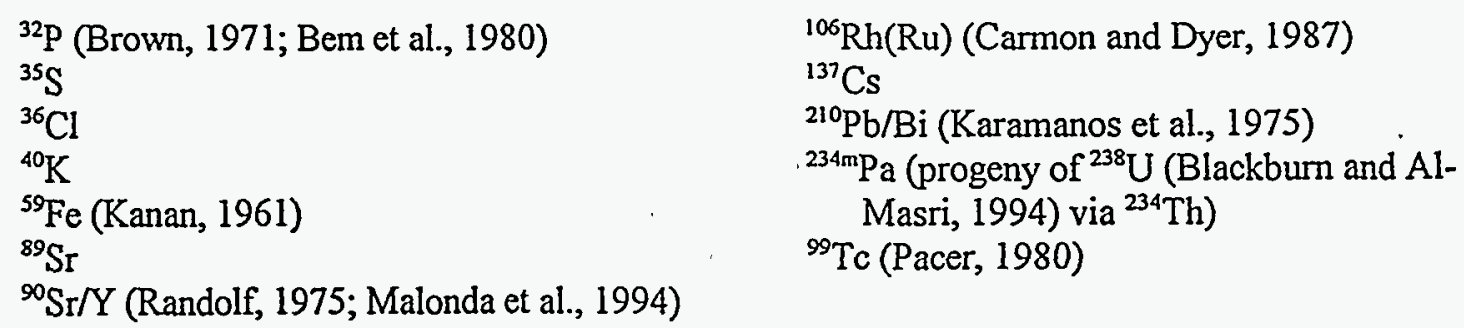
Cerenkov counting is an adjunct to liquid scintillation analysis (LSA) which does not require a scintillating cocktail. Various wavelength shifters (Haberer, 1966; Karamanos et al., 1975; Scarpitta and Fisenne, in press; Lauchli, 1969) have been used to enhance the CCE by $10-20 \%$ using commercially available LS spectrometers. Waveshifters are organic substances that shift the Cerenkov photon energies from a region of low detector sensitivity to a region of high detector sensitivity.

\section{ENERGY CALIBRATION CURVES FOR CERENKOV COUNTING}

Standardized solutions, containing the equivalent of about $17 \mathrm{~Bq}(1000 \mathrm{dpm})$, were dispensed gravimetrically, in triplicate, into either 20 -mL plastic or low borosilicate glass vials. Each vial was counted for 15-30 min with a Cerenkov window setting of $0-50 \mathrm{keV}$ so that the 1 sigma counting error was $<2 \%$.

In the absence of alpha emitters, the optimum CCE was obtained using $10 \mathrm{~mL}$ of $25 \mathrm{mM}$ ANSA (7-Amino 1,3 Naphthalene di-Sulfonic Acid) as a wavelength shifter. Figure 11 shows the beta energy versus CCE calibration curve obtained from standardized solutions counted in plastic vials containing $10 \mathrm{~mL}$ of $25 \mathrm{mM}$ ANSA solution. The data show that the CCE increases proportionately as beta energy increases from 0.300 to $3.54 \mathrm{MeV}$, achieving a maximum value of $80 \%$ for ${ }^{106} \mathrm{Ru} /{ }^{106} \mathrm{Rh}\left(\mathrm{E}_{\max }=3.54 \mathrm{MeV}\right)$. It is inferred that the ${ }^{90} \mathrm{Y} \mathrm{CCE}$ is overestimated by $5 \%$ due to ${ }^{00} \mathrm{Sr}\left(0.546 \mathrm{MeV}\right.$ beta), based on the ${ }^{59} \mathrm{Fe}$ ( $0.475 \mathrm{MeV}$ beta) CCE. The relationship is linear above the Cerenkov threshold energy of $0.263 \mathrm{MeV}$ up to $2 \mathrm{MeV}$ with a correlation coefficient, $\mathrm{R}^{2}$, of 0.96 , and slope of $41.9 \%$ efficiency $\mathrm{MeV}^{-1}$.

The use of a wavelength shifter to enhance the CCE may also enhance the alpha detection efficiency (if these nuclides are present) because the additive will act as a scintillant, converting alpha particles into detectable light. Figure 12 shows that the detection efficiency in $25 \mathrm{mM}$ ANSA in plastic vials is typically $20 \%$ - $30 \%$ for alpha emitting only nuclides (i.e., ${ }^{232} \mathrm{U},{ }^{242} \mathrm{Pu},{ }^{244} \mathrm{Cm}$ ). Figure 13 shows the increase in Cerenkov and alpha counting efficiency as a function of the wavelength shifter, ANSA concentration, using alpha emitting ${ }^{244} \mathrm{Cm}(5.76,5.81 \mathrm{MeV})$, alpha and beta emitting ${ }^{210} \mathrm{~Pb}(3.72 \mathrm{MeV}$ alpha as ${ }^{210} \mathrm{~Pb} ; 1.16 \mathrm{MeV}$ as ${ }^{210} \mathrm{Bi}$ beta), and internal conversion electron emitting ${ }^{207} \mathrm{Bi}$. Table 3 compares the LS and CCEs obtained for 15 radionuclides (in order of increasing beta energy) using a Packard TriCarb-2250CA LS spectrometer. The ratio of the LS counting efficiency to that of the CCE shows that LS counting is preferred for radionuclides whose maximum beta energy is $<0.514 \mathrm{MeV}\left({ }^{137} \mathrm{Cs}\right)$, which includes EC nuclides. In general, the CCE is $20-50 \%$ less than the LS counting efficiency for radionuclides with beta energies in excess of $1 \mathrm{MeV}$. A detailed description of this work can be found in Scarpitta and Fisenne (in press).

\section{CTIVTTY CALIBRATION DATA}

For completeness, activity calibration curves were produced for one pure beta and several EC/gamma emitters in order to demonstrate linearity. 


\section{BETA AND GAMMA EMITTING NUCLIDES}

The data in Figures 14 and 15 show that the detection efficiency for ${ }^{99} \mathrm{Tc}\left(E_{\max }=0.292 \mathrm{MeV}\right)$ and several gamma emitting nuclides that produce K-L3 Auger electrons is linear $\left(R^{2}>0.997\right)$ over a three order of magnitude range of acivitiy $(1-1000 \mathrm{dpm})$.

\section{CERENKOV COUNTING}

Figure 16 shows the CCE versus ${ }^{40} \mathrm{~K}$ activity in plastic vials containing $25 \mathrm{mM}$ ANSA, a wavelength shifter used to enhance the CCE. Potassium chloride salt (Fisher Scientific Co.) was used to determine the $C C E$ calibration curve. $\mathrm{KCl}$ contains ${ }^{40} \mathrm{~K}$, an electron capture/beta emitter $\left(\mathrm{E}_{\max }=1.32 \mathrm{MeV}\right)$ with a natural abundance of $0.0117 \%$ (Browne and Firestone, 1986). One gram of $\mathrm{KCl}$ is expected to contain $14.2 \mathrm{~Bq}(850 \mathrm{dpm})$ of beta activity due to ${ }^{40} \mathrm{~K}$. Serial dilutions (i.e., I:I) were made from a stock solution containing $1 \mathrm{~g}$ of $\mathrm{KCl}$ per $10 \mathrm{~mL}$ of $25 \mathrm{mM}$ ANSA. The data in Figure 16 show a linear relationship $\left(\mathrm{R}^{2}=0.9981\right)$ between the observed count rate and added ${ }^{40} \mathrm{~K}$ activity over a three order of magnitude range. The average of 11 independent CCE measurements for ${ }^{40} \mathrm{~K}$ was $0.58 \pm 0.09$. The LLD for a $1-\mathrm{h}$ count using a $25 \mathrm{mM}$ ANSA solution was $0.039 \mathrm{cps}$ for plastic vials. Based on this LLD, the minimum detectable activity for Cerenkov producing radionuclides, assuming a $50 \% \mathrm{CCE}$ and $100 \%$ yield of the nuclide of interest, is about $80 \mathrm{mBq}$ for a $1-\mathrm{h}$ count.

\section{VALIBRATIONOF LS SYSTEM FOR QUENCHING}

The LS stability and operational acceptance criteria were checked before running any standards or samples. This was performed by counting the background, a ${ }^{3} \mathrm{H}$ standard, and a ${ }^{14} \mathrm{C}$ standard provided by the instrument's manufacturer using an appropriate spreadsheet program, and comparing the count rate with previously established quality control charts developed at EML for this instrument.

The LS detection efficiencies over a range of quench values are determined from the known activities added to each vial containing chilled Insta-Gel XF LS cocktail and increasing quantities of the quenching agent. The data were analyzed by regression and are utilized to construct quench calibration curves (i.e., counting efficiency versus degree of quench).

For a given nuclide, three efficiency curves (efficiency versus QIP) were usually developed for the alpha, beta, and low energy ROI, respectively. In some cases, the full energy region $(0-2000 \mathrm{keV})$ is presented and is useful for FSA applications. To obtain a range of quenching from high to low efficiency, various volumes of a quenching agent (i.e., nitro-methane) were pipetted into the separately labeled vials. The following quenching agent volumes were used: $0,0.02,0.04,0.06$, and $0.08 \mathrm{~mL}$ of nitromethane. Fifteen milliliters of scintillation cocktail was dispensed into each glass vial.

The detection efficiencies in Regions $A, B, C\left(E f f_{A, B, C}\right)$ were determined for each sample vial in units of counts $\mathrm{s}^{-1}$ per $\mathrm{Bq}$ by dividing the net activity measured in cps by the added activity in $\mathrm{Bq}$. The efficiency curves were generated by plotting $\left(\mathrm{Eff}_{\mathrm{A}, \mathrm{B}, \mathrm{C}}\right)$ versus the $\mathrm{QIP}$ value. Many LSC systems are equipped with programs to generate efficiency curves. If these applications are used, the operating manual should be referenced as method documentation. 
Least squares fits on the plots were performed. The fitted coefficients $(m)$ and $(b)$ for the equation $\operatorname{Eff}_{A, B, C}=(m$ QIP $)+b$ were obtained from the intercept [b] and the slope [m]. The fitted coefficients are stored in the computer software for routine use. The parameters describing the quench-efficiency curves should be checked annually. If any major component of the instrumentation is replaced or repaired, the instrument must be recalibrated for the nuclides of interest.

The figures presented in Appendix B, arranged in order of increasing atomic mass, show: 1) the nuclide spectra in the $0-2000 \mathrm{keV}$ energy region, 2) the quench-efficiency curves, and 3 ) the SIS versus QIP curves that are useful for the FSA. The regression data for the plots shown in Appendix B as Figures B1-B24 are also presented as Tables B1-B4.

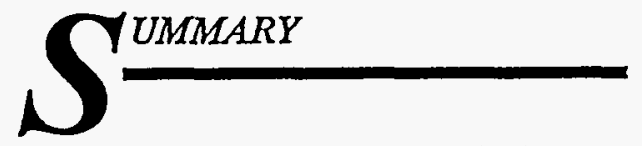

In general, about $50 \%$ of the instrument background was in the $0-50 \mathrm{keV}$ energy region. The average instrument background, using $20 \mathrm{~mL}$ plastic vials containing $10 \mathrm{~mL}$ of ultra-pure water was $0.255 \pm 0.018 \mathrm{cps}$ for a $0-50 \mathrm{keV}$ ROI. The average background count rate for glass vials $(0.346 \pm 0.010 \mathrm{cps})$ was about $30 \%$ higher than the plastic vials. Based on replicate background measurements, the lower limit of detection (LLD) for a 1-h count at the $95 \%$ confidence level, using water as a solvent, was $0.024 \mathrm{cps}$ and $0.028 \mathrm{cps}$ for plastic and glass vials, respectively. The LLD for a I h count, using $10 \mathrm{~mL}$ of a waveshifter solution, was $0.039 \mathrm{cps}$ for plastic vials. The LLD, expressed as activity, ranged from 46 to $56 \mathrm{mBq}(2.8-3.4 \mathrm{dpm})$ for conventional LS counting. This assumes a $100 \%$ counting efficiency, a $50 \%$ yield of the nuclide of interest, a 1-h measurement time using low background plastic vials, and a $0-50 \mathrm{keV}$ ROI. The LLD may reduced an order of magnitude if the yield recovery exceeds $90 \%$ and a lower background region (i.e., $100-500 \mathrm{keV}$ alpha ROD) is used.

Detection efficiencies were linear over a three orders of magnitude range in beta activity $(10-10,000 \mathrm{mBq})$ for both LS and Cerenkov counting. A linear relationship was observed for the CCE as beta energy increased from 0.300 to $2 \mathrm{MeV}$, whereas the LS efficiency was $>90 \%$ for betas with energy in excess of $0.250 \mathrm{MeV}$. A comparison of the data showed that the CCE was $20-50 \%$ less than the LS counting efficiency for beta particles with maximum energies in excess of $1 \mathrm{MeV}$.

In some cases, Cerenkov counting can be performed prior to LS counting when it is desirable to measure only beta emitters with maximum energies in excess of the Cerenkov threshold, while eliminating unwanted signals from alpha, Auger electron or gamma emitting nuclide that may be present in a sample.

\section{PRERENCES}

Bem, E. M., H. Bem and W. Reimchussel

"Determination of ${ }^{32} \mathrm{P}$ and ${ }^{45} \mathrm{Ca}$ in Biological Samples by Cerenkov and Liquid Scintillation Counting" J. Appl. Rad. Iso., 31, 371-374 (1980) 
Berger, S. and M. King

"A Simple Method for Quantifying ${ }^{32} \mathrm{P}$ in Submicroliter Samples"

Biotechniques, 2, 38-46, Jan.- Feb. (1985)

Blackburn, R and M. S. Al-Masri

"Determination of Uranium by Liquid Scintillation Counting and Cerenkov Counting"

Analyst, $119,465-468$ (1994)

Brown, L. C.

"Determination of ${ }^{32} \mathrm{P}$ and ${ }^{33} \mathrm{P}$ in Aqueous Solution"

Anal. Chem, $\underline{43}$, 1326-1328 (1971)

Browne, E. and R. B. Firestone

"Table of Radioactive Isotopes"

John Wiley and Sons, New York (1986)

Carmon, B. and A. Dyer

"Cerenkov Spectroscopic Assay of Fission Isotopes: Cerenkov Counting of ${ }^{106} \mathrm{Ru}$ on UV-ColorQuenched Solutions Containing Other Beta Emitters"

J. Radiol. Nucl. Chem. Art., 109, 229-236 (1987)

De Filippis, S.

"Activity Analysis in Liquid Scintillation Counting. A Technical Comparative Summary-Part I"

Radioactivity and Radiochemistry, 1, 22-35 (1990)

Fisenne, I. M.

"Alpha Radioassay"

in: EML Procedures Manual, 27th Edition, Vol. I (1992)

Fujii, H. and M. Takiue

"Radio-assay of Dual Labeled Samples by Sequential Cerenkov Counting and Liquid Scintillation Efficiency Tracing Technique"

Nucl. Inst. Meth. Phys Res., A273, 377-380 (1988)

Haberer, $\mathrm{K}$.

"Measurement of Beta Activities in Aqueous Samples Utilizing Cerenkov Radiation"

Packard Technical Bulletin No. 16, Packard Instrument Co., Downers Grove, IL, January (1966)

Horowitz, E. P., M. L. Dretz and D. E. Fisher

"Separation and Preconcentration of Strontium from Biological Environmental and Nuclear Waste Samples by Extraction Chromatography"

Anal Chem., 63, 522-525 (1991)

Kanaan, S.

"Measurement of ${ }^{59} \mathrm{Fe}$ in Plant Material Using Cerenkov Radiation"

Int. J. Appl. Isot., 26, 558-561 (1961) 
Karamanos, R, J. Bettany and D. Rennie

"Lead-210 Assay in Soil and Plant Material Using Cerenkov Radiation"

Canadian. J. Soil Sci., 55, 407-13 (1975)

Kellogg, T.

"The Effect of Sample Composition and Vial Type on Cerenkov Counting in a Liquid Scintillation . Counter"

Anal. Biochem, 134, 137-143 (1983)

Pacer, R. A.

"Evaluation of Counting Efficiency, Possible Container Sorption and Quenching Charactristics in the Liquid Scintillation Counting of ${ }^{99} \mathrm{Tc}$ "

Int. J. Appl. Rad. Isotopes, 31, 731-736 (1980)

Kessler, M.

"Cerenkov Counting"

Packard Application Bulletin No. 7, Packard Instrument Company, Downers Grove, IL, December (1986)

Klein, R. C. and E. L.Gershey

"Biodegradable Liquid scintillation counting coctails"

Health Phys., 59, 461-470 (1990)

Lauchli, A.

"Radioassay for Beta Emitters in Biological Materials Using Cerenkov Radiation"

Int. J. Appl. Rad. Isotpes, 20, 265-27 (1969)

Malonda, A. G., L. R. Barquero and A. G. Carles

"Radioactivity Determination of ${ }^{90} \mathrm{Y},{ }^{90} \mathrm{Sr}$ and ${ }^{89} \mathrm{Sr}$ Mixtrues by Spectral Deconvolutio"

Nucl. Instr. Methods. Phys. Res., A339, 31-37 (1994)

Moir, A. T.

"Channels Ratio Quench Correction Using Cerenkov Radiation for the Assay of ${ }^{42} \mathrm{~K}$ in Biological Samples"

Int. J. Appl. Rad. Iso., 22, 213-216 (1971)

Passo, C. J. and G. T. Cook

"Handbook of Environmental Liquid Scintillation Spectrometry. A Compilation of Theory and Methods"

Packard Instrument Co. 800 Research Parkway, Meriden, CT. 06450.

Pasternack, B. S. and N. H. Harley

"Detection Limits for Radionuclides in the Analysis of Multi-Component Gamma Ray Spectrometer Data"

Nucl. Instr. Methods, 21, 533-540 (1971)

Randolph, R. B.

"Determination of ${ }^{89} \mathrm{Sr}$ and ${ }^{90} \mathrm{Sr}$ by Cerenkov and Liquid Scintillation Counting"

Int. J. Appl. Rad. Isotopes, 26, 9-16 (1975) 
Scarpitta, S. C. and I. M. Fisenne

"Cerenkov Counting as a Complement to Liquid Scintillation Counting".

Appl. Radiat. Isotopes (in press)

Stubbs, R. D. and A. Jackson

"Channel Ratio Color Quenching in Cerenkov Counting"

Appl. Radiat. Isotopes, 18, 867-868 (1967) 
- TABLE 1

DECAY DATA FOR SOME RADIONUCLIDES*

\begin{tabular}{|c|c|c|c|c|c|}
\hline & \multirow[b]{2}{*}{$\mathrm{t}-1 / 2$} & \multicolumn{2}{|c|}{ Decay Mode } & \multirow[b]{2}{*}{$\begin{array}{c}\text { K-L3 Auger } \\
(\mathrm{keV})\end{array}$} & \multirow[b]{2}{*}{$\begin{array}{c}\text { Cerenkov } \\
\text { Detection** }\end{array}$} \\
\hline & & $\begin{array}{c}\text { Beta } \\
(\mathrm{MeV})\end{array}$ & $\begin{array}{c}\text { Gamma } \\
(\mathrm{MeV})\end{array}$ & & \\
\hline${ }^{3} \mathrm{H}$ & $12.33 \mathrm{y}$ & 0.019 & & & \\
\hline${ }^{14} \mathrm{C}$ & $5730 y$ & 0.156 & & & \\
\hline${ }^{45} \mathrm{Ca}$ & $163.8 \mathrm{~d}$ & 0.257 & & · & Slight \\
\hline${ }^{54} \mathrm{Mn}$ & $312.2 \mathrm{~d}$ & & $0.835(100 \%)$ & 4.94 & \\
\hline${ }^{s 5} \mathrm{Fe}$ & $2.73 y$ & Pure EC & & 5.30 & \\
\hline${ }^{59} \mathrm{Fe}$ & $45 \mathrm{~d}$ & $0.475(51 \%)$ & & & Yes \\
\hline${ }^{85} \mathrm{Sr}$ & $64.84 \mathrm{~d}$ & & $0.514(100 \%)$ & 11.6 & \\
\hline${ }^{89} \mathrm{Sr}$ & $50.55 \mathrm{~d}$ & 1.492 & weak & & Yes \\
\hline${ }^{90} \mathrm{Sr}$ & $28.5 \mathrm{y}$ & 0.546 & & & Yes \\
\hline${ }^{90 Y}$ & $2.671 \mathrm{~d}$ & 2.28 & , & & Yes \\
\hline${ }^{95 \mathrm{~m}} \mathrm{Tc}$ & $61 \mathrm{~d}$ & & $0.204(66 \%)$ & 14.96 & \\
\hline${ }^{99} \mathrm{Tc}$ & $2.13 \mathrm{E} 5 \mathrm{y}$ & 0.292 & & & Slight \\
\hline${ }^{106} \mathrm{Ru}$ & $1.020 \mathrm{y}$ & 0.039 & & & \\
\hline \multirow[t]{2}{*}{${ }^{106} \mathrm{Rh}$} & $29.8 \mathrm{~s}$ & $3.54(68 \%)$ & & & \\
\hline & & $3.1(11 \%)$ & & & Yes \\
\hline${ }^{133} \mathrm{Ba}$ & $10.54 d$ & & $0.356(69 \%)$ & 25.96 & - \\
\hline${ }^{137} \mathrm{Cs}$ & $30.0 y$ & $0.514(95 \%)$ & & & \\
\hline${ }^{137 m \mathrm{ma}}$ & $2.6 \mathrm{~m}$ & $0.66(9.8 \% \mathrm{ICE})$ & $0.662(85 \%)$ & & Yes \\
\hline${ }^{210} \mathrm{Bi}$ & $5.01 \mathrm{~d}$ & 1.160 & weak & & \\
\hline${ }^{210} \mathrm{~Pb}$ & $22.3 y$ & 0.060 & 0.047 & & \\
\hline
\end{tabular}

* Data from Browne and Firestone (1986).

**Cerenkov threshold $=0.263 \mathrm{MeV}$. 
TABLE 2

DECAY DATA FOR SOME ALPHA EMITTING RADIONUCLIDES*

\begin{tabular}{|c|c|c|c|c|c|}
\hline & \multirow[b]{2}{*}{$t-1 / 2$} & \multirow[b]{2}{*}{$\begin{array}{c}\text { Beta } \\
(\mathrm{MeV})\end{array}$} & \multicolumn{2}{|c|}{ Decay Mode } & \multirow[b]{2}{*}{ Progeny } \\
\hline & & & $\begin{array}{l}\text { Gamma } \\
(\mathrm{MeV})\end{array}$ & $\begin{array}{l}\text { Alpha } \\
(\mathrm{MeV})\end{array}$ & \\
\hline${ }^{210} \mathrm{~Pb}$ & $22.3 \mathrm{y}$ & 0.060 & & & ${ }^{210} \mathrm{Bi}$ \\
\hline${ }^{210} \mathrm{Bi}$ & $5.01 \mathrm{~d}$ & 1.160 & & weak & ${ }^{210} \mathrm{Po}$ \\
\hline${ }^{226} \mathrm{Ra}$ & $1600 y$ & & & $4.784(95 \%) 4.601(6 \%)$ & ${ }^{222} \mathrm{Rn}$ and Progeny \\
\hline${ }^{236} \mathrm{Pu}$ & $2.851 \mathrm{y}$ & & & ${ }^{228} \mathrm{Th}$ Progeny & ${ }^{232} \mathrm{U}$ \\
\hline${ }^{238} \mathrm{Pu}$ & $8.774 \mathrm{El} \mathrm{y}$ & & & $5.456(28 \%) 5.499(72 \%)$ & \\
\hline${ }^{238} \mathrm{U}$ & $4.468 \mathrm{E} 9 \mathrm{y}$ & & & $4.196(77 \%) 4.147(23 \%)$ & 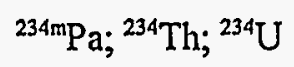 \\
\hline${ }^{239} \mathrm{Pu}$ & $2.411 \mathrm{E} 4 \mathrm{y}$ & & & $5.156(73 \%) 5.143(15 \%)$ & \\
\hline${ }^{240} \mathrm{Pu}$ & $6.563 \mathrm{E} 3 \mathrm{y}$ & & & $5.168(74 \%) 5.124(26 \%)$ & \\
\hline${ }^{241} \mathrm{Pu}$ & $1.44 \mathrm{E} 1 \mathrm{y}$ & 0.021 & & & \\
\hline${ }^{241} \mathrm{Am}$ & $4.327 \mathrm{E} 2 \mathrm{y}$ & & & $5.486(85 \%) 5.443(13 \%)$ & \\
\hline${ }^{242} \mathrm{Am}$ & $16 \mathrm{~h}$ & $\mathrm{EC}(17 \%)$ & $0.628(83 \%)$ & & \\
\hline${ }^{243} \mathrm{Am}$ & $7.380 \mathrm{E} 3 \mathrm{y}$ & & $0.0746(60 \%)$ & $5.277(88 \%) 5.234(11 \%)$ & ${ }^{239} \mathrm{No} ;{ }^{239} \mathrm{Pu}$ \\
\hline${ }^{242} \mathrm{Pu}$ & 3.763 E5 y & & & 4.90 (78\%) $4.856(22 \%)$ & \\
\hline${ }^{244} \mathrm{Cm}$ & $18.11 \mathrm{y}$ & & & $5.763(24 \%) 5.805(76 \%)$ & \\
\hline${ }^{237} \mathrm{~Np}$ & $2.140 E 6 \mathrm{y}$ & & & $4.988(47 \%) 4.772(25 \%)$ & ${ }^{243} \mathrm{Am}$ \\
\hline${ }^{232} \mathrm{U}^{\circ}$ & $68.9 \mathrm{y}$ & & & $5.32(68 \%) 5.27(32 \%)$ & ${ }^{228} \mathrm{Th}$ and Progeny \\
\hline
\end{tabular}


TABLE 3

RATIO OF LS TO CERENKOV DETECTION EFFICIENCIES IN ORDER OF INCREASING BETA ENERGY

\begin{tabular}{lcccc}
\hline & $\begin{array}{c}\text { Energy } \\
(\mathrm{MeV})\end{array}$ & $\begin{array}{c}\text { \% Cerenkov } \\
\text { Efficiency }\end{array}$ & $\begin{array}{c}\text { \% LS Efficiency } \\
\text { (Unqueched) }\end{array}$ & $\begin{array}{c}\text { Ratio of } \\
\text { LS Efficiency/CE }\end{array}$ \\
\hline Beta & & & & \\
${ }^{3} \mathrm{H}$ & 0.0190 & 0.0 & 36 & - \\
${ }^{14} \mathrm{C}$ & 0.1560 & 0.0 & 62 & - \\
${ }^{45} \mathrm{Ca}$ & 0.2570 & 0.5 & 89 & 178 \\
${ }^{99} \mathrm{Tc}$ & 0.2920 & 31.0 & 96 & 15.9 \\
${ }^{59} \mathrm{Fe}$ & 0.4750 & 5.8 & 92 & 12 \\
${ }^{137} \mathrm{Cs}$ & 0.5140 & 10.0 & 112 & 9.3 \\
${ }^{210} \mathrm{~Pb} / \mathrm{Bi}$ & 1.1600 & 37.0 & $295 *$ & 1.8 \\
${ }^{89} \mathrm{Sr}$ & 1.4920 & 54.0 & 98 & 1.2 \\
${ }^{90} \mathrm{Y}$ & 2.2800 & 79.0 & 93 & 20.4 \\
${ }^{106} \mathrm{Ru} / \mathrm{Rh}$ & 3.5400 & 83.0 & 97 & - \\
${ }^{\mathrm{K}}-\mathrm{L3}$ Auger & & & & 48 \\
${ }^{54} \mathrm{Mn}$ & 0.0049 & 2.9 & 59 & - \\
${ }^{55} \mathrm{Fe}$ & 0.0053 & 0.0 & 58 & - \\
${ }^{85} \mathrm{Sr}$ & 0.0116 & 1.7 & 82 & \\
${ }^{95 \mathrm{~m}} \mathrm{Tc}$ & 0.0150 & 0.0 & 93 & \\
${ }^{133} \mathrm{Ba}$ & 0.0260 & 0.0 & & \\
\hline${ }^{15}$ & & & & \\
\hline
\end{tabular}

${ }^{210} \mathrm{~Pb}$ beta $(.060 \mathrm{MeV})+{ }^{210} \mathrm{Bi}$ beta $(1.16 \mathrm{MeV})+{ }^{210} \mathrm{Po}$ alpha (5.3 MeV) 


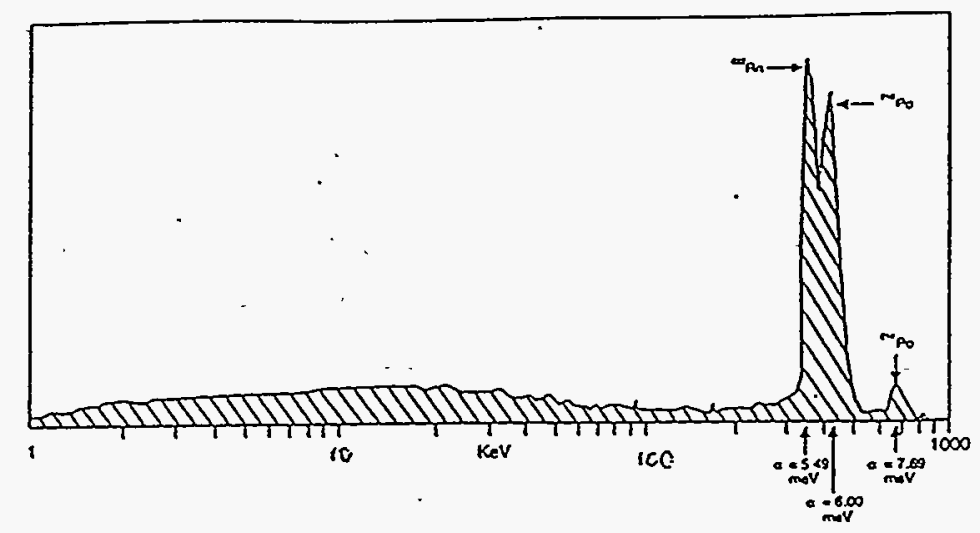

(a)

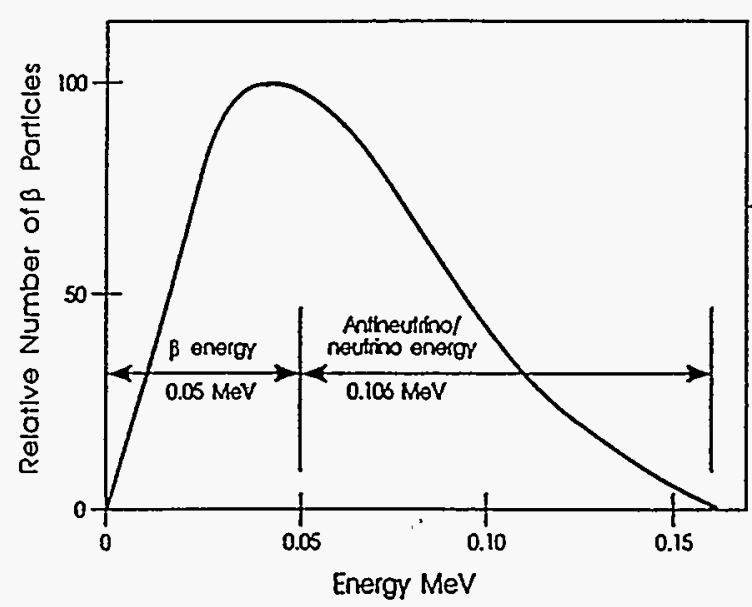

(b)

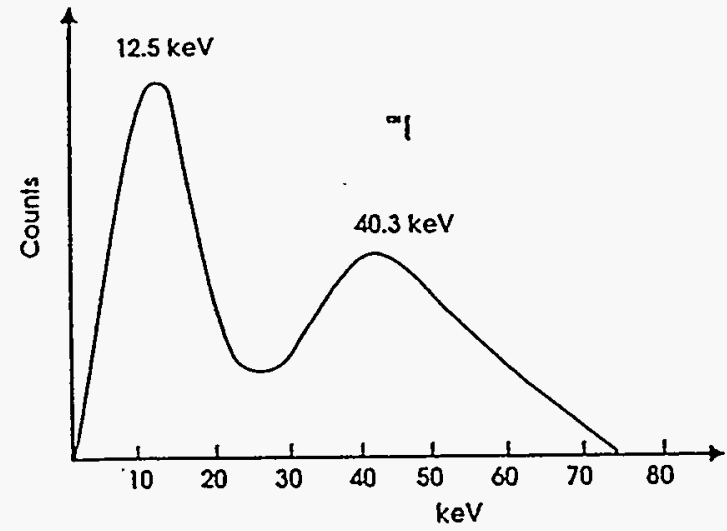

(c)

Figure 1. Alpha, beta and gamma spectra in an LS counter:

(a) energy spectrum of alpha emissions from Radon and progeny. (one photon of light produced per keV of decay energy);

(b) energy spectrum of ${ }^{14} \mathrm{C}$ showing beta and anti-neutrino contributions (10 photons of light per keV of beta energy);

(c) energy spectrum of gamma emitting ${ }^{125}$. 


\begin{tabular}{|c|c|c|c|c|c|}
\hline Solute & - & $\begin{array}{l}\text { Optimum } \\
\text { Solute } \\
\text { Concentration } \\
\text { (g/iter) }\end{array}$ & $\begin{array}{l}\text { Fuorescence } \\
\text { Moodmum } \\
\text { (nm) }\end{array}$ & $\begin{array}{l}\text { Decay } \\
\text { Time } \\
\text { (nsec) }\end{array}$ & $\begin{array}{l}\text { Quantum } \\
\text { Yield } \\
\therefore\end{array}$ \\
\hline PPO & & $5-7$ & 375 & 1.4 & 0.83 \\
\hline PBD & & $8-10$ & 375 & 1.0 & 0.69 \\
\hline Butyi-PBD & & 12 & 385 & 1.0 & 0.69 \\
\hline BBOT & & 7 & 446 & 1.6 & 0.61 \\
\hline
\end{tabular}

(a)

\begin{tabular}{|c|c|c|c|}
\hline Compound & Abbrevlation & $\begin{array}{l}\text { Concentration } \\
\text { (g/liter) }\end{array}$ & $\begin{array}{l}\text { Ruorescence } \\
\text { Maximum } \\
\text { Wavelength } \\
\text { (nm) }\end{array}$ \\
\hline & POPOP & $0.05-0.2$ & 415 \\
\hline & $M_{2}-P O P O P$ & $0.1-0.5$ & 427 \\
\hline & bls-MSB & 1.5 & 425 \\
\hline
\end{tabular}

(b)

\begin{tabular}{|c|c|c|c|}
\hline Solvent & $\begin{array}{l}\text { Chemical } \\
\text { Structure }\end{array}$ & $\begin{array}{l}\text { Relative } \\
\text { Pulse } \\
\text { Helght }\end{array}$ & $\begin{array}{l}\text { Fosh } \\
\text { Point } \\
\text { "C }\end{array}$ \\
\hline $\begin{array}{l}1.2 \mathrm{~A} \text { - Timethylbenzene } \\
\text { (pseudocumene) }\end{array}$ & & 112 & 50 \\
\hline p-xylene & & 110 & 30 \\
\hline Toluene & & 100 & 5 \\
\hline Benzene & & 85 & -11 \\
\hline $\begin{array}{l}\text { Unear Alkylbenzene } \\
\text { (high flash polnt) }\end{array}$ & & 91 & 150 \\
\hline $\begin{array}{l}\text { Phenyl-ortho-xylylethane } \\
\text { (PXE) }\end{array}$ & & 114 & 150 \\
\hline $\begin{array}{l}\text { dl-lsopropyinaphthalene } \\
\text { (DIN) }\end{array}$ & & 114 & 150 \\
\hline
\end{tabular}

(c)

Figure 2. Properties of LS solvents, primary and secondary scintillators:

(a) Primary scintillants, (b) secondary scintillants and

(c) LS solvents. 


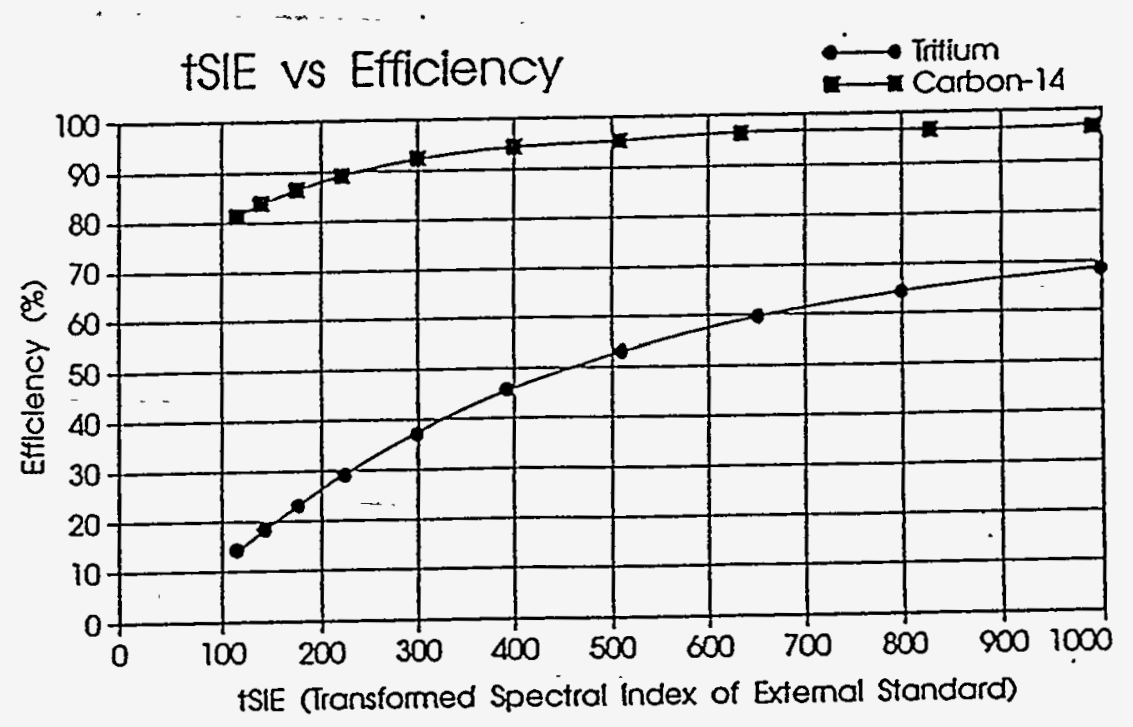

(a)

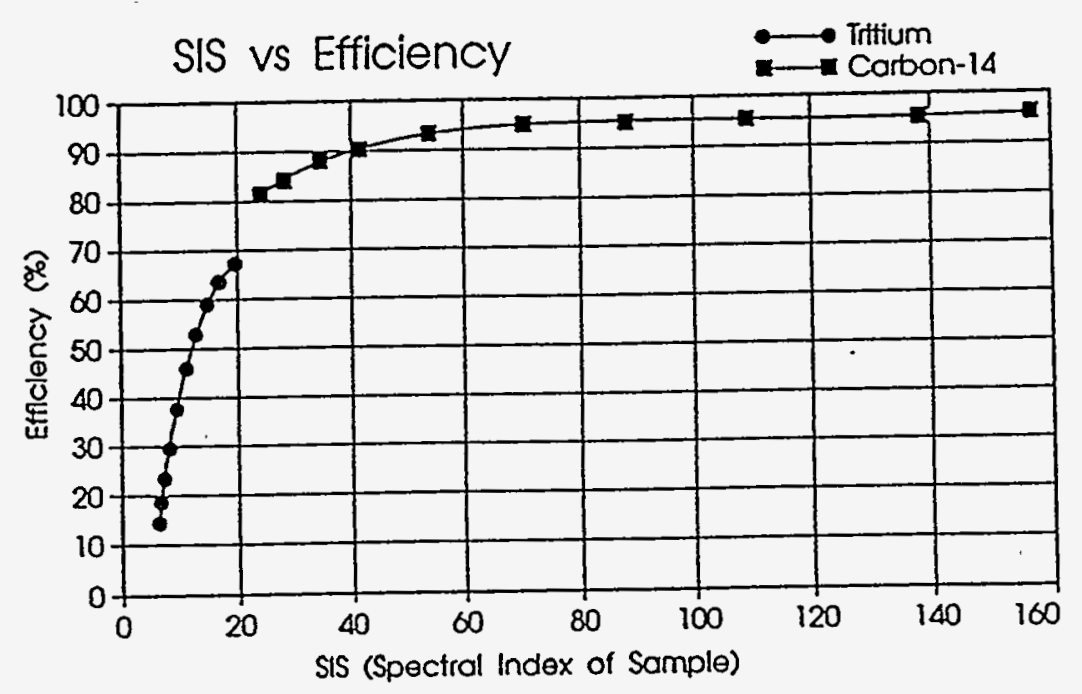

(b)

Figure 3. $t-S I E$ and SIS relationships for Tritium and Carbon-14:

(a) $\mathrm{t}$-SIE quench curve for Tritium and ${ }^{14} \mathrm{C}$,

(b) spectral index of sample (SIS) quench curve. 

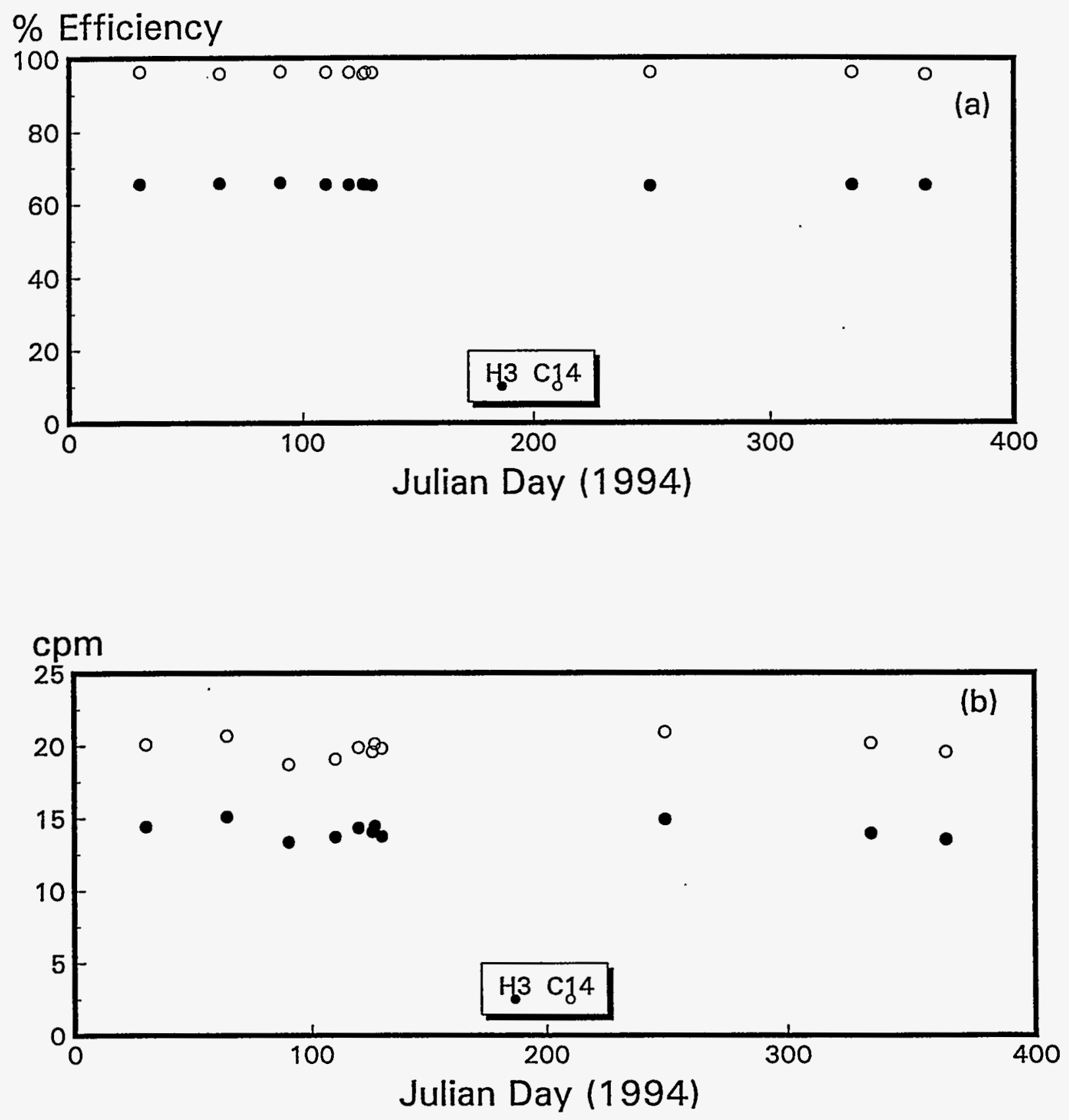

Figure 4. Tri-Carb 2250CA instrument performance.

(a) ${ }^{3} \mathrm{H}$ and ${ }^{14} \mathrm{C}$ efficiency and (b) ${ }^{3} \mathrm{H}$ and ${ }^{14} \mathrm{C}$ background. 


\section{$\mathrm{cpm}$}
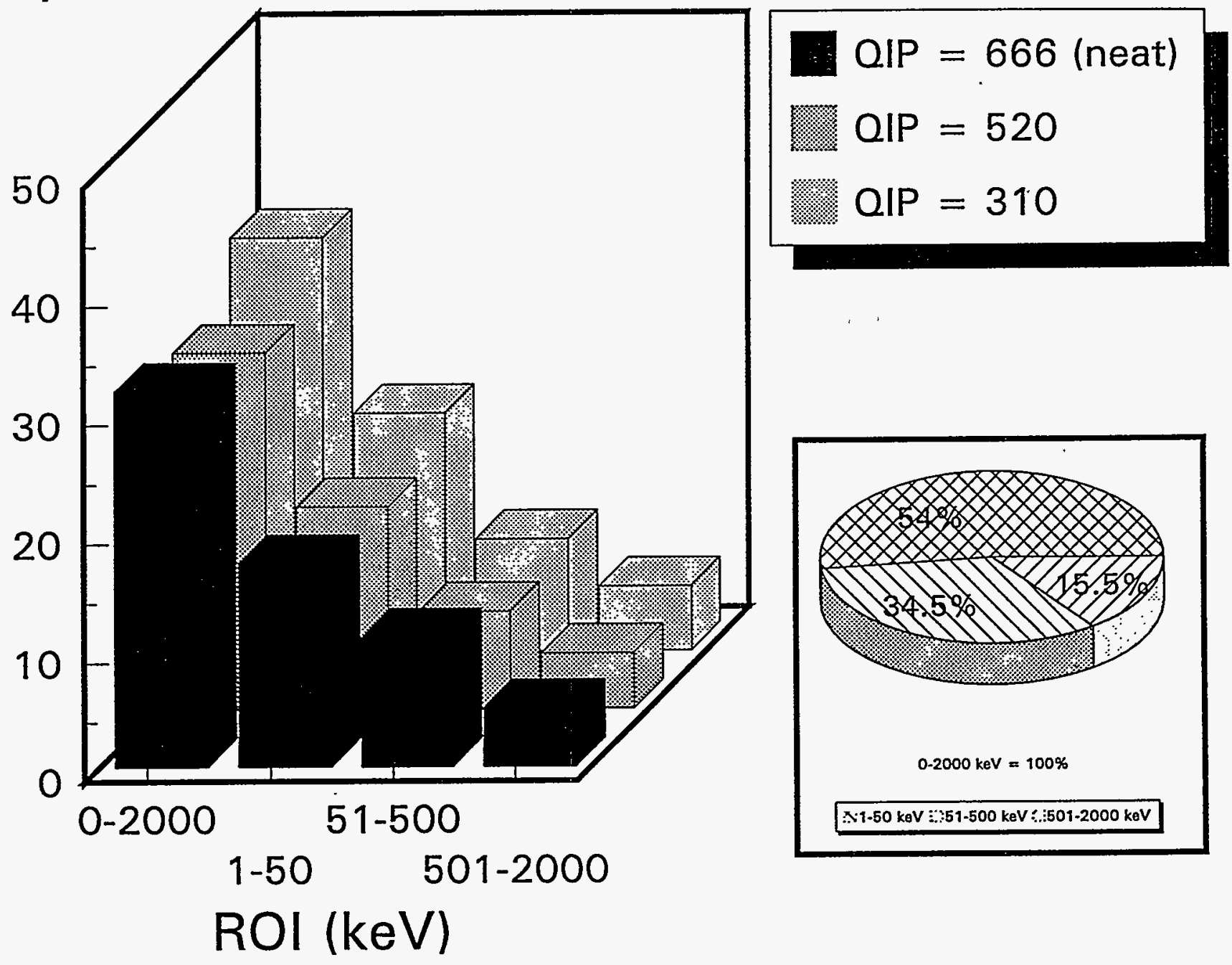

Figure 5. Packard Tri-Carb 2250CA background for $15 \mathrm{~mL}$ Insta-Gel in glass vials. 

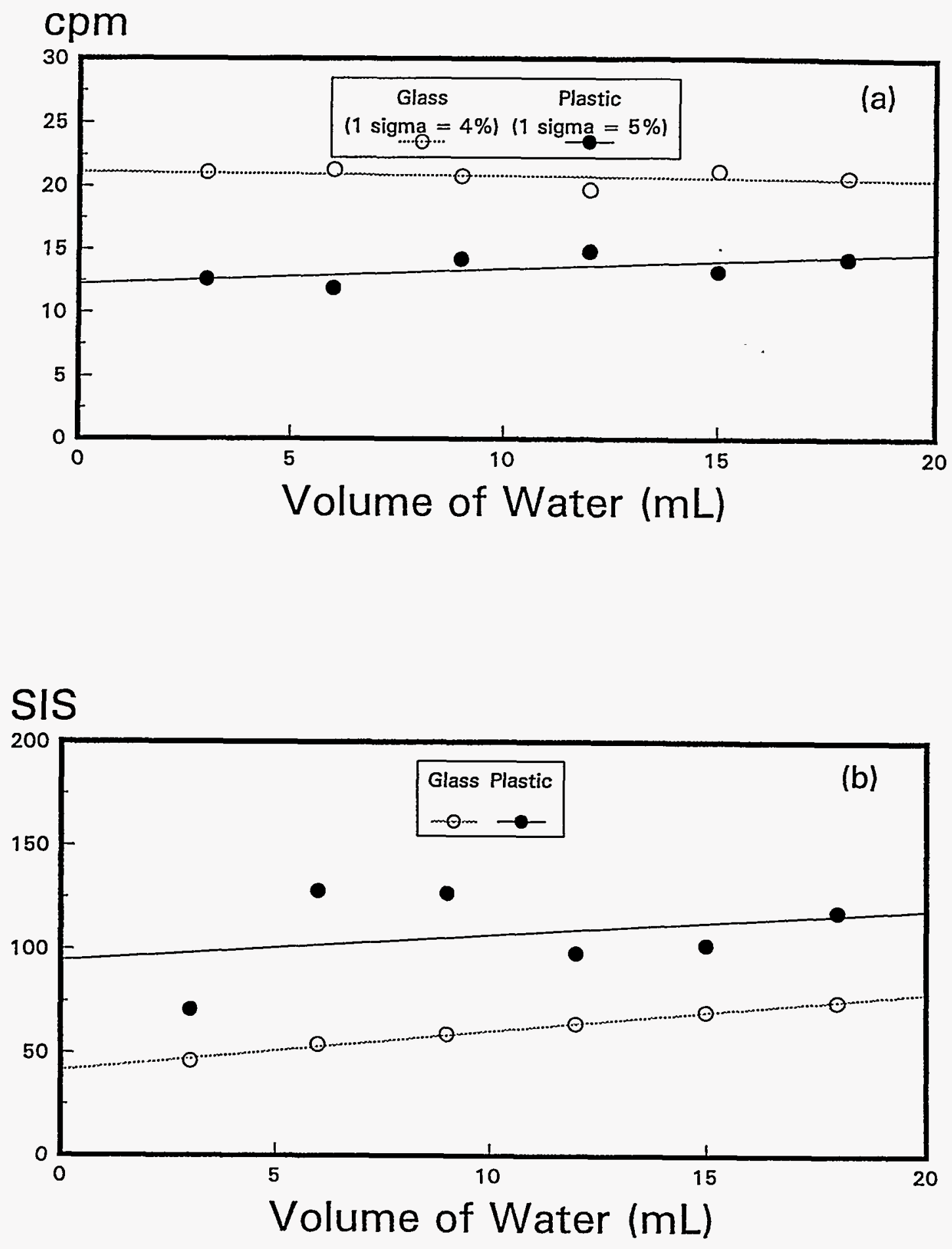

Figure 6. Background for glass and plastic vials.

(a) $\mathrm{ROI}=0-50 \mathrm{keV} ; 30$ min count time.

(b) SIS = spectral index of sample. 
$\%$ Efficiency (0-2000 keV Window)

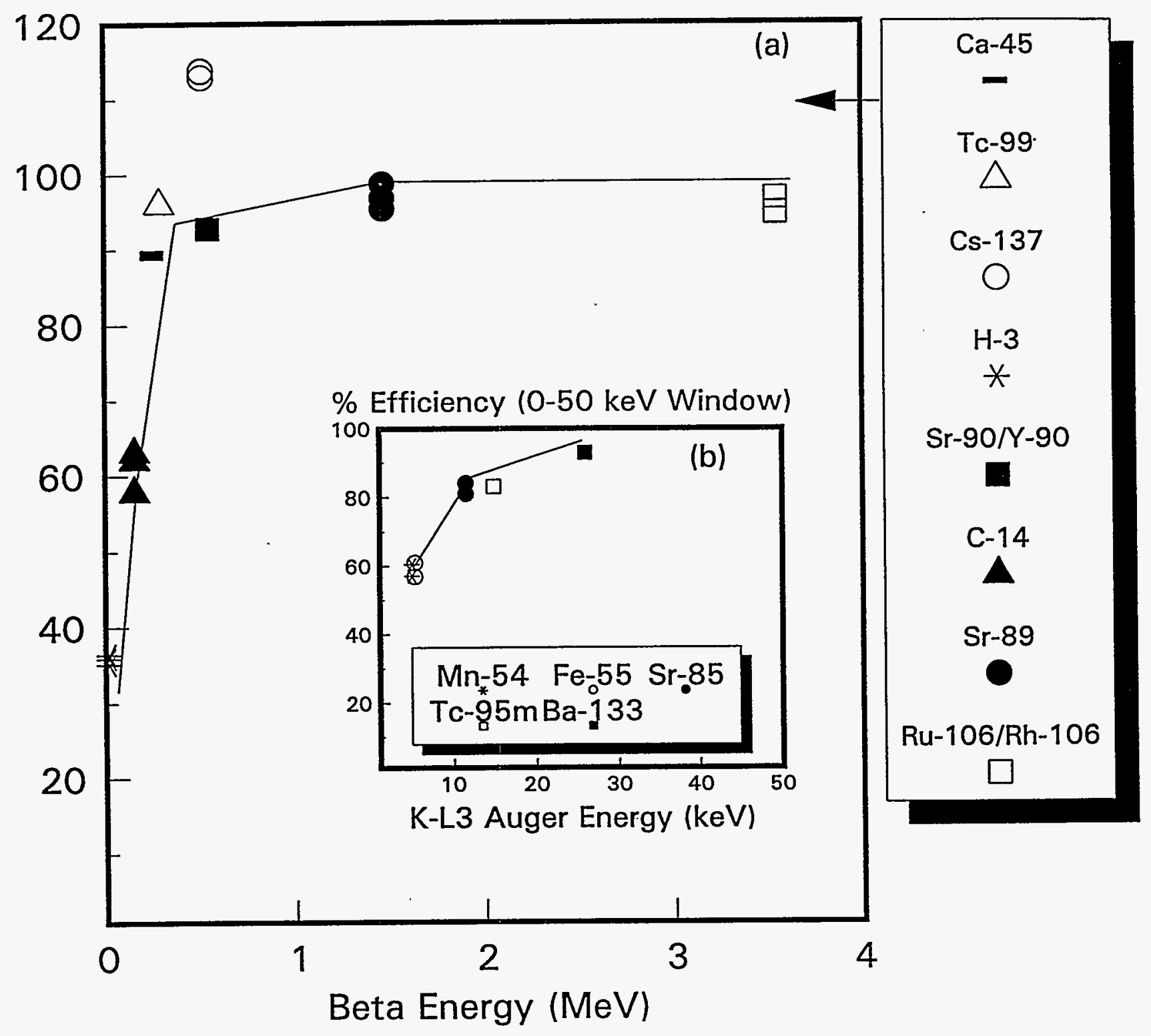

Figure 7. Unquenched LS counting efficiencies in $15 \mathrm{~mL}$ Insta-Gel using glass vials. (a) beta emitters and (b) gamma emitters. 


\section{\% Efficiency}

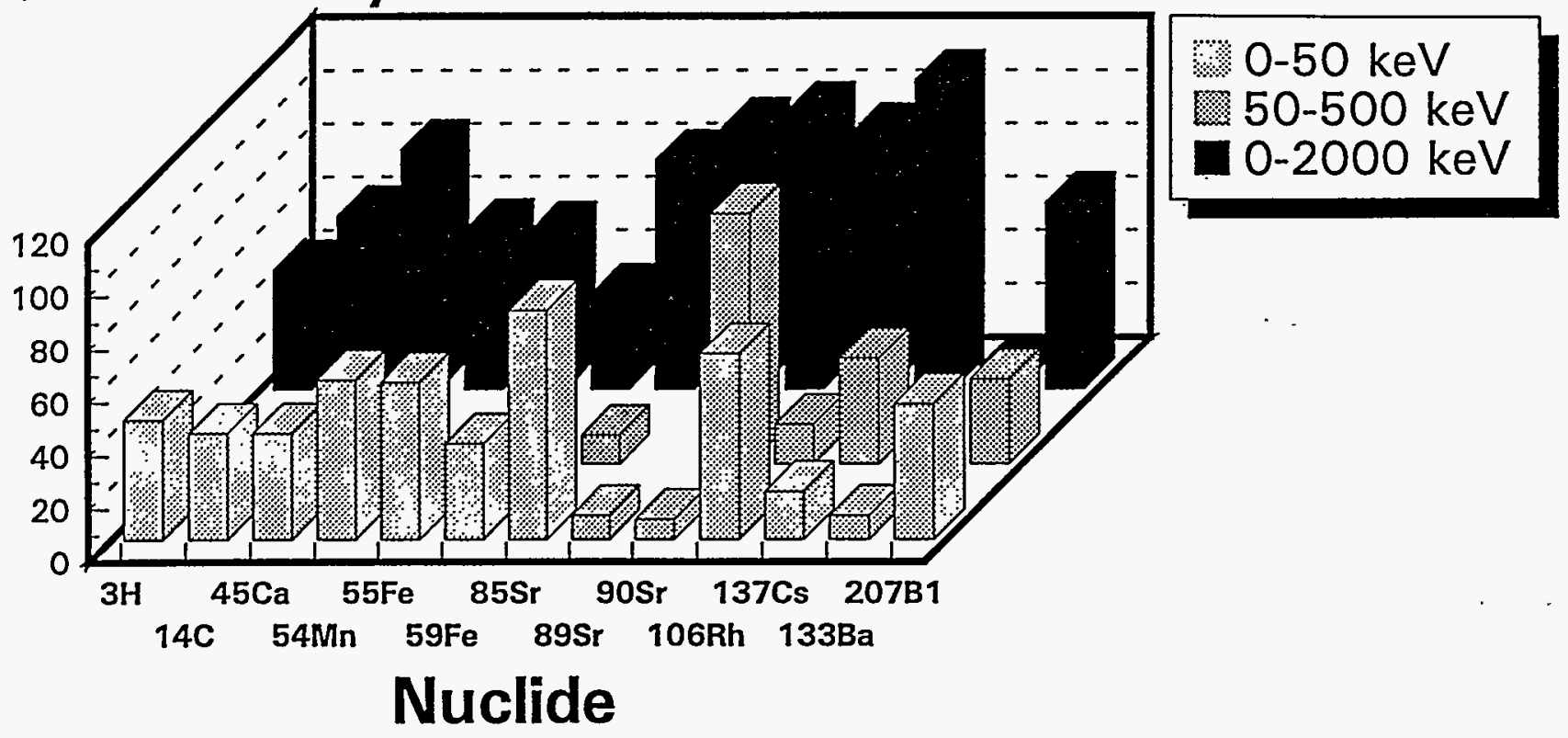

\% Efficiency

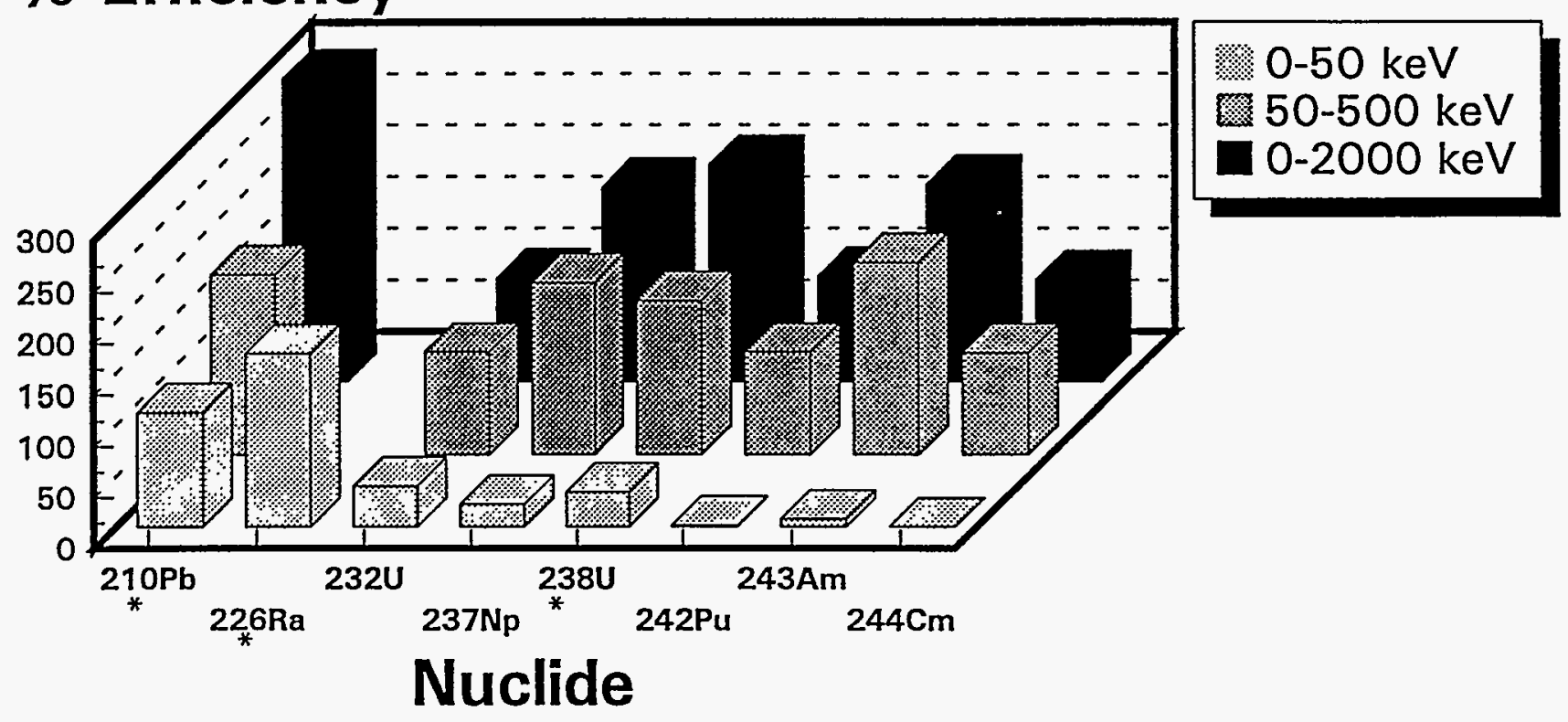

Figure 8. Unquenched efficiencies by ROI.

(a) beta and gamma emitters and

(b) alpha emitters.

* plus progeny 


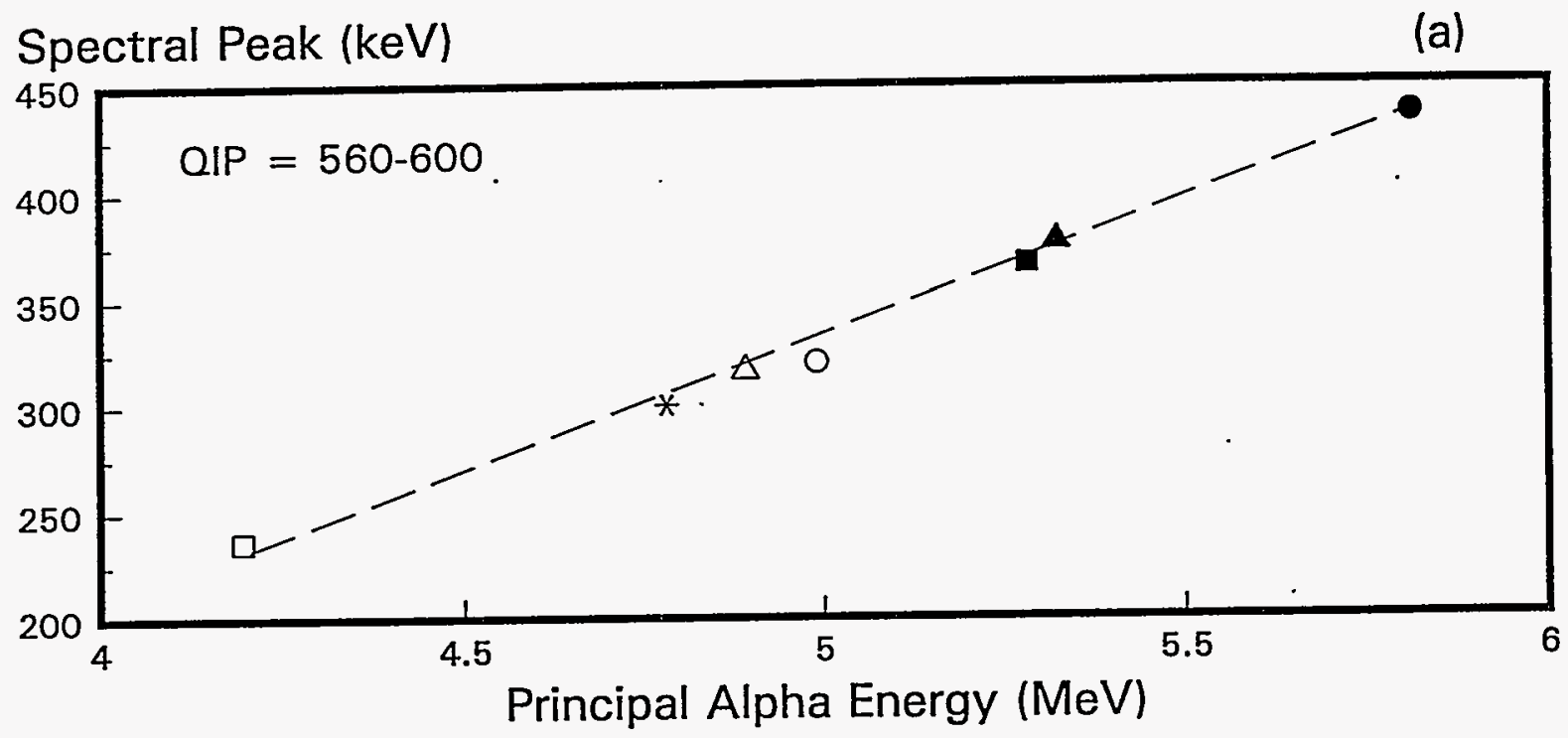

U-238 Pu-242 Np-237 Ra-226 Am-243 U-23232 Cm-244

Alpha Peak (keV)

(b)

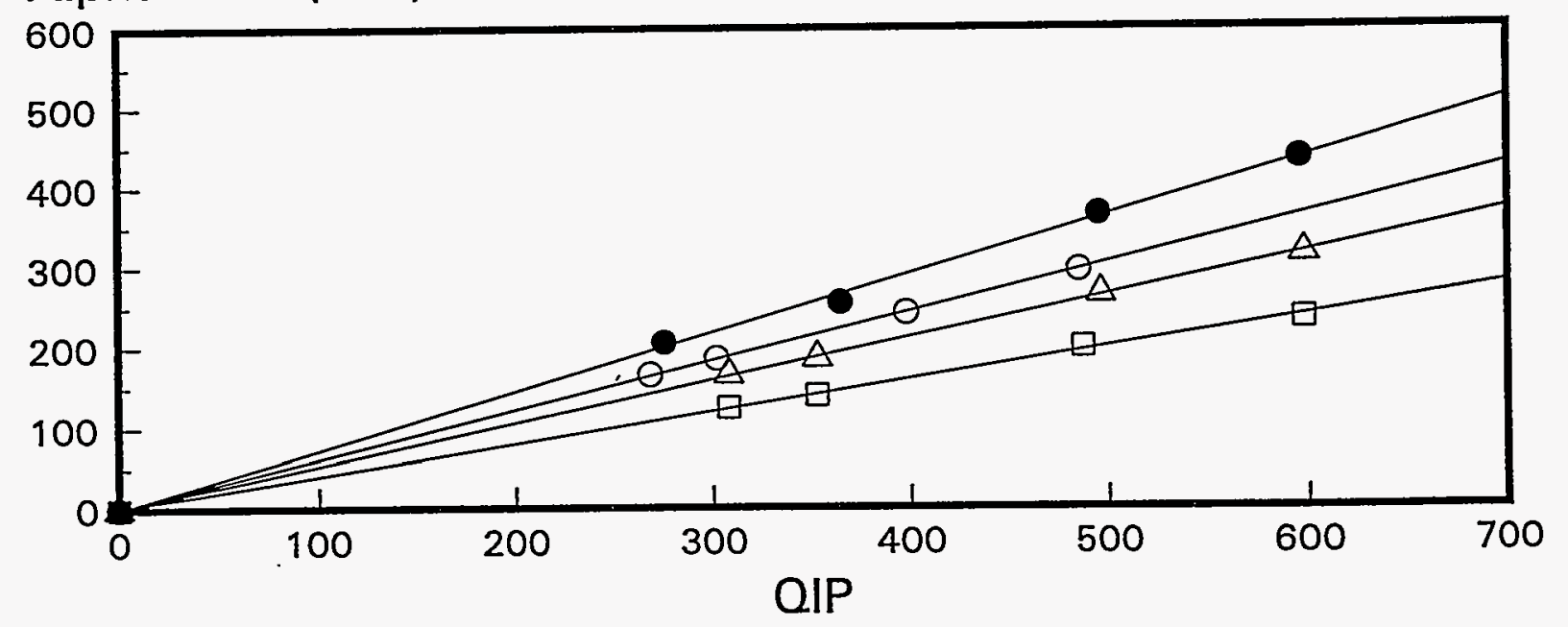

$\begin{array}{cccc}\mathrm{U}-238 & \mathrm{Pu}-242 & \text { Po-210 } & \mathrm{Cm}-244 \\ (4196 \mathrm{keV}) & (490 \mathrm{gkV}) & (5305 \mathrm{keV}) & (5805 \mathrm{keV})\end{array}$

Figure 9. Spectral parameters for alpha emitters.

(a) spectal peak vs alpha energy and

(b) quench index parameter vs alpha peak. 


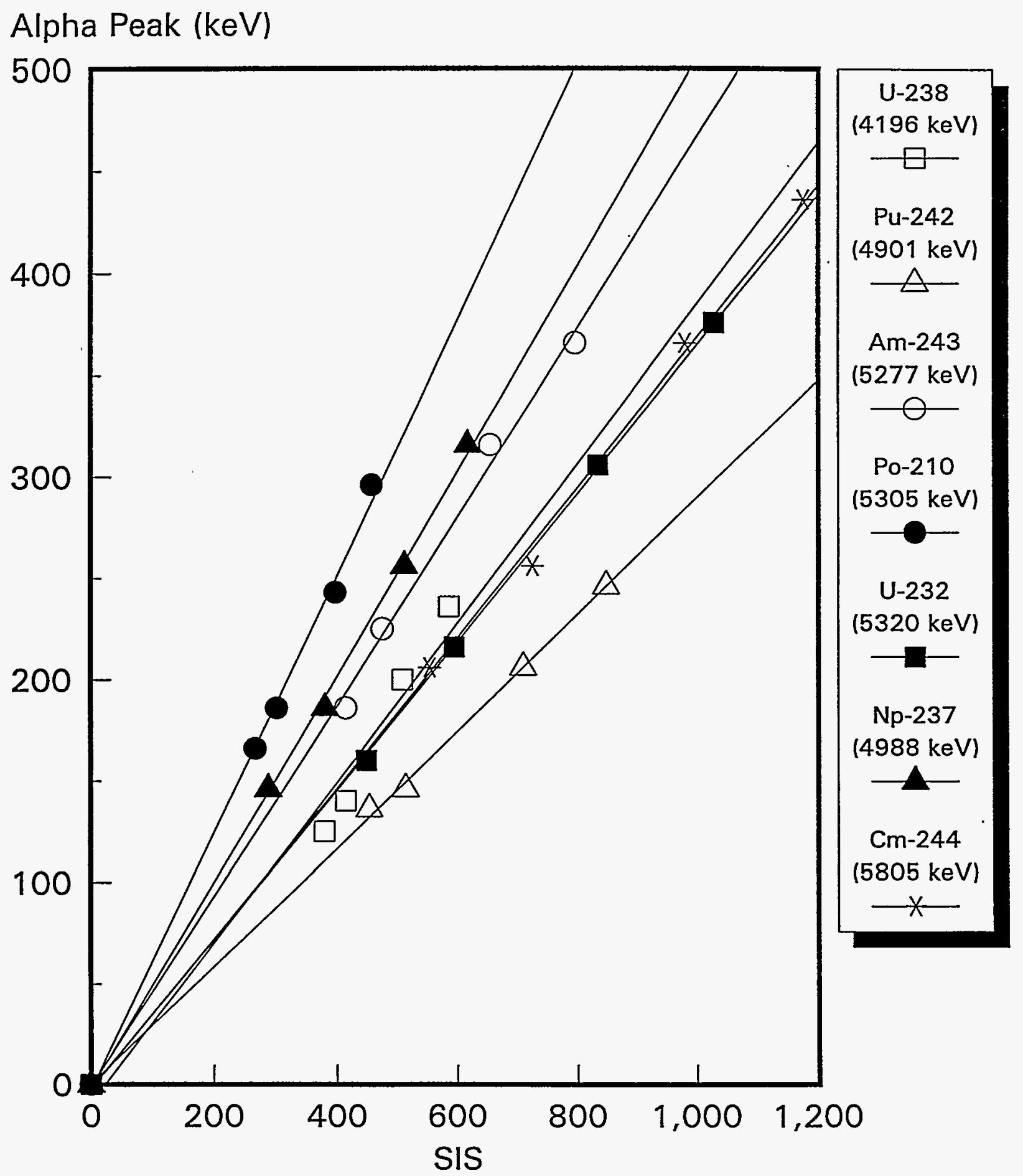

Figure 10. Spectral peak shifting due to quenching. 
$\%$ Efficiency $(0-50 \mathrm{keV})$

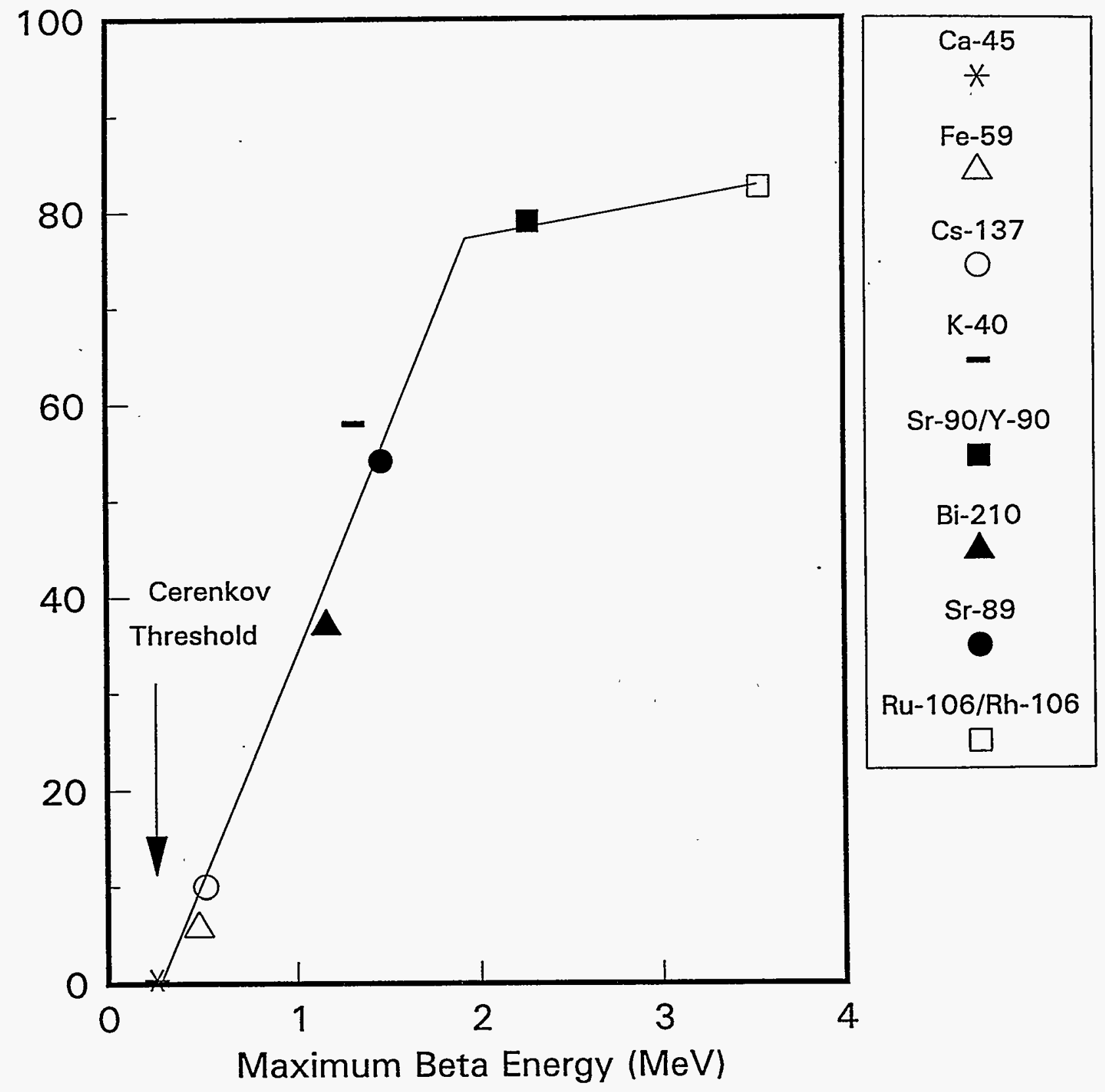

Figure 11. Cerenkov efficiency in $10 \mathrm{~mL}$ of $25 \mathrm{mM}$ ANSA. 


\section{\% Efficiency}

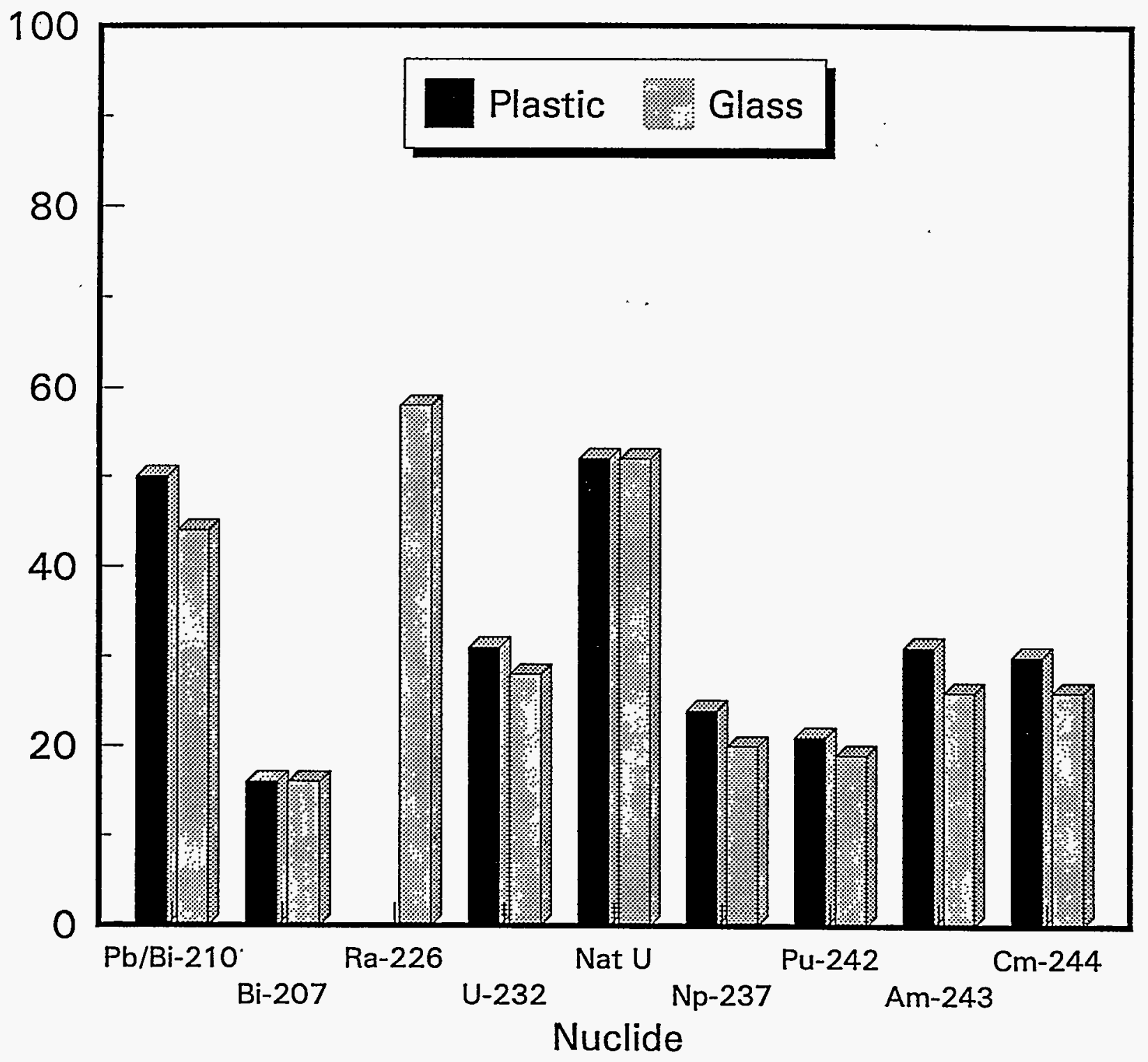

Figure 12. Cerenkov counting efficiencies of alpha emitters in glass and plastic vials containing $10 \mathrm{~mL}$ of $25 \mathrm{mM}$ ANSA. 


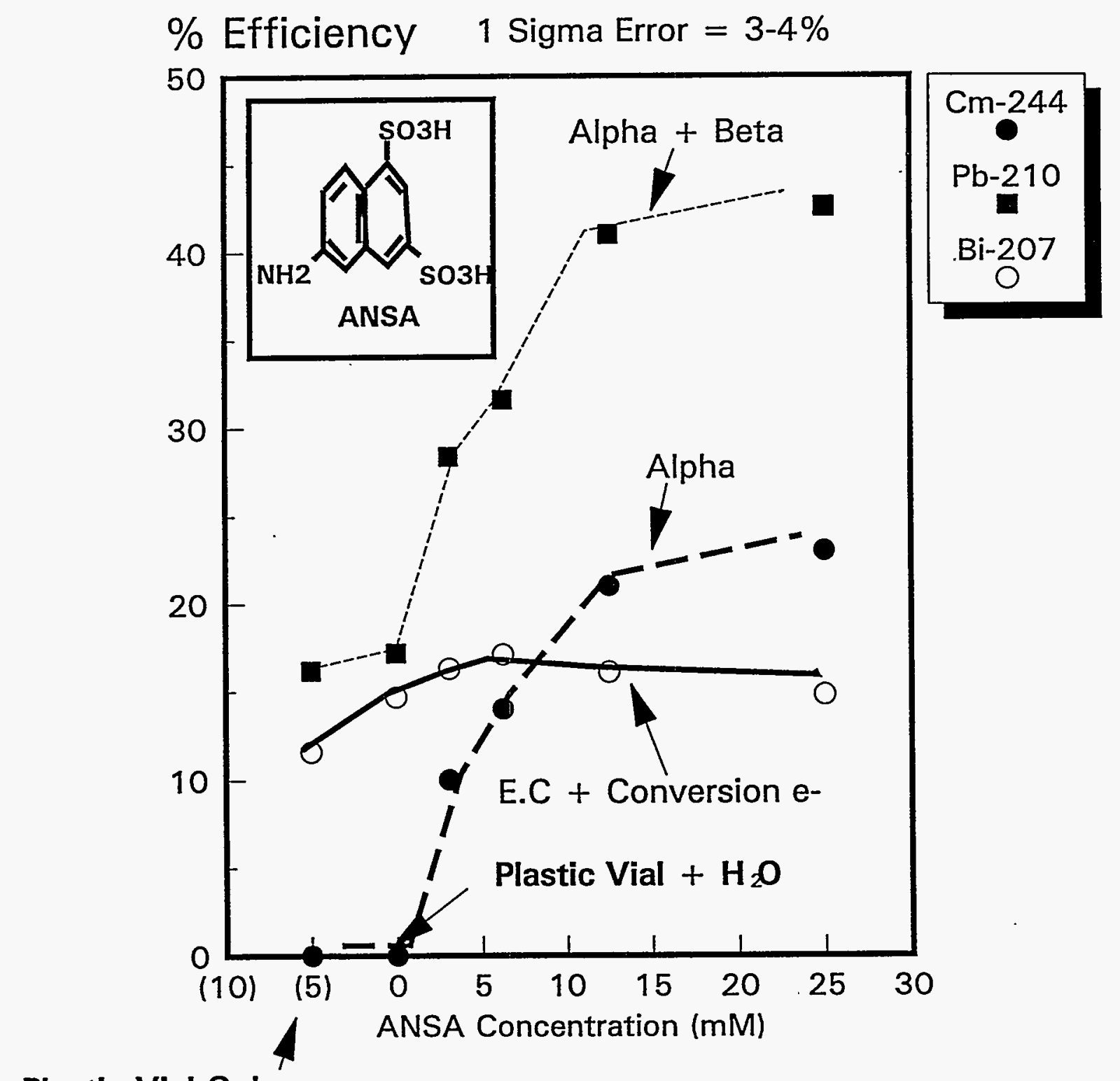

Plastic Vial Only

Figure 13. Cerenkov counting efficiency as function of ANSA in plastic vials. 


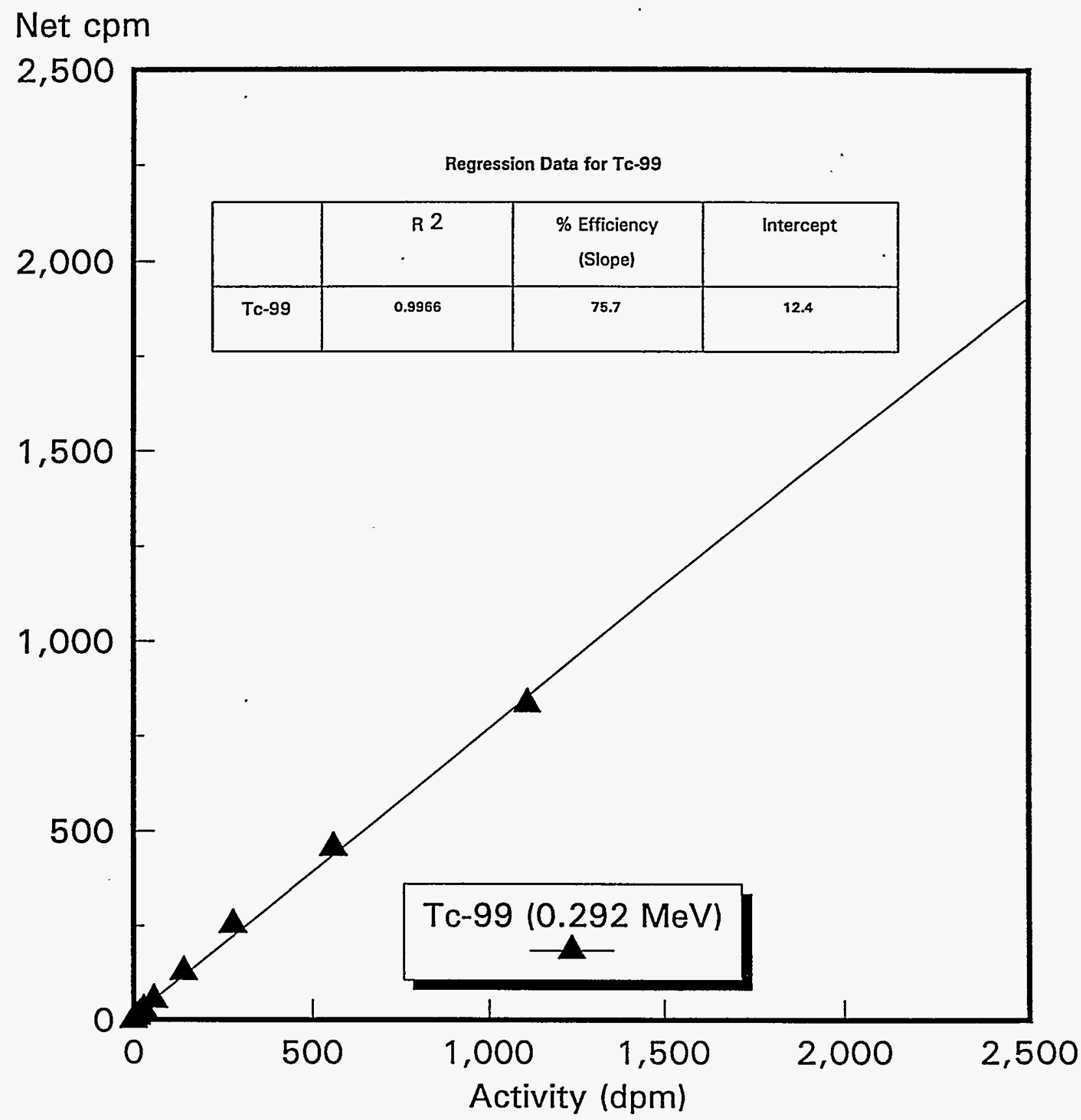

Figure 14. Efficiency calibration curve for ${ }^{99} \mathrm{Tc}$ in Insta-Gel and $2 \mathrm{~mL}$ of water. 


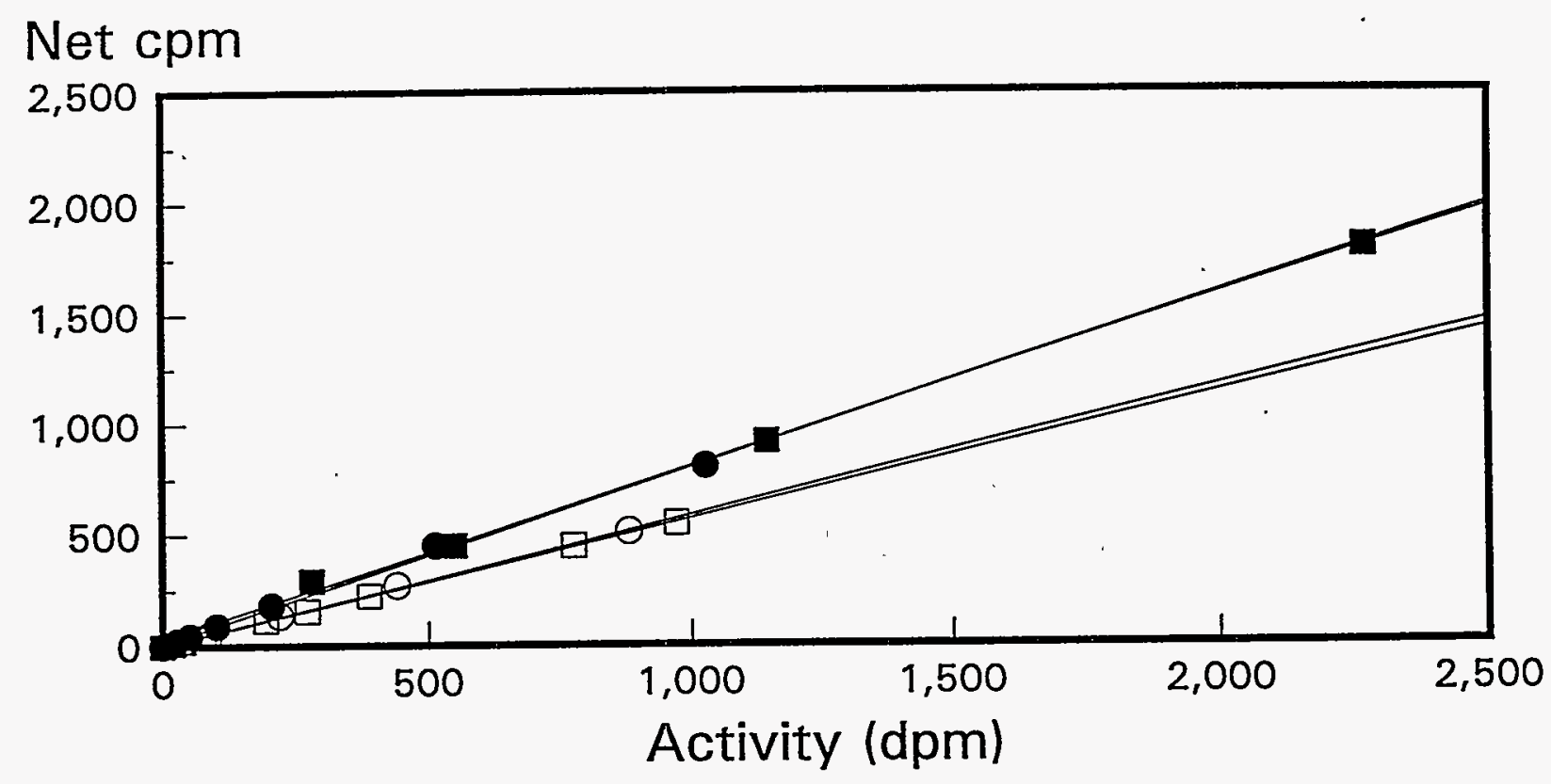

\section{$\stackrel{\mathrm{Mn}-54}{\mathrm{Sr}-85} \mathrm{Fe-55}$ Tc-95m}

\section{Regression Data}

\begin{tabular}{|c|c|c|c|c|}
\hline & $\mathrm{R}^{2}$ & \% Efficiency & Intercept & K-L3 Auger (keV) \\
\hline $\mathrm{Mn}-54(0-50 \mathrm{keV})$ & 0.9993 & 58.2 & 2.3 & 4.94 \\
\hline Fe-55 $(0-50 \mathrm{keV})$ & 0.9967 & 56.9 & 0.6 & 5.30 \\
\hline $\mathrm{Sr}-85(0-50 \mathrm{keV})$ & 0.9997 & 70.1 & 8.6 & 11.60 \\
\hline Tc-95m (1-500 keV) & 0.9990 & 77.7 & 29.5 & 14.90 \\
\hline
\end{tabular}

Figure 15. Efficiency calibration curves for EC and gamma emitters producing K-L3 Auger electrons in Insta-Gel. 

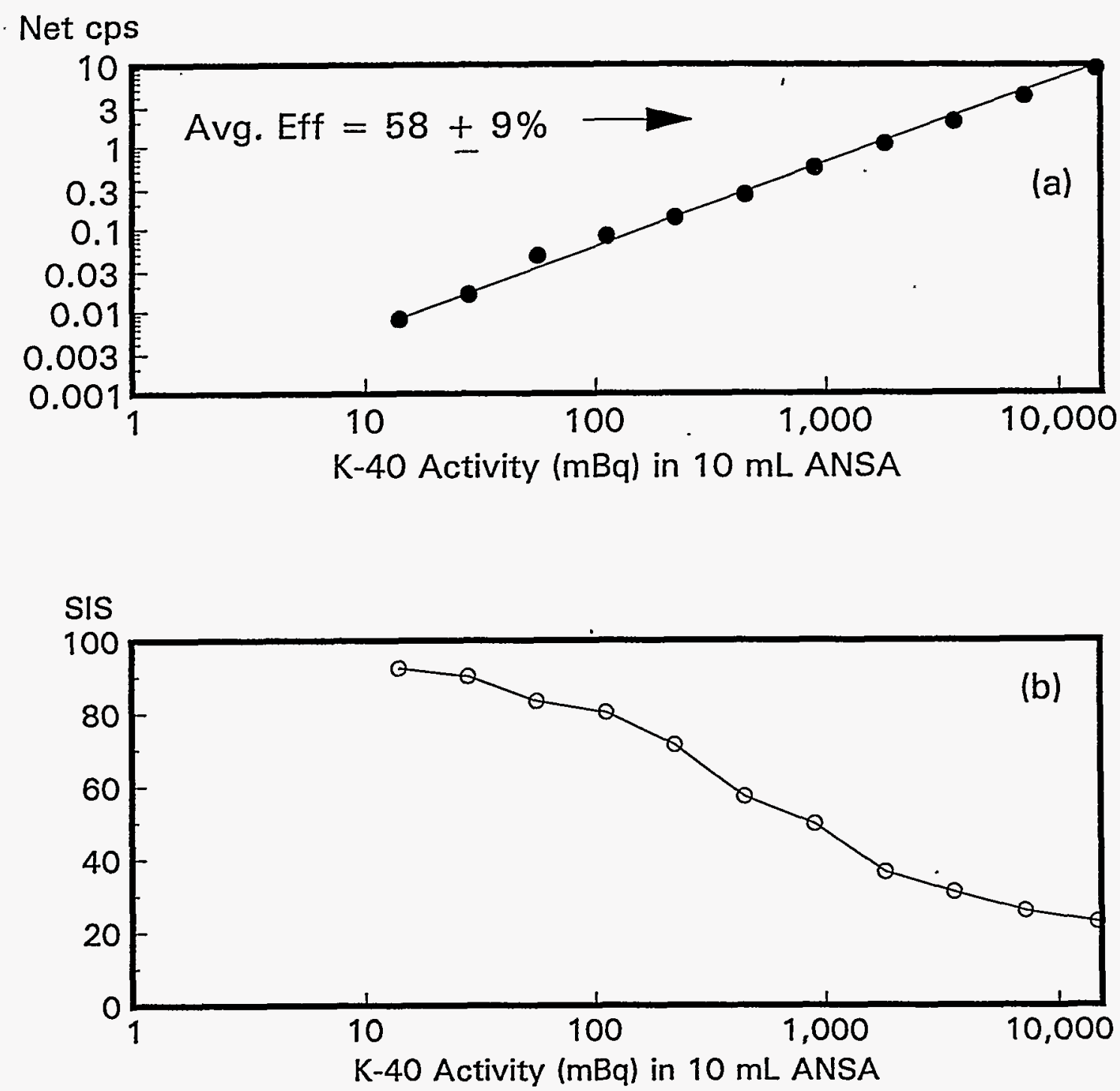

Figure 16. Cerenkov counting activity calibration curve for ${ }^{40} \mathrm{~K}$ as $\mathrm{KCl}$. (a) efficiency curve in $25 \mathrm{mM}$ ANSA and (b) SIS vs activity curve? 


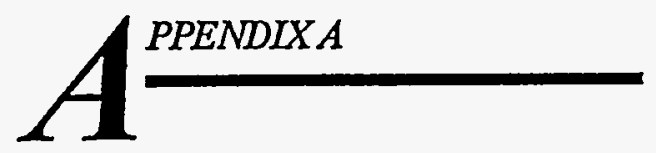

\section{FULL SPECTRUM ANALYSIS}

FSA is a dual-tracer counting method, unique to the Packard instrument, that is based on using a single counting region of the LSA for the entire spectral energy distribution of the sample (De Filippis, 1990). It requires the counting of a series of quenched standards for each radionuclide. A relationship is first established between the degree of quench (QIP) and each radionuclide's counting efficiency. Each standard contains a known and equivalent activity $(\mathrm{Bq})$ into which, in successive standards, increasing amounts of a chemical quenching agent (nitromethane) is introduced.

The advantage of the FSA method is that each radionuclide can be measured with the maximum counting efficiency possible, and there is no count loss due to the use of discrete energy regions. Samples containing two radionuclides (beta or gamma emitting isotopes that produce internal conversion electrons) can usually be measured with equal or higher counting efficiency by a ISA than with a gamma counter. The chemical yield can be determined directly from the LS data by taking the ratio of the observed yield determinant activity present to the known amount added.

Spectrum unfolding is a ratio method that can deconvolute the composite spectrum of a sample containing two nuclides into its components. Each component of a dual-tracer sample represents the count contribution of the particular radionuclide to the total activity (cpm) of the dual-tracer sample. The method requires the use of a second quench parameter, the SIS, which is an additional feature of the Packard Tri-Carb LS counting.

At a given level of quenching, each radionuclide has a definite mean pulse height distribution and hence a unique SIS value. The basis of nuclide separation is that, at a given quench (QIP) value, the combined pulse height distribution of a dual labeled sample produces a combined total sample pulse height $\left(\mathrm{SIS}_{\mathrm{Mix}}\right)$ made up of the combination of the individual low and high energy radionuclide pulse heights, SIS $_{\mathrm{L}}$ and $\mathrm{SIS}_{\mathrm{H}}$, both of which are measured using single labeled standards of known activity. At a given QIP value, the SIS value of the dual tracer, SIS $_{\text {Mix, }}$, will always lie between the SIS values of the individual radionuclides $\left(\right.$ SIS $_{\mathrm{L}}$ and $\mathrm{SIS}_{\mathrm{H}}$ ). The ratio of the difference between the SIS value of the dual labeled sample and that of the radionuclide of interest $\left(\mathrm{SIS}_{\mathrm{Mix}}-\mathrm{SIS}_{\mathrm{H}}\right)$ to the difference between the individual radionuclides SIS values $\left(\mathrm{SIS}_{\mathrm{H}}-\mathrm{SIS}_{\mathrm{L}}\right)$ is the fraction of the total measured net count rate attributable to the nuclide of interest. Once the individual counts are separated by the ratio method, the corresponding activity $(\mathrm{Bq})$ is computed by the system software using the relationship between the LS counting efficiency (cpm Bq ${ }^{-1}$ ) and degree of sample quenching (QIP). With appropriate standards, both QIP and SIS values are automatically loaded into a programmed LS counter and can be used to quantify the activities of two radionuclides present in a sample.

The analysis may be performed manually using the following procedure. The spectral index of a dual labeled sample (SIS $\mathrm{Mix}_{\text {) }}$, as a function of the nuclide of interest $\left(\right.$ SIS $\left._{1}\right)$ is described by the following relationship:

$$
\operatorname{LnSIS}_{\mathrm{I}} \times \operatorname{LnSIS}_{\mathrm{Mix}}=\operatorname{Ln} \mathrm{SIS}_{\mathrm{Tr}} \times \operatorname{Ln} \mathrm{SIS}_{\mathrm{BI}}
$$


where

SIS $_{\mathrm{I}}=$ spectral index of nuclide of interest as a function of increasing activity (dpm) without the yield tracer present,

SIS $_{\mathrm{Mix}}=$ spectral index of dual-tracer sample,

SIS $_{\mathrm{Tr}}=$ spectral index of yield tracer alone, and

SIS $_{\mathrm{Bl}}=$ spectral index of blank sample.

The difference between the SIS value of the dual labeled sample $\left(\mathrm{SIS}_{\mathrm{Mix}}\right)$, and that of the yield tracer sample is determined from the output data of the instrument. Equation (Al) is then used to determine the SIS value of the nuclide of interest's component (at the SIS value for the dual labeled sample, SIS $_{\text {Mix }}$ ). Finally, the difference between the calculated SIS $_{\mathrm{I}}$ value and the $\mathrm{SIS}_{\mathrm{Ir}}$ value is obtained. The ratio of the two differences is the fractional contribution to the net total sample count rate (cpm) attributable to the nuclide of interest. The net residual count rate (cpm) is that due to the yield tracer. Sample activity $(\mathrm{dpm})$ is determined from the observed (fractional) count rate using the QIP value of the sample and the efficiency calibration curve. The complete expression used to calculate the nuclide of interest's activity, I $\left(\mathrm{Bq} \mathrm{kg}{ }^{-1}\right)$, in a dual labeled sample is:

$$
I\left(\mathrm{Bqkg}^{-1}\right)=\frac{\text { net total cps } \times\left(\mathrm{SIS}_{\mathrm{I}}-\mathrm{SIS}_{\mathrm{Tr}}\right)}{\mathrm{E}_{\mathrm{I}} \mathrm{RW} \times\left(\mathrm{SIS}_{\mathrm{MIX}}-\mathrm{SIS}_{\mathrm{TI}}\right)}
$$

where $E_{T}=$ counting efficiency for nuclide, $I\left(\mathrm{cps} \mathrm{Bq}^{-1}\right)$, at the $\mathrm{QIP}$ value of the sample, $\mathrm{R}=$ fractional yield recovery, $\mathrm{W}=$ weight of sample $(\mathrm{kg})$, and $S I S_{\mathrm{I}}$ is calculated using Equation (Al) with measured values of SIS $_{\text {Binb }}$ SIS Ir $_{\text {and }}$ SIS $\mathrm{Mix}_{\text {. }}$

The relationship between the SIS and QIP for both ${ }^{99} \mathrm{Tc}$ and ${ }^{95 \mathrm{~m}} \mathrm{Tc}$ activity is presented in Figure AI which shows the decrease in the SIS with increasing degree of quench. Figure Al also shows that the -SIS values for equivalent activities of ${ }^{99} \mathrm{Tc}$ and ${ }^{95 \mathrm{~m} T \mathrm{~T}}$ are sufficiently separated so that FSA can be performed using Equations (A1) and (A2)..

The data in Table Al shows the capability of the FSA method to resolve the activity concentrations present in a dual labeled sample that contained beta emitting ${ }^{99} \mathrm{Tc}$ and gamma emitting ${ }^{95 \mathrm{~m}} \mathrm{Tc}$ in disproportionate ratios. The values for SIS $\mathrm{Mix}_{\mathrm{x}}$ are presented in column 2 of Table Al. The counting efficiencies $\left(E_{1}\right)$ for ${ }^{99} \mathrm{Tc}$ and ${ }^{95 m} \mathrm{Tc}$, at the QIP values shown in column 3 of Table $\mathrm{Al}$, were $97 \%$ and $83 \%$, respectively. The FSA method is accurate to within $10 \%$ for ${ }^{95 \mathrm{~m}} \mathrm{Tc} .{ }^{.99} \mathrm{Tc}$ activity ratios ranging from $15: 1$ to $0.5: 1$. The mean ratio of found to added ${ }^{99} \mathrm{Tc}$ for six samples, ranging in activity from 16.6 to 558 $\mathrm{dpm}$, was $0.998 \pm 0.07$, whereas the mean ${ }^{95 m} \mathrm{Tc}$ activity, measured concurrently, was $258 \pm 24 \mathrm{dpm}$. The latter value compared favorably with the $252 \mathrm{dpm}$ of yield tracer that was added to each sample. 
TABLE A 1

RESULTS OF TECHNETIUM FULL SPECTRUM ANALYSIS

${ }^{99} \mathrm{Tc}$ Standards Contain $252 \mathrm{dpm}{ }^{95 \mathrm{~m}} \mathrm{Tc}+2 \mathrm{~mL} \mathrm{H}_{2} \mathrm{O}+$ Insta-Gel-XF

\begin{tabular}{rcccccc}
\hline $\begin{array}{c}\text { Added }{ }^{99} \mathrm{Tc} \\
(\mathrm{dpm})\end{array}$ & SIS & QIP & $\begin{array}{l}\text { Gross } \\
\mathrm{cpm}^{*}\end{array}$ & $\begin{array}{c}{ }^{99} \mathrm{Tc} \\
(\mathrm{dpm})\end{array}$ & $\begin{array}{r}{ }^{95 \mathrm{Tm}} \\
(\mathrm{dpm})\end{array}$ & $\begin{array}{c}\text { Ratio F/A** } \\
{ }^{99} \mathrm{Tc}\end{array}$ \\
\hline 0.0 & 112.1 & 424 & 240.3 & 0.0 & 248 & \\
8.3 & 114.4 & 426 & 249.5 & 12.5 & 346 & 1.50 \\
16.6 & 114.7 & 420 & 255.7 & 14.8 & 251 & 0.89 \\
27.7 & 116.5 & 419 & 267.0 & 27.4 & 251 & 0.99 \\
55.4 & 116.5 & 423 & 294.6 & 55.8 & 253 & 1.00 \\
138.7 & 124.0 & 425 & 376.8 & 145.7 & 261 & 1.05 \\
277.4 & 128.1 & 428 & 498.5 & 305.1 & 243 & 1.10 \\
558.8 & 128.9 & 432 & 712.3 & 538.8 & 317 & 0.96 \\
1110.0 & 125.3 & 422 & 1120.2 & 642.5 & 754 & 0.31 \\
\hline
\end{tabular}

$* 1 \mathrm{~h}$ count with 1 sigma $=1-4 \%:$ ROI $=1-500 \mathrm{keV}$

** $\mathrm{F}=$ Found $\quad \mathrm{A}=$ Added 


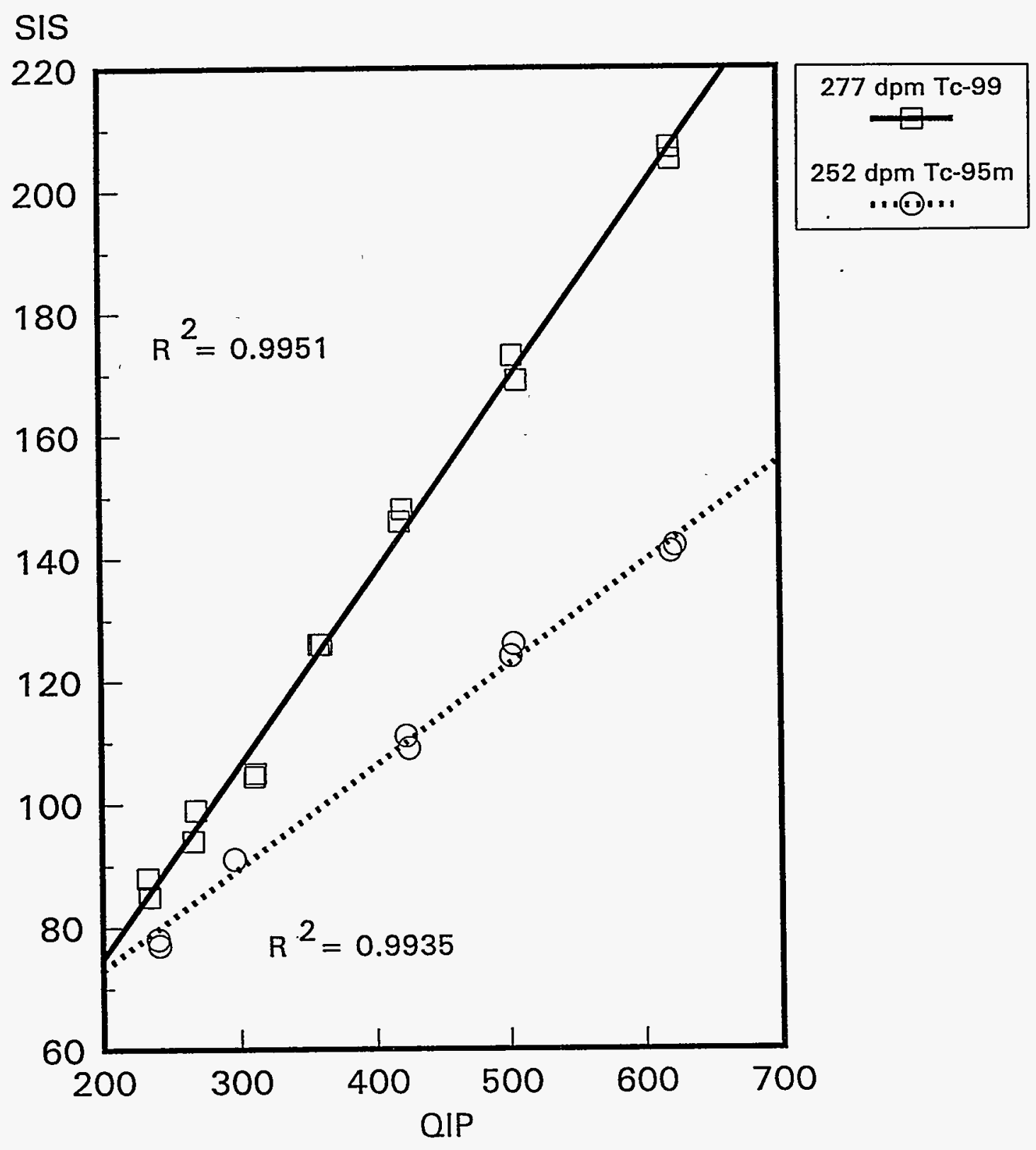

Figure A1. Full Spectrum analysis QIP vs SIS in $15 \mathrm{~mL}$ Insta-Gel. 


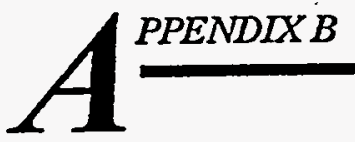

SPECTRAL DATA (IN ORDER OF ATOMIC MASS)

\begin{tabular}{|c|c|}
\hline Beta/Gamma/EC Emitters & Alpha Emitters \\
\hline $\begin{array}{l}\text { Fig. } \\
\text { B1: }{ }^{3} \mathrm{H} \\
\text { B2: } \\
\text { B3: }{ }^{45} \mathrm{Ca} \\
\text { B4: }{ }^{54} \mathrm{Mn} \\
\text { B5: }{ }^{55} \mathrm{Fe} \\
\text { B6: }{ }^{59} \mathrm{Fe} \\
\text { B7: }{ }^{85} \mathrm{Sr} \\
\text { B8: }{ }^{89} \mathrm{Sr} \\
\text { B9: }{ }^{90} \mathrm{Sr} \\
\text { B10: }{ }^{90} \mathrm{Y} / \mathrm{Sr} \\
\text { B11: }{ }^{95 \mathrm{~m}} \mathrm{Tc} \\
\text { B12: }{ }^{99} \mathrm{Tc} \\
\text { B13: }{ }^{106} \mathrm{Ru} / \mathrm{Rh} \\
\text { B14: }{ }^{133} \mathrm{Ba} \\
\text { B15: }{ }^{137} \mathrm{Cs} /{ }^{137} \mathrm{Ba} \\
\text { B16: }{ }^{207} \mathrm{Bi}\end{array}$ & $\begin{array}{l}\text { Fig. } \\
\text { B17: }{ }^{210} \mathrm{~Pb} / \mathrm{Bi} \\
\text { B18: }{ }^{226} \mathrm{Ra}+\text { Progeny } \\
\text { B19: }{ }^{232} \mathrm{U} \\
\text { B20: }{ }^{237} \mathrm{~Np} \\
\text { B21: nat } \\
\text { B22: }{ }^{242} \mathrm{Pu} \\
\text { B23: }:{ }^{243} \mathrm{Am} \\
\text { B24: }:{ }^{244} \mathrm{Cm}\end{array}$ \\
\hline
\end{tabular}


TABLE B1

REGRESSION DATA FOR EFFICIENCY VERSUS QIP IN FIGURES B1-B17

$\%$ Efficiency $=(m \times Q I P)+b$

\begin{tabular}{lccccc}
\hline & $\begin{array}{c}\text { E-max } \\
(\mathrm{MeV})\end{array}$ & $\begin{array}{c}\text { Slope } \\
(\mathrm{m})\end{array}$ & $\begin{array}{c}\text { Intercept } \\
(\mathrm{b})\end{array}$ & $\begin{array}{c}\text { Correlation } \\
\text { Coefficient }\left(\mathrm{R}^{2}\right)\end{array}$ & $\begin{array}{c}\text { ROI } \\
(\mathrm{keV})\end{array}$ \\
\hline${ }^{3} \mathrm{H}$ & 0.009 & 0.0560 & 9.50 & 0.976 & $0-35$ \\
${ }^{14} \mathrm{C}$ & 0.142 & 0.1170 & $(10.40)$ & 0.987 & $1-300$ \\
${ }^{45} \mathrm{Ca}$ & 0.256 & 0.0090 & 84.10 & 0.584 & $1-300$ \\
${ }^{54} \mathrm{Mn}$ & $* *$ & 0.0910 & 1.26 & 0.989 & $0-50$ \\
${ }^{55} \mathrm{Fe}$ & $* *$ & 0.1040 & $(7.90)$ & 0.933 & $0-50$ \\
${ }^{59} \mathrm{Fe}$ & 0.475 & $(0.0600)$ & 74.60 & 0.990 & $0-50$ \\
${ }^{85} \mathrm{Sr}$ & $*$ & 0.0230 & 71.10 & 0.340 & $0-20$ \\
${ }^{89} \mathrm{Sr}$ & 1.492 & 0.0090 & 92.00 & 0.424 & $1-2000$ \\
${ }^{90} \mathrm{Sr} *$ & 0.546 & $(0.0200)$ & 116.60 & 0.355 & $1-2000$ \\
${ }^{90} \mathrm{Y} / \mathrm{Sr}$ & $0.546,2.28$ & 0.0140 & 76.20 & 0.541 & $1-2000$ \\
${ }^{95 \mathrm{~m}} \mathrm{Tc}$ & $* *$ & 0.0160 & 70.50 & 0.443 & $1-100$ \\
${ }^{99} \mathrm{Tc}$ & 0.292 & $(0.0130)$ & 91.70 & 0.158 & $1-500$ \\
${ }^{106} \mathrm{Rh} / \mathrm{Ru}$ & $0.039 ; 3.54$ & 0.0090 & 90.70 & 0.426 & $1-2000$ \\
${ }^{133} \mathrm{Ba}$ & $* *$ & $(0.0045)$ & 9.80 & 0.924 & $1-50$ \\
${ }^{137} \mathrm{Cs}$ & 0.514 & 0.0260 & 99.50 & 0.847 & $1-2000$ \\
${ }^{210} \mathrm{Bi} / \mathrm{Pb}$ & $0.060 ; 1.160$ & 0.0220 & 301.00 & 0.339 & $1-2000$ \\
\hline${ }^{54}$ & & & &
\end{tabular}

*Contains 3\% ${ }^{90} Y$ following EiChrom's separation (Horowitz and Dietz, 1991).

**E.C. and K-L3 Auger electrons (0-50 keV). 
TABLE B2

REGRESSION DATA FOR ALPHA EMITTERS: QIP VERSUS EFFICIENCY IN FIGURES B18-B28

$\%$ Efficiency $=(m \times Q I P)+b$

\begin{tabular}{lccccc}
\hline & $\begin{array}{c}\text { Principal Alpha } \\
(\mathrm{MeV})\end{array}$ & $\begin{array}{c}\text { Slope } \\
(\mathrm{m})\end{array}$ & $\begin{array}{c}\text { Intercept (b) } \\
(\%)\end{array}$ & $\begin{array}{c}\text { Correlation } \\
\text { Coefficient }\left(\mathrm{R}^{2}\right)\end{array}$ & $\begin{array}{c}\text { ROI } \\
(\mathrm{keV})\end{array}$ \\
\hline${ }^{207} \mathrm{Bi}$ & E.C. & 0.059 & 69 & 0.922 & $0-2000$ \\
${ }^{226} \mathrm{Ra}$ & 4.784 & -1.083 & 991 & 0.967 & $0-2000$ \\
${ }^{232} \mathrm{U}$ & 5.320 & -0.004 & 103.4 & 0.372 & $0-2000$ \\
${ }^{237} \mathrm{~Np}$ & 4.873 & 0.004 & 186.5 & 0.012 & $0-2000$ \\
${ }^{n a t} \mathrm{U}$ & $4.196 ; 4.776$ & 0.005 & 207.5 & 0.135 & $0-2000$ \\
${ }^{242} \mathrm{Pu}$ & 4.901 & 0 & 102.7 & 0.002 & $0-2000$ \\
${ }^{243} \mathrm{Am}$ & 5.277 & 0.007 & 196.9 & 0.052 & $0-2000$ \\
${ }^{244} \mathrm{Cm}$ & 5.805 & -0.0001 & 100.8 & 0.117 & $0-2000$ \\
\hline
\end{tabular}


TABLE B3

REGRESSION DATA FOR SIS VERSUS QIP DATA IN FIGURES B1-B17

$\mathrm{SIS}=(\mathrm{m} \times \mathrm{QIP})+\mathrm{b}$

\begin{tabular}{rccccc}
\hline & $\begin{array}{c}\text { E-max } \\
(\mathrm{MeV})\end{array}$ & $\begin{array}{c}\text { Slope } \\
(\mathrm{m})\end{array}$ & $\begin{array}{c}\text { Intercept } \\
(\mathrm{b})\end{array}$ & $\begin{array}{c}\text { Correlation } \\
\text { Coefficient }\left(\mathrm{R}^{2}\right)\end{array}$ & $\begin{array}{r}\text { Sample } \\
(\text { dpm })\end{array}$ \\
\hline${ }^{3} \mathrm{H}$ & 0.009 & 0.009 & 32.20 & 0.284 & 100 \\
${ }^{14} \mathrm{C}$ & 0.142 & 0.142 & 19.84 & 0.999 & 1500 \\
${ }^{45} \mathrm{Ca}$ & 0.256 & 0.240 & 15.22 & 0.999 & 950 \\
${ }^{54} \mathrm{Mn}$ & $*$ & $(0.100)$ & 297.20 & 0.180 & 220 \\
${ }^{55} \mathrm{Fe}$ & $*$ & & & & \\
${ }^{59} \mathrm{Fe}$ & 0.475 & 0.424 & 127.30 & 0.977 & 208 \\
${ }^{85} \mathrm{Sr}$ & $*$ & $(0.158)$ & 187.20 & 0.517 & 176 \\
${ }^{89} \mathrm{Sr}$ & 1.492 & 0.322 & 485.70 & 0.890 & 1200 \\
${ }^{90} \mathrm{Sr}$ & 0.546 & 0.582 & 46.10 & 0.998 & 120 \\
${ }^{90} \mathrm{Y} / \mathrm{Sr} *$ & $0.546 ; 2.28$ & 0.290 & 297.70 & 0.947 & 240 \\
${ }^{95 m} \mathrm{Tc}$ & $* *$ & 0.162 & 41.50 & 0.995 & 252 \\
${ }^{99} \mathrm{Tc}$ & 0.292 & 0.315 & 11.80 & 0.994 & 277 \\
${ }^{106} \mathrm{Rh} / \mathrm{Ru}$ & $0.039 ; 3.54$ & $(0.427)$ & 547.00 & 0.988 & 950 \\
${ }^{133} \mathrm{Ba}$ & $* *$ & 0.198 & 47.00 & 0.989 & 1500 \\
${ }^{137} \mathrm{Cs}$ & 0.514 & 0.670 & 37.70 & 0.988 & 250 \\
${ }^{210} \mathrm{Bi} / \mathrm{Pb}$ & $0.060 ; 1.160$ & 0.882 & 33.70 & 0.998 & \\
\hline
\end{tabular}

*Contains 3\% ${ }^{90} \mathrm{Y}$ following EiChrom separation (Horowitz and Dietz, 1991).

**E C and K-L3 Auger electrons (0-50 keV). 
TABLE B4

REGRESSION DATA FOR ALPHA EMITTERS SIS VERSUS QIP DATA IN FIGURES 18-24

$$
\mathrm{SIS}=(\mathrm{m} \times \mathrm{QIP})+\mathrm{b}
$$

\begin{tabular}{cccccc}
\hline & $\begin{array}{c}\text { Principal Alpha } \\
(\mathrm{MeV})\end{array}$ & $\begin{array}{c}\text { Slope } \\
(\mathrm{m})\end{array}$ & $\begin{array}{c}\text { Intercept } \\
(\mathrm{b})\end{array}$ & $\begin{array}{c}\text { Correlation } \\
\text { Coefficient }\left(\mathrm{R}^{2}\right)\end{array}$ & dpm in Sample \\
\hline${ }^{207} \mathrm{Bi}$ & E.C. & -0.221 & 270.4 & 0.862 & 1100 \\
${ }^{226} \mathrm{Ra}$ & 4.784 & 0.513 & 343.9 & 0.943 & 250 \\
${ }^{232} \mathrm{U}$ & 5.320 & 1.60 & 55.2 & 0.999 & 1750 \\
${ }^{237} \mathrm{~Np}$ & 4.873 & 1.10 & 21.4 & 0.999 & 1250 \\
${ }_{\mathrm{nat}} \mathrm{U}$ & $4.196 ; 4.776$ & 0.513 & 252 & 0.881 & 1150 \\
${ }^{242} \mathrm{Pu}$ & 4.901 & 1.345 & 43.6 & 0.999 & 980 \\
${ }^{243} \mathrm{Am}$ & 5.277 & 1.289 & 13.4 & 0.998 & 980 \\
${ }^{244} \mathrm{Cm}$ & 5.805 & 1.920 & 28.4 & 0.999 & 1000 \\
\hline
\end{tabular}




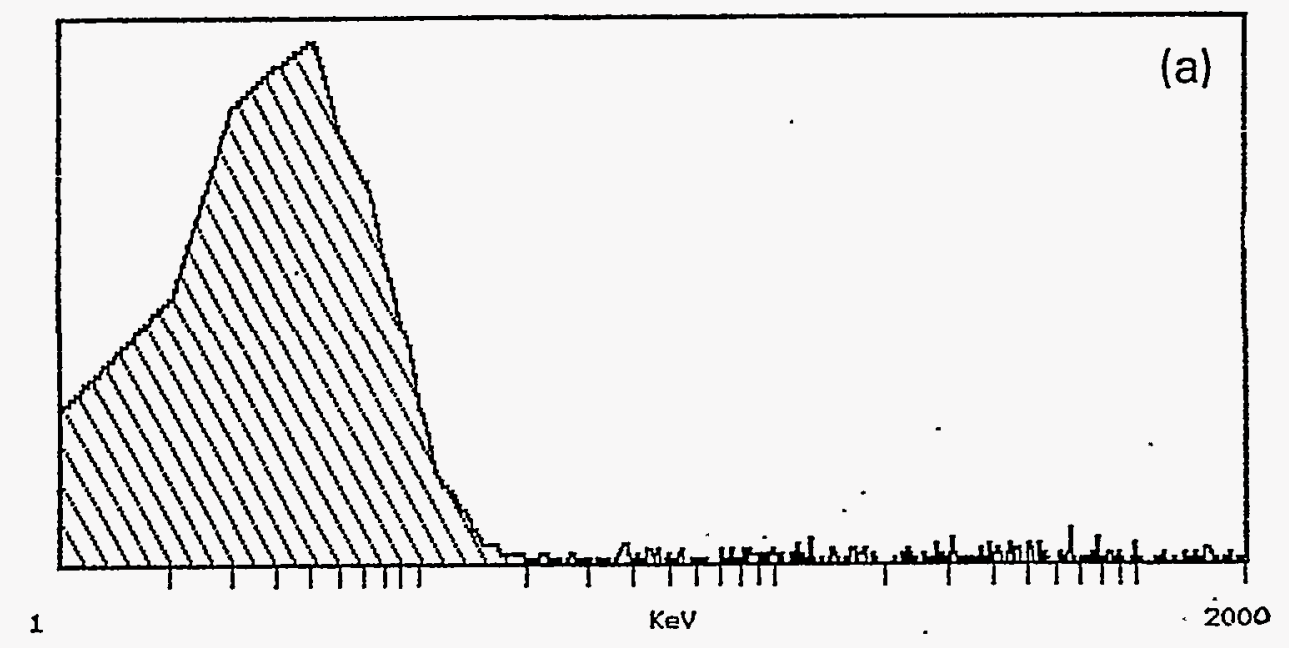

\% Efficiency

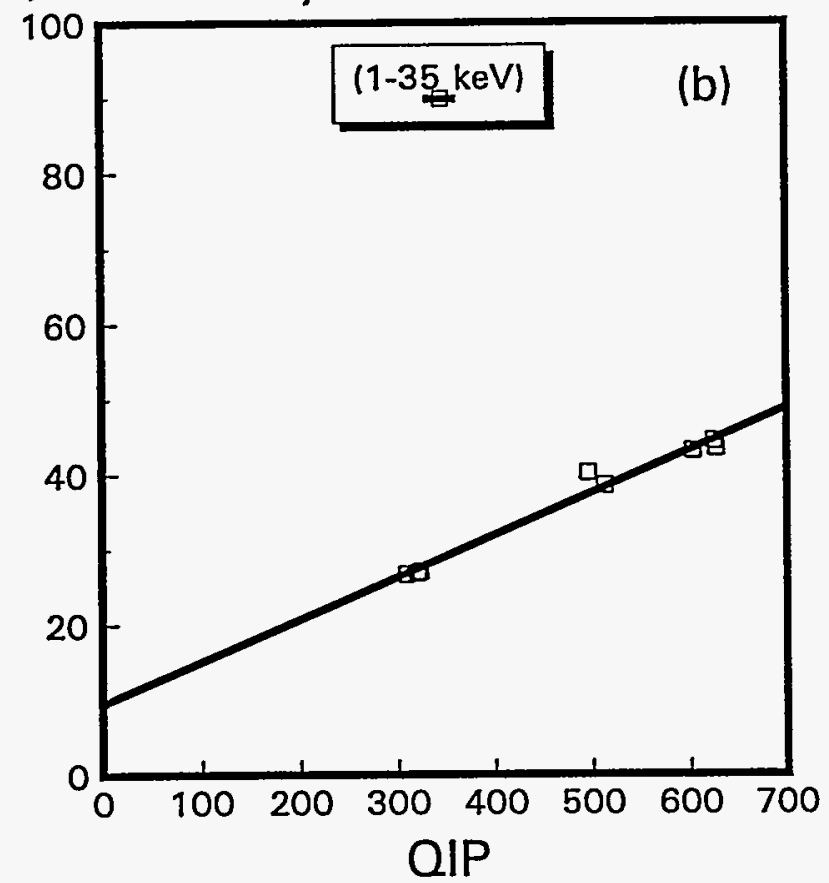

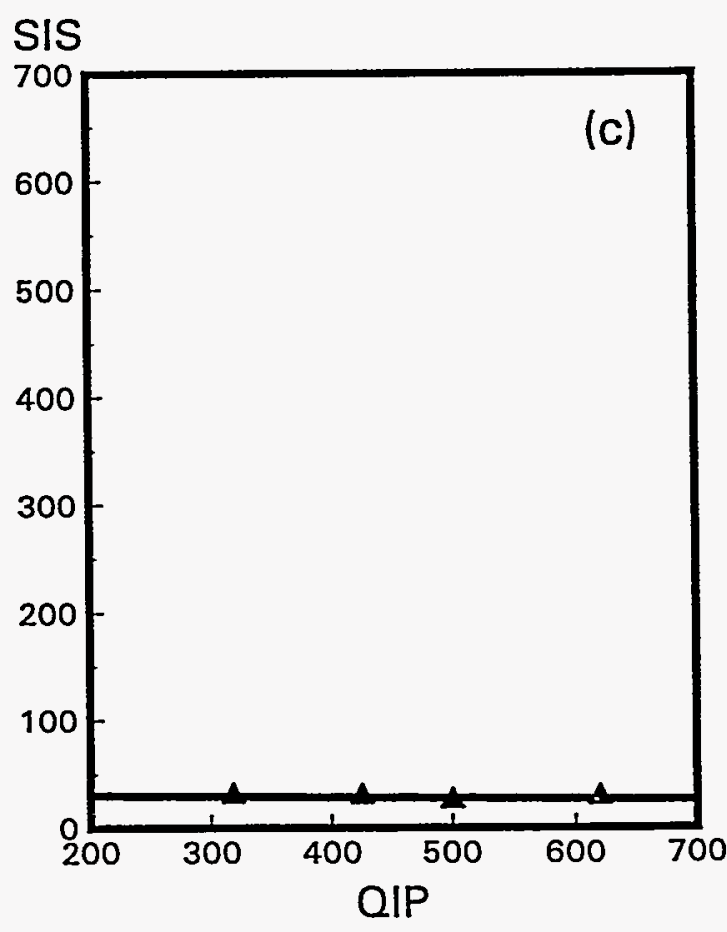

Figure B1. ${ }^{3} \mathrm{H}$ Nuclide Spectral Data: (a) Spectrum;

(b) Efficiency versus OIP (quench index parameter);

(c) SIS (spectral index of sample) versus QIP. 

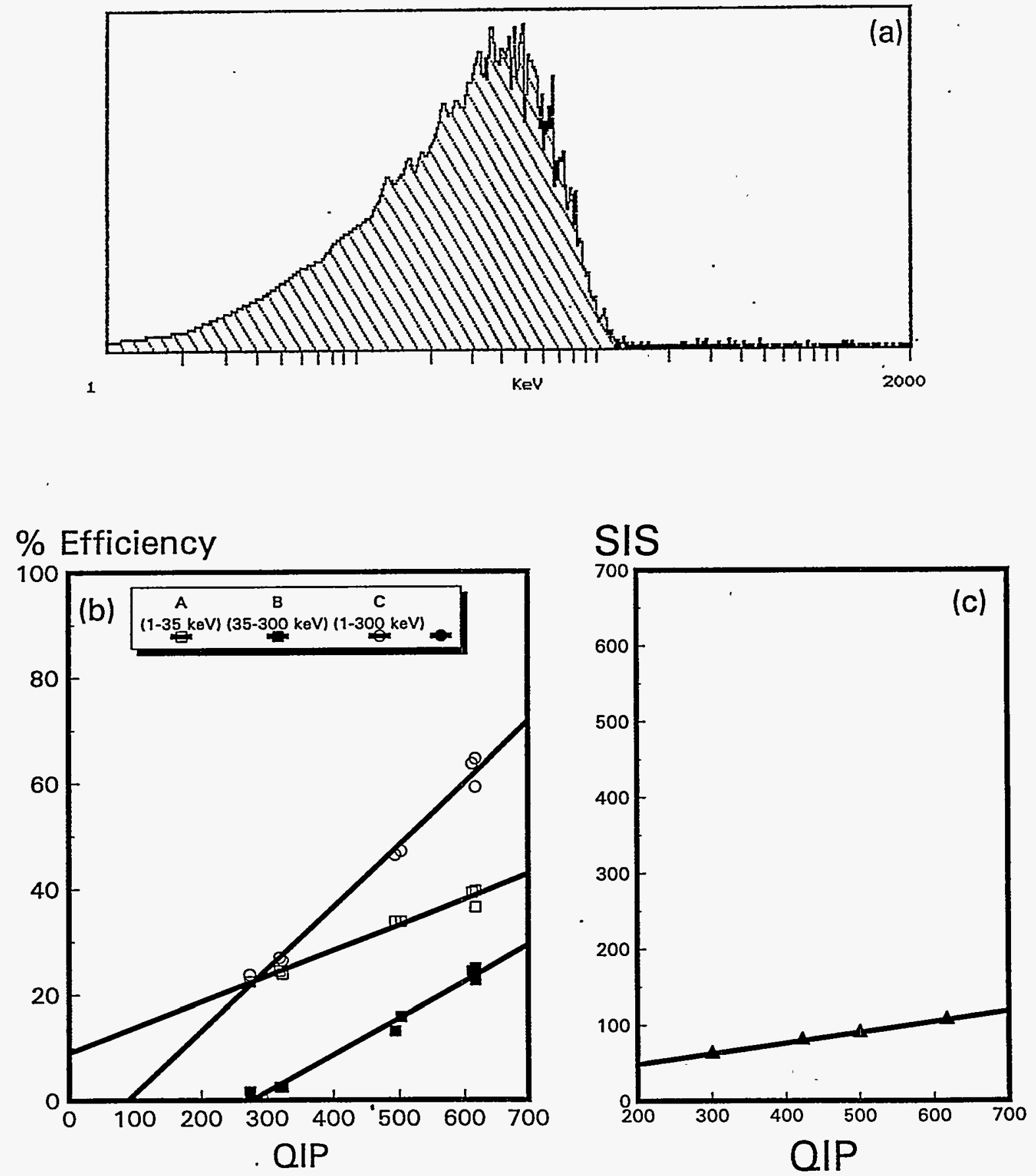

Figure B2. ${ }^{14} \mathrm{C}$ Nuclide Spectral Data: (a), (b), (c) same as Figure B1. 

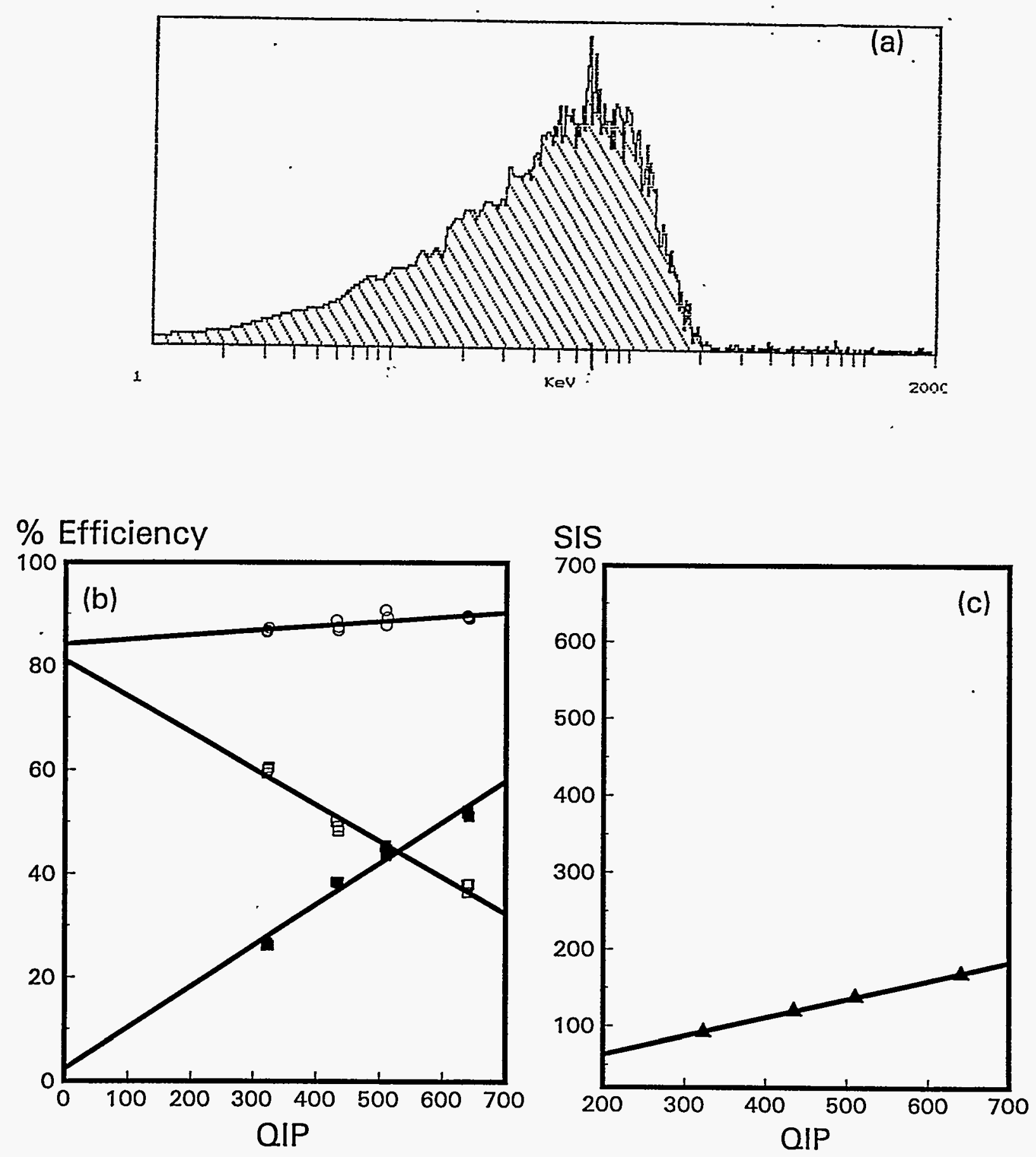

Figure B3. ${ }^{45}$ Ca Nuclide Spectral Data: (a), (b), (c) same as Figure B1. 

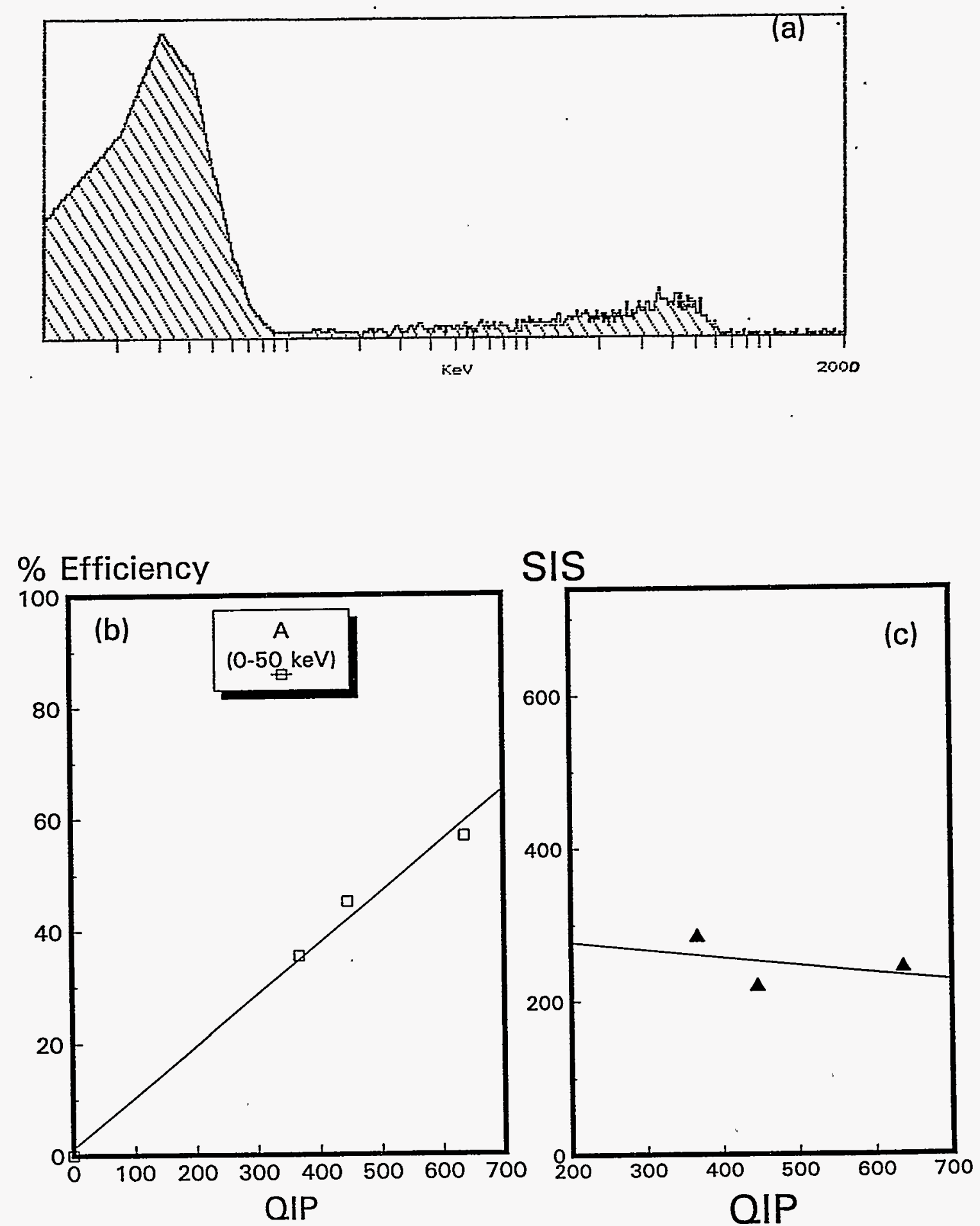

Figure B4. ${ }^{54} \mathrm{Mn}$ Nuclide Spectral Data: (a), (b), (c) same as Figure B1. 

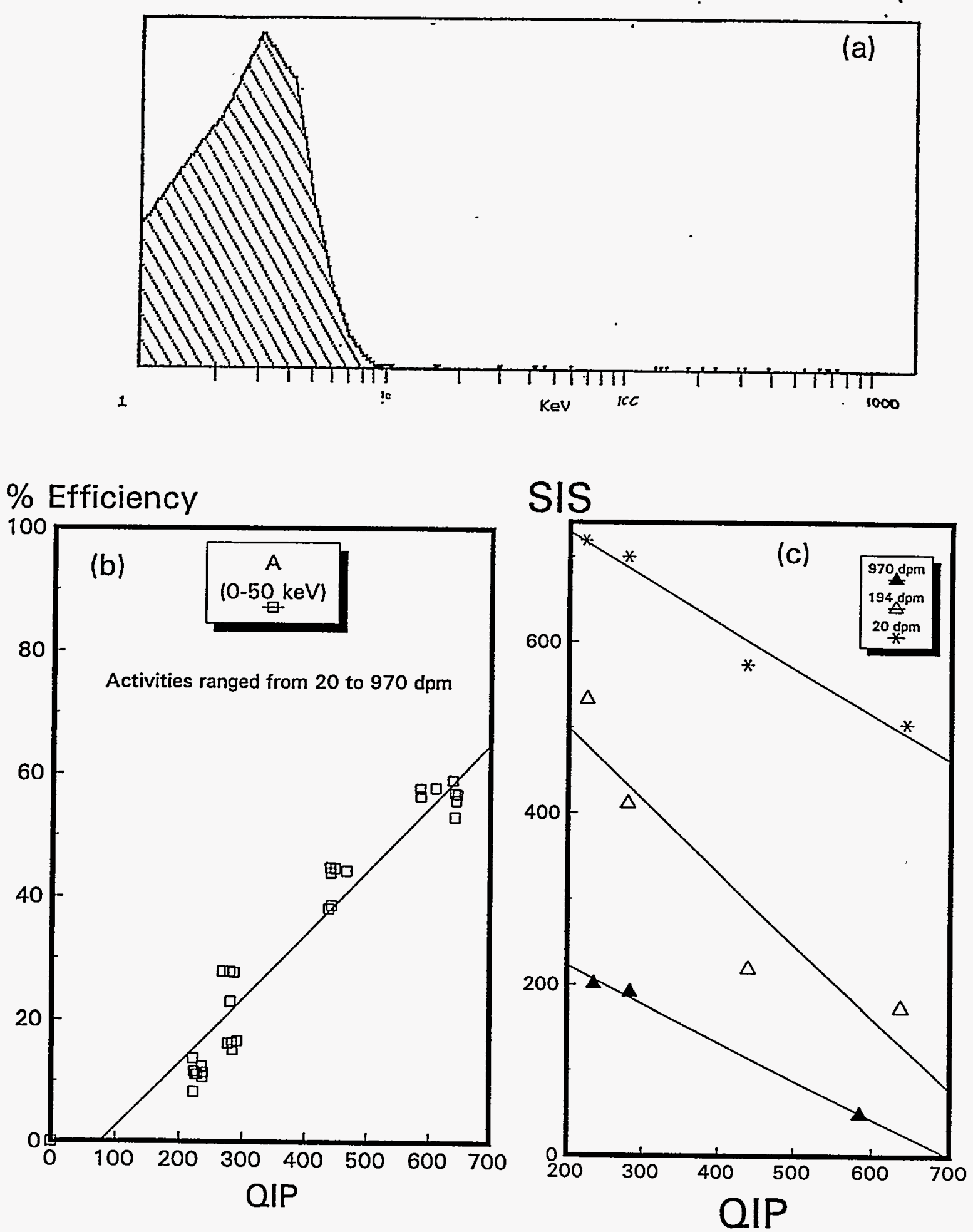

Figure B5. ${ }^{55} \mathrm{Fe}$ Nuclide Spectral Data: (a), (b), (c) same as Figure B1. 


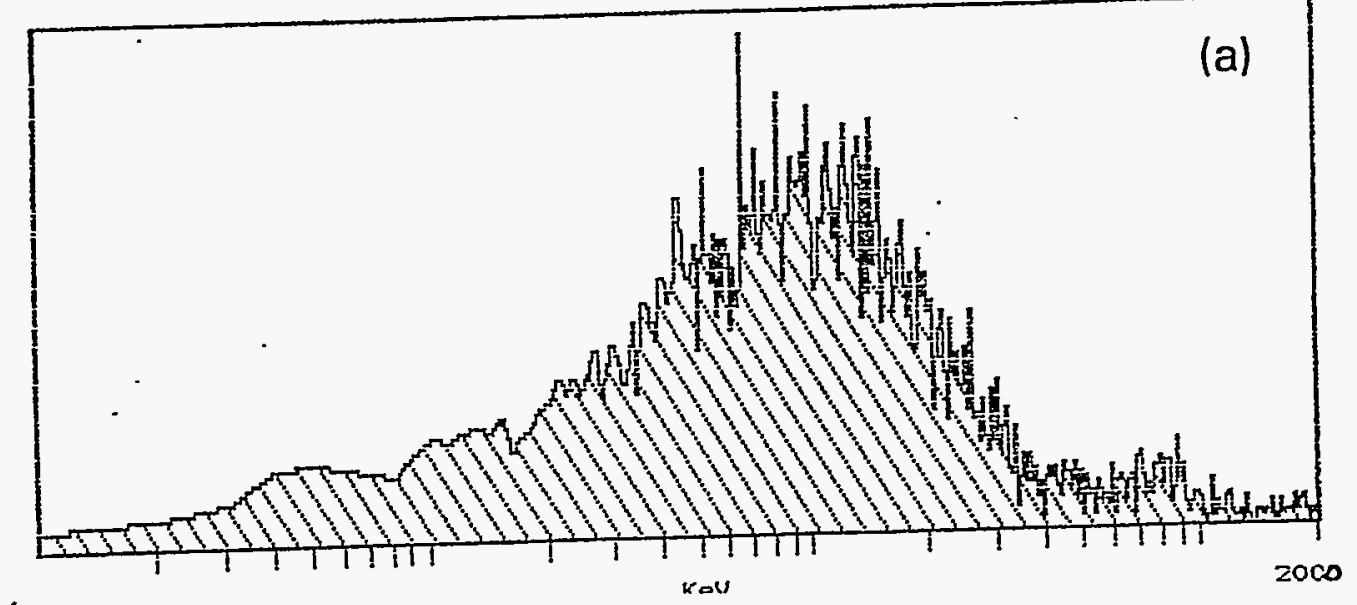

\% Efficiency

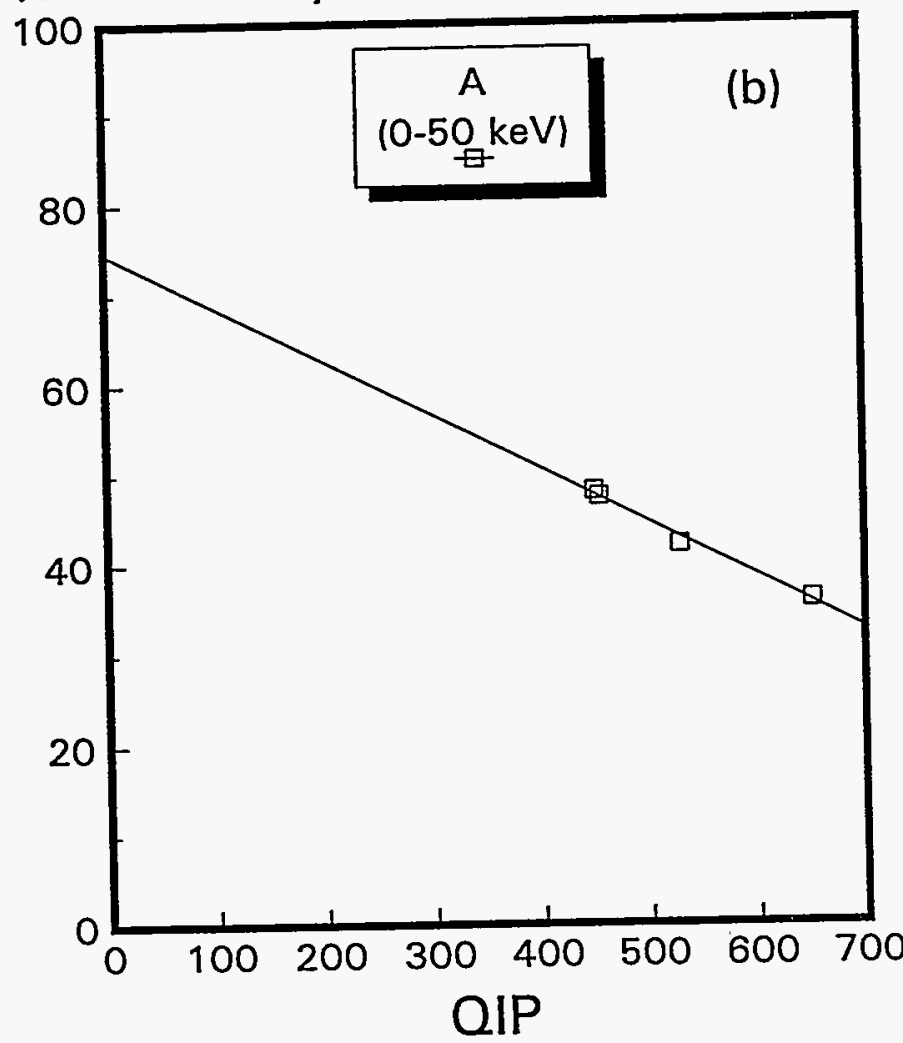

SIS

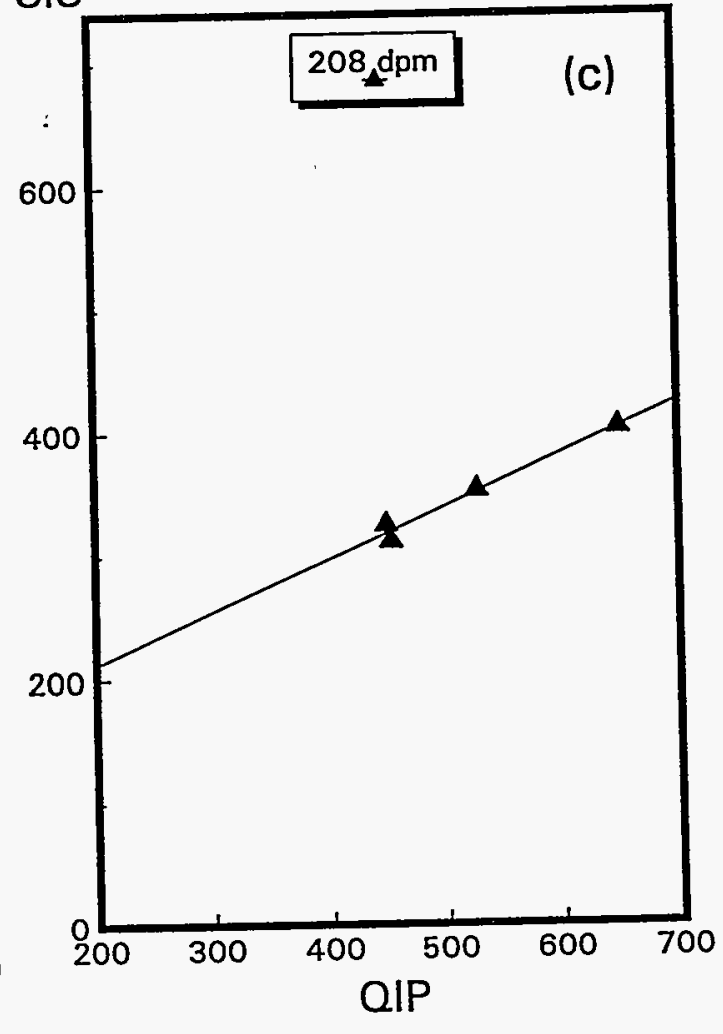

Figure B6. ${ }^{59} \mathrm{Fe}$ Nuclide Spectral Data: (a), (b), (c) same as Figure B1. 


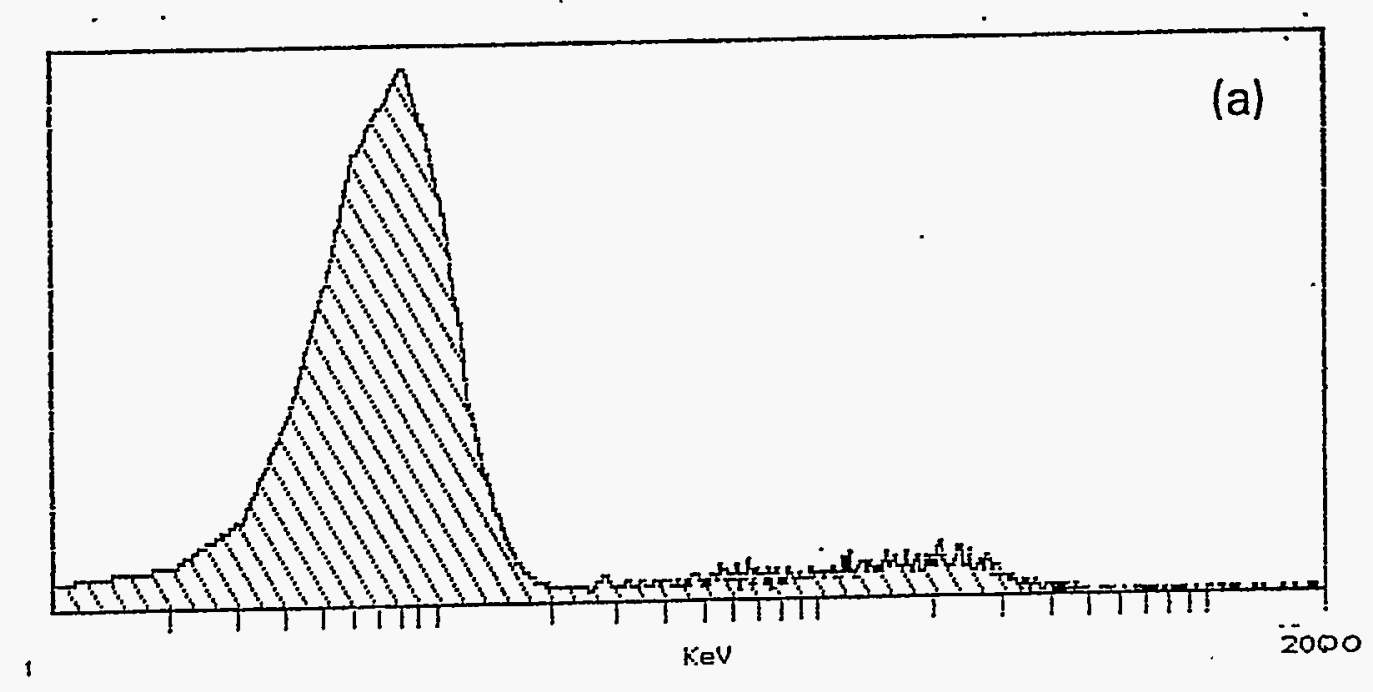

$\%$ Efficiency

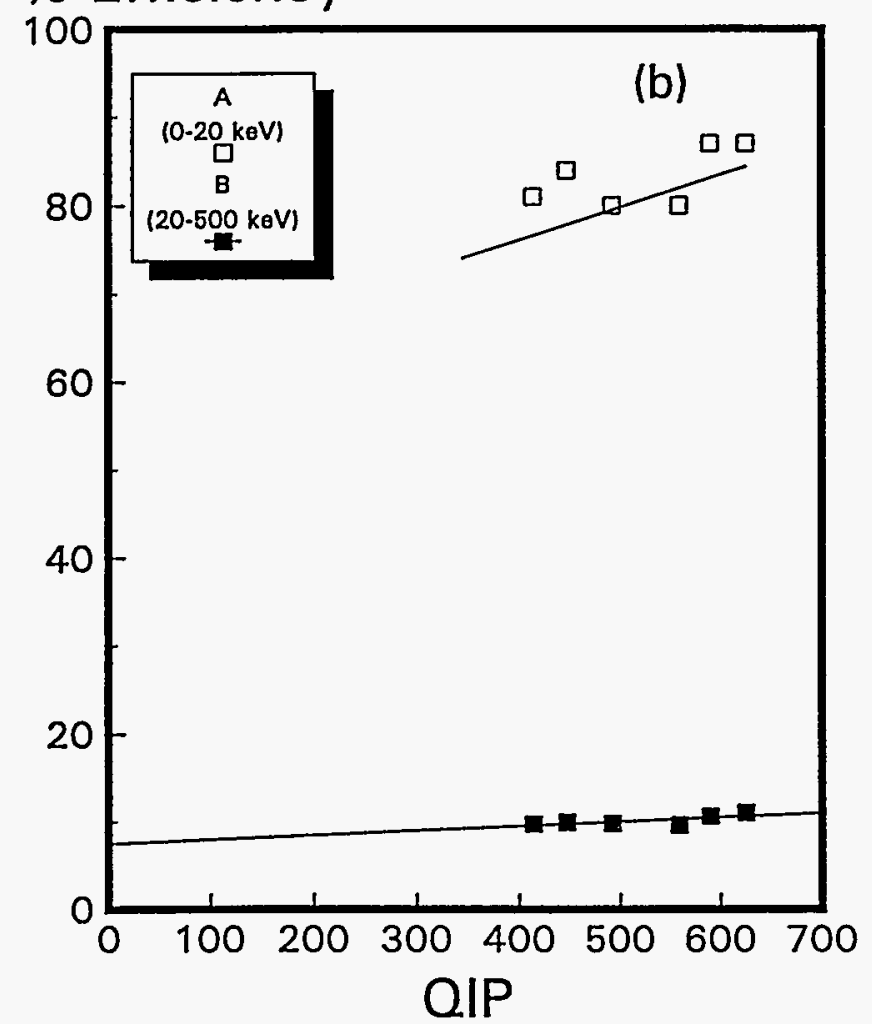

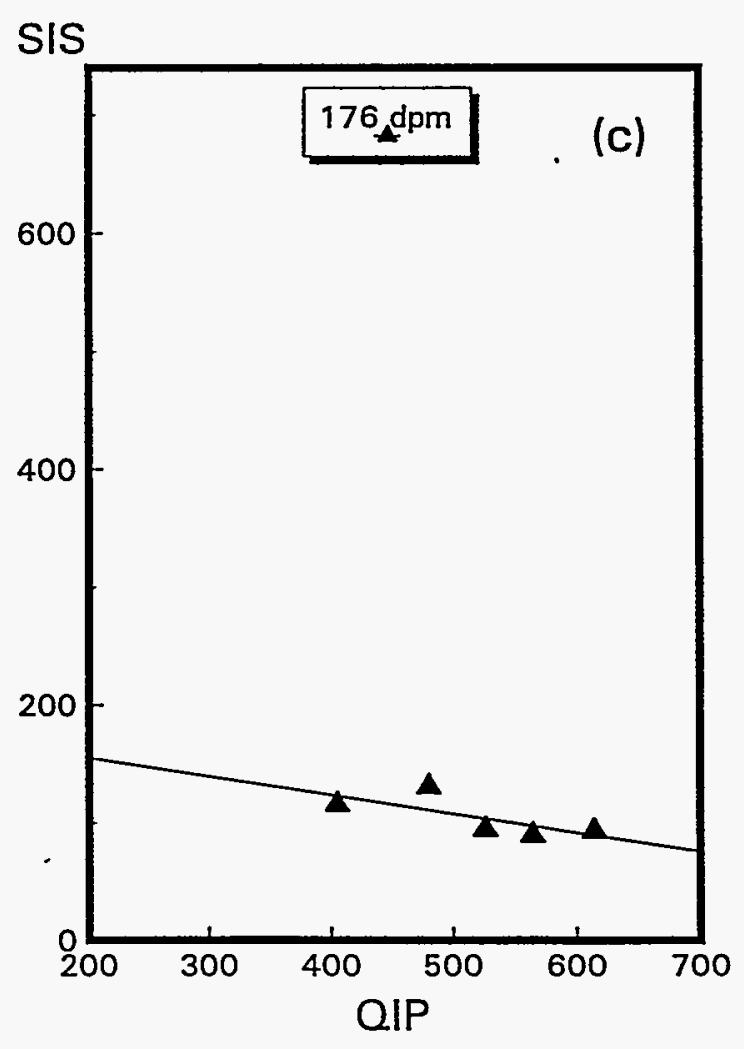

Figure B7. ${ }^{85} \mathrm{Sr}$ Nuclide Spectral Data: (a), (b), (c) same as Figure B1. 


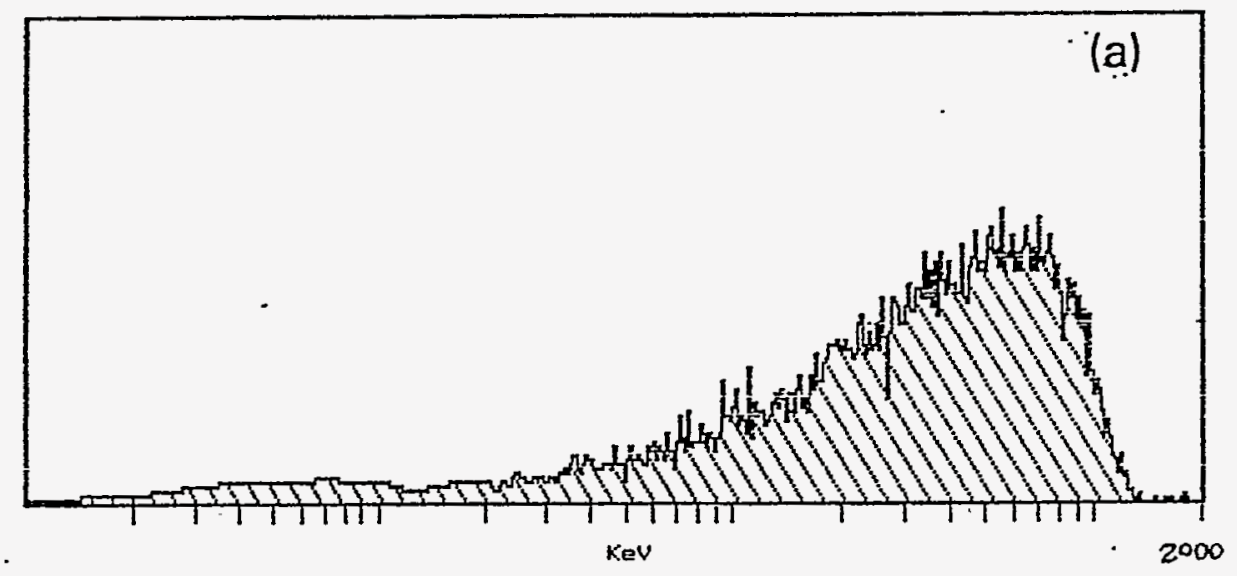

$\%$ Efficiency

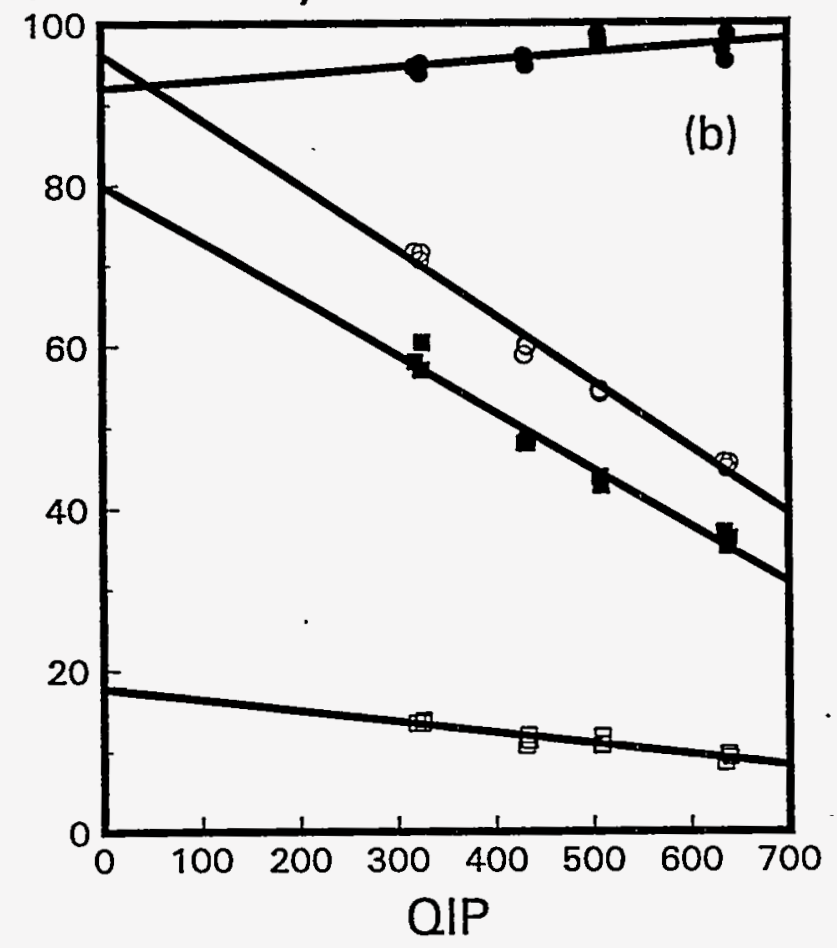

SIS

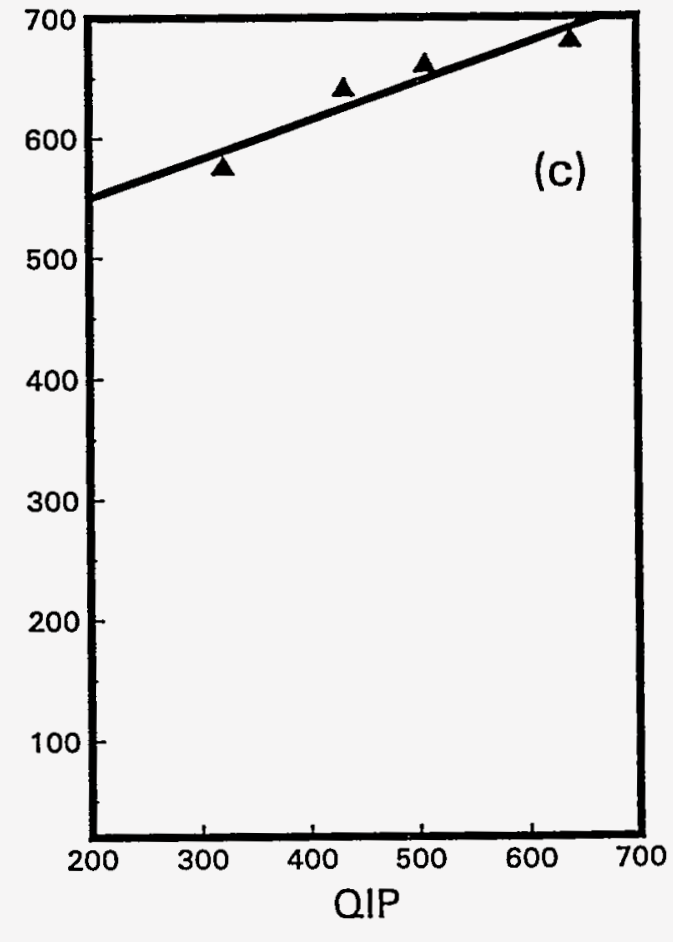

Figure B8. ${ }^{89} \mathrm{Sr}$ Nuclide Spectral Data: (a), (b), (c) same as Figure B1. 

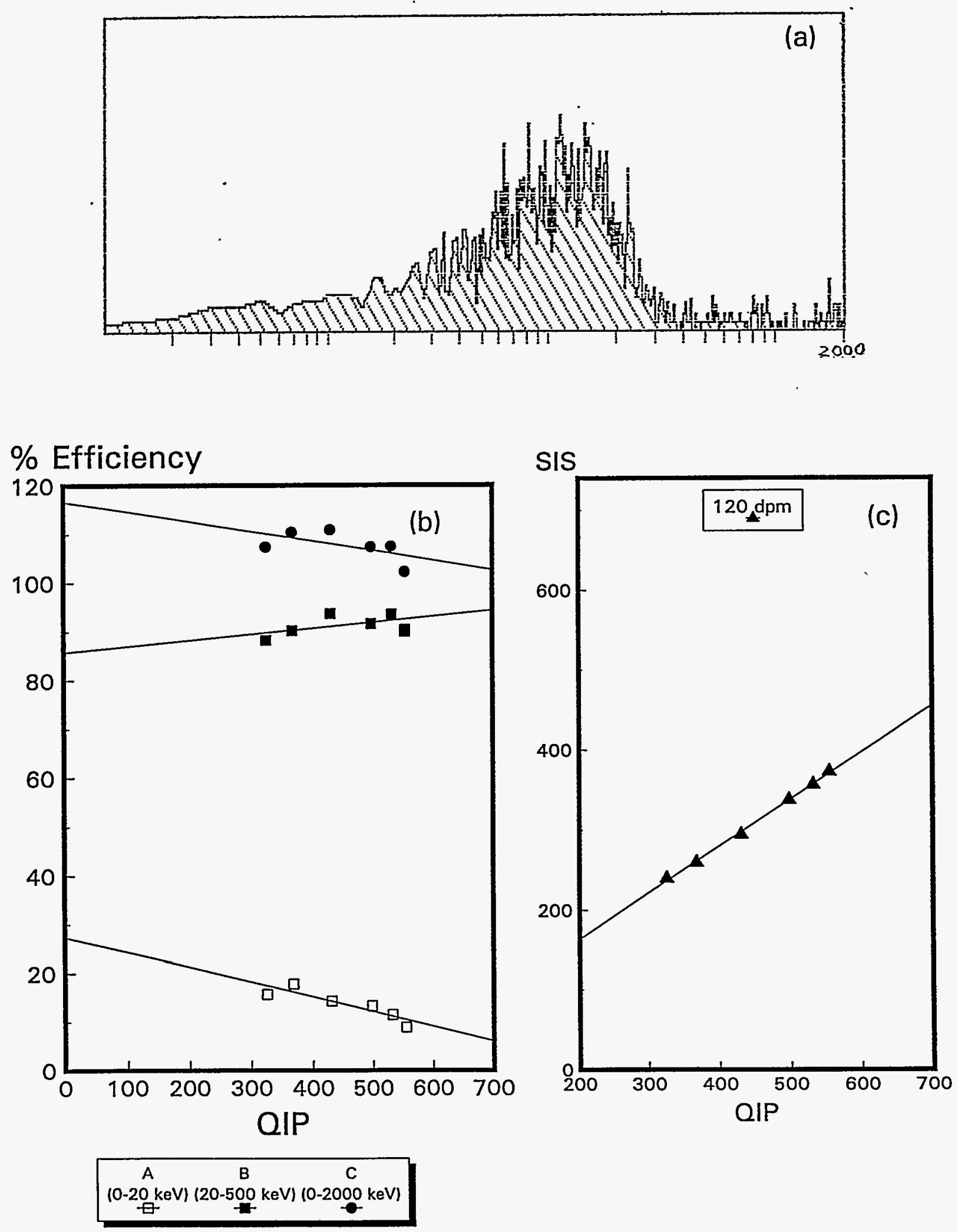

Figure B9. ${ }^{90} \mathrm{Sr}$ Nuclide Spectral Data $2 \mathrm{~h}$ post separation of ${ }^{9 \mathrm{Y}}$ :
(a), (b), (c) same as Figure B1. 


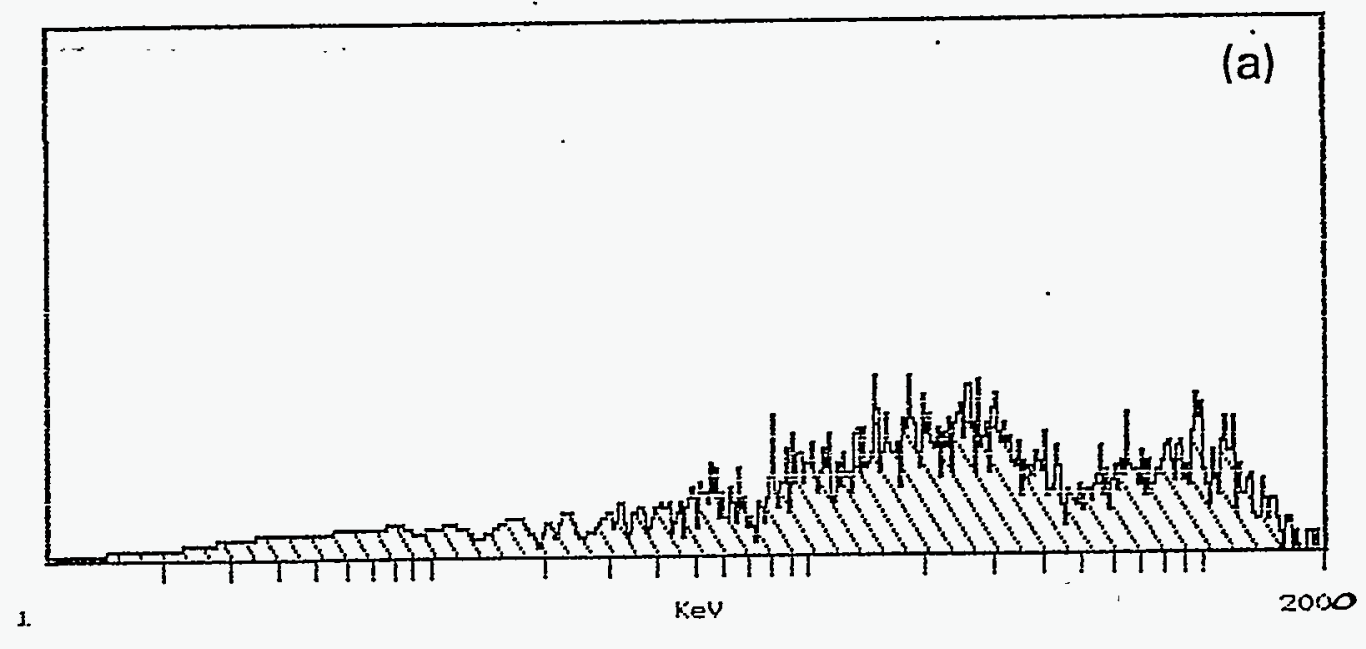

\% Efficiency

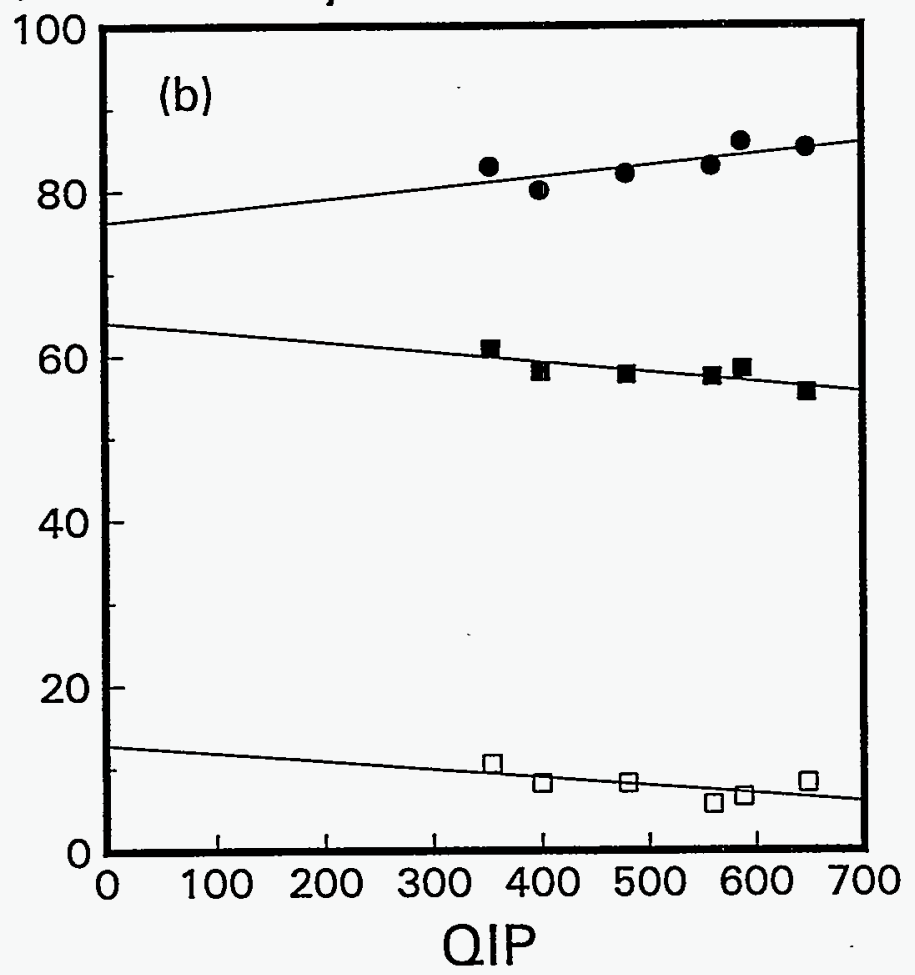

SIS

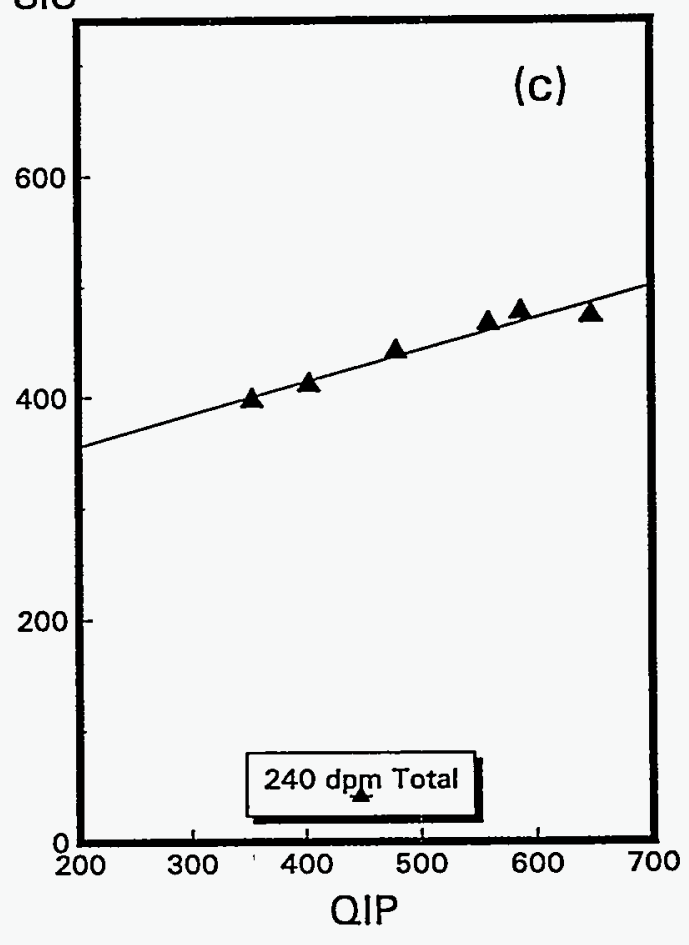

Figure B10. ${ }^{90} \mathrm{Sr} / \mathrm{Y}$ Nuclide Spectral Data: (a), (b), (c) same as Figure B1. 

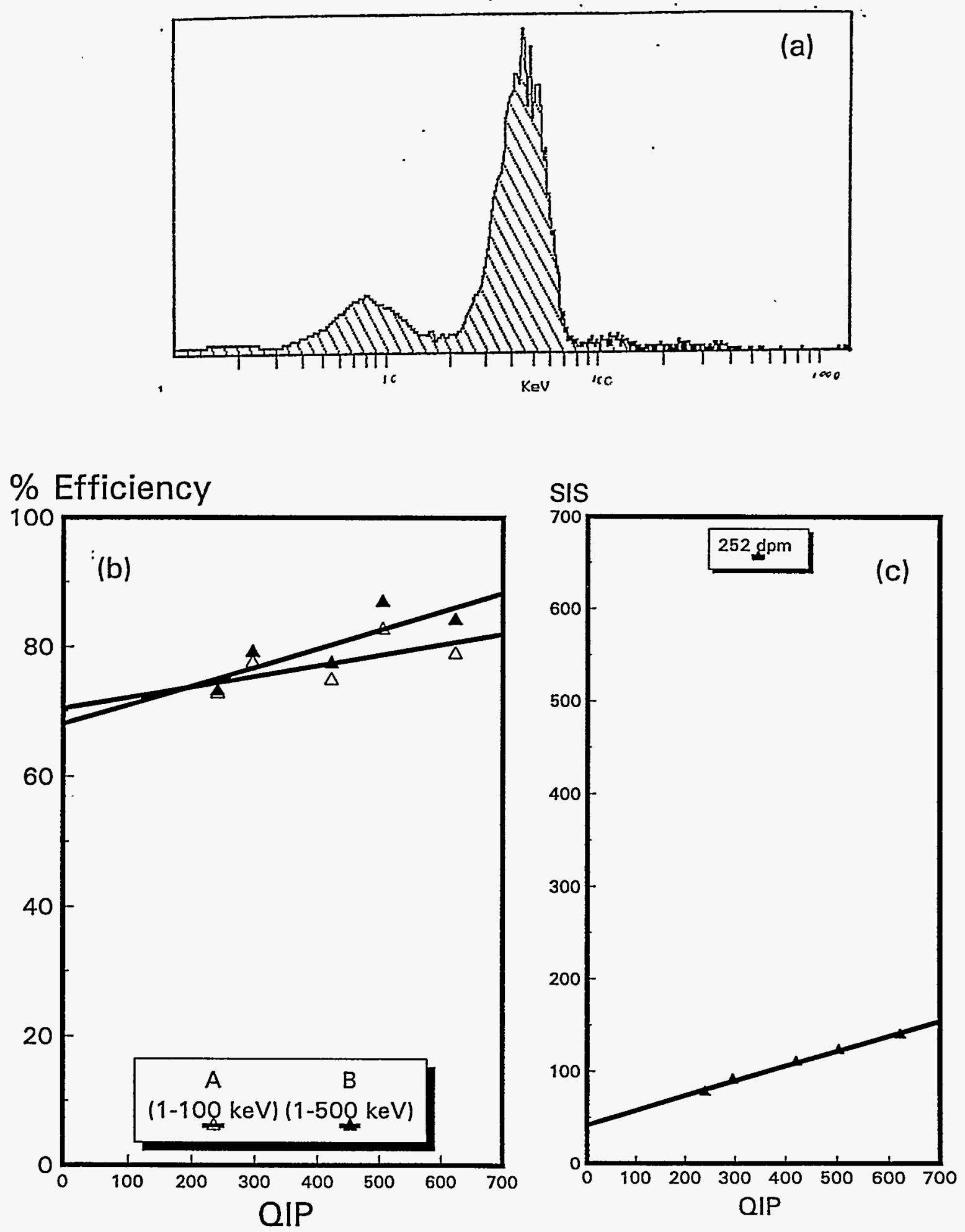

Figure B11. ${ }^{95 \mathrm{~m}}$ Tc Nuclide Spectral Data: (a), (b), (c) same as Figure B1. 

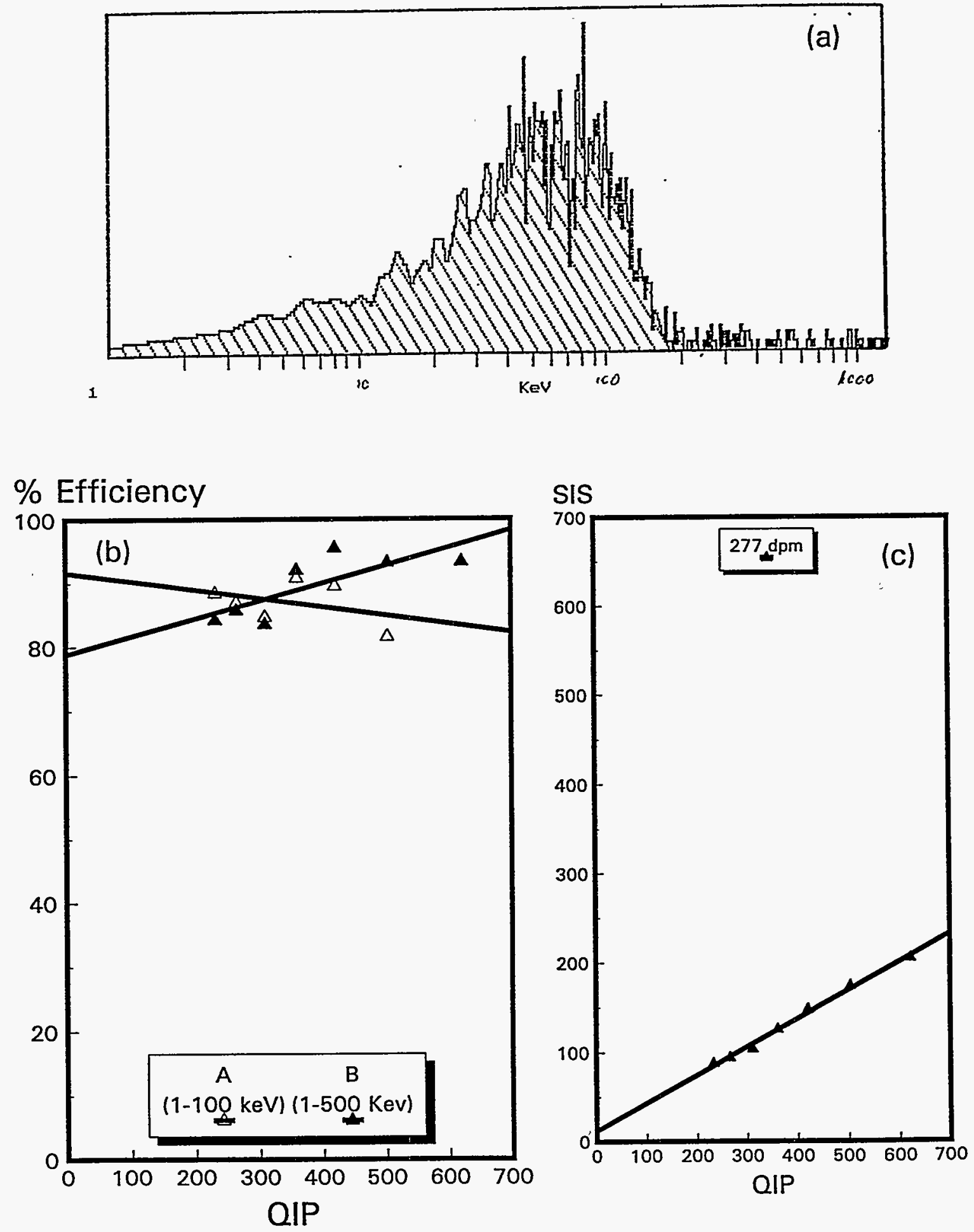

Figure B12. ${ }^{99}$ Tc Nuclide Spectral Data: (a), (b), (c) same as Figure B1. 


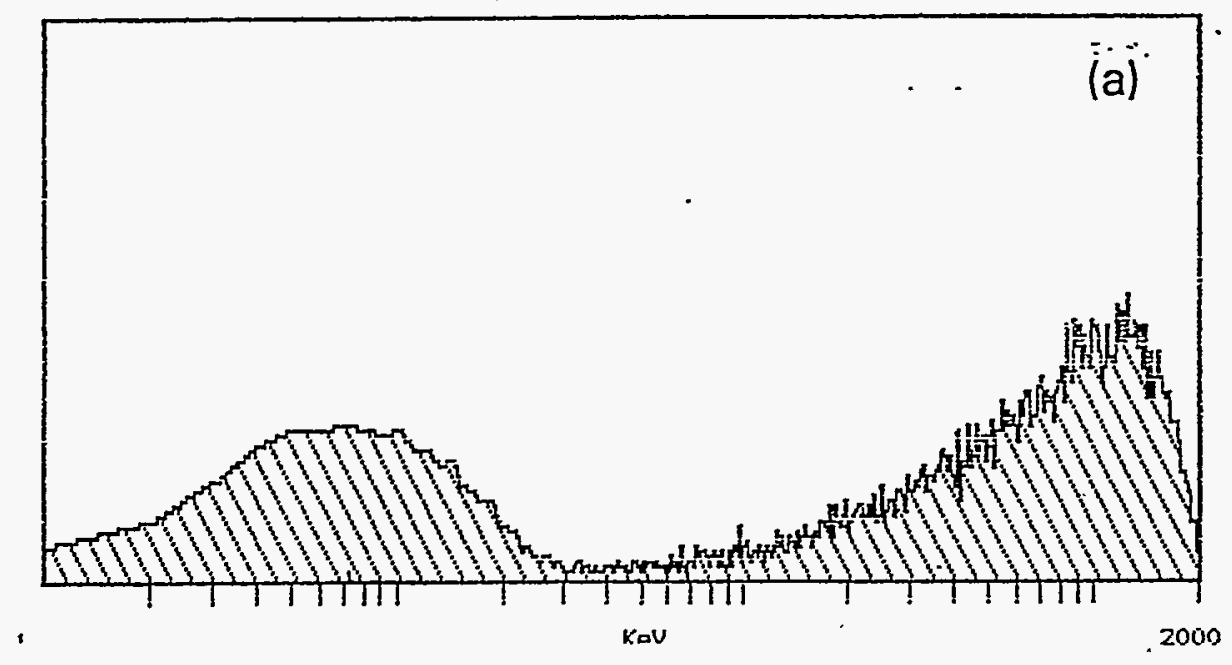

\% Efficiency

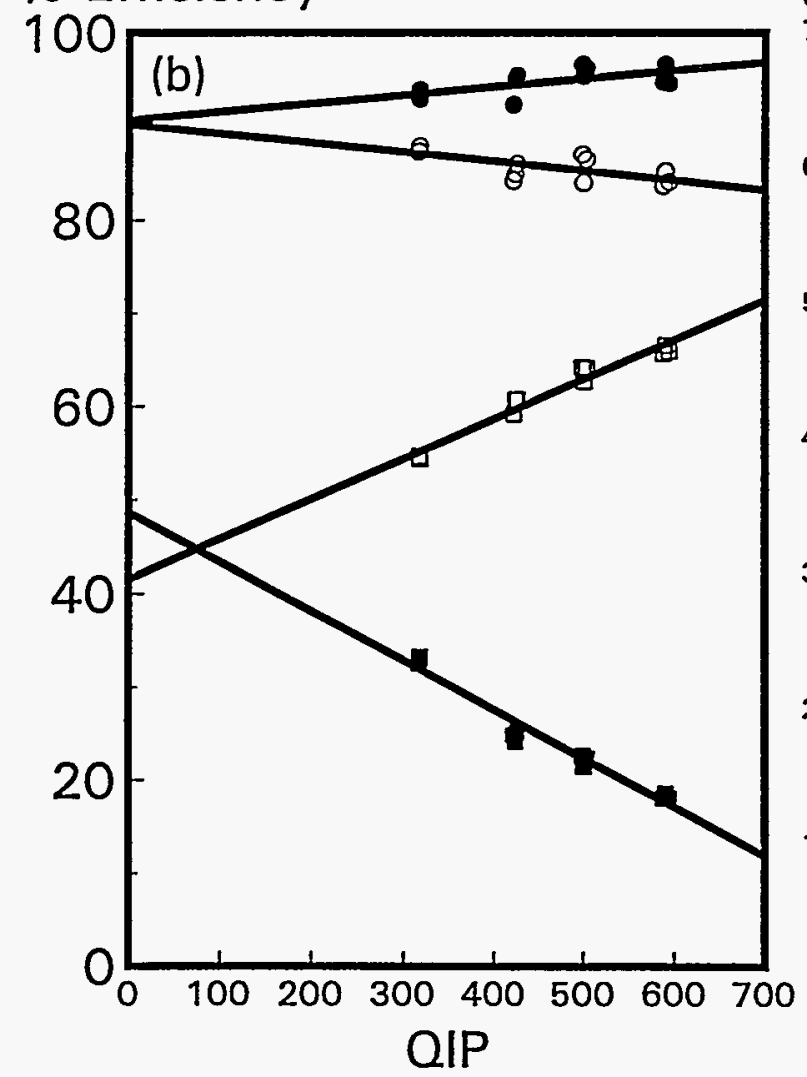

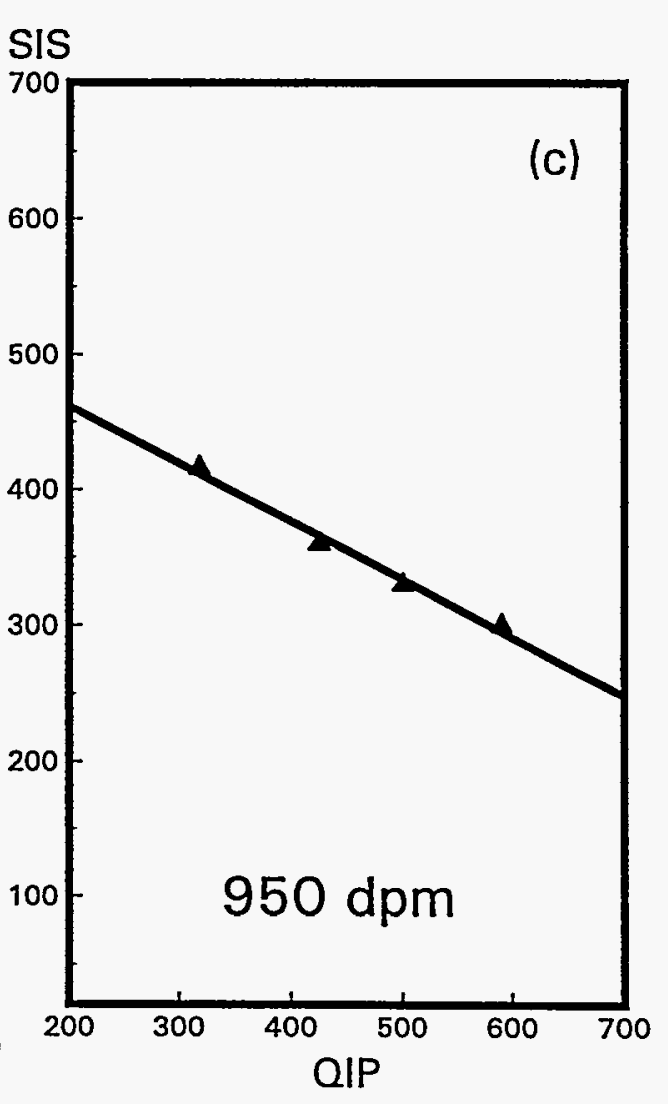

\begin{tabular}{cccc|}
\hline A & B & C & D \\
$(1-35 \mathrm{keV})$ & $(35-300 \mathrm{keV})$ & $(1-300 \mathrm{keV})$ & $(1-2000 \mathrm{keV})$ \\
\hline
\end{tabular}

Figure B13. ${ }^{106}$ Ru/Rh Nuclide Spectral Data: (a), (b), (c) same as Figure B1. 


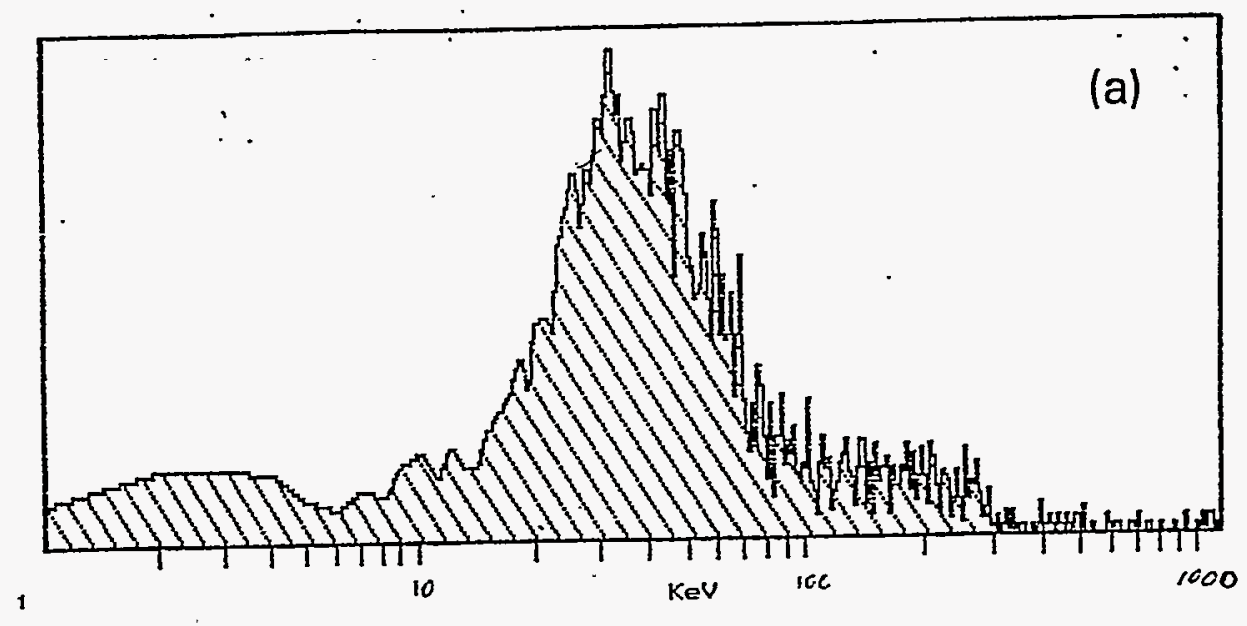

\% Efficiency

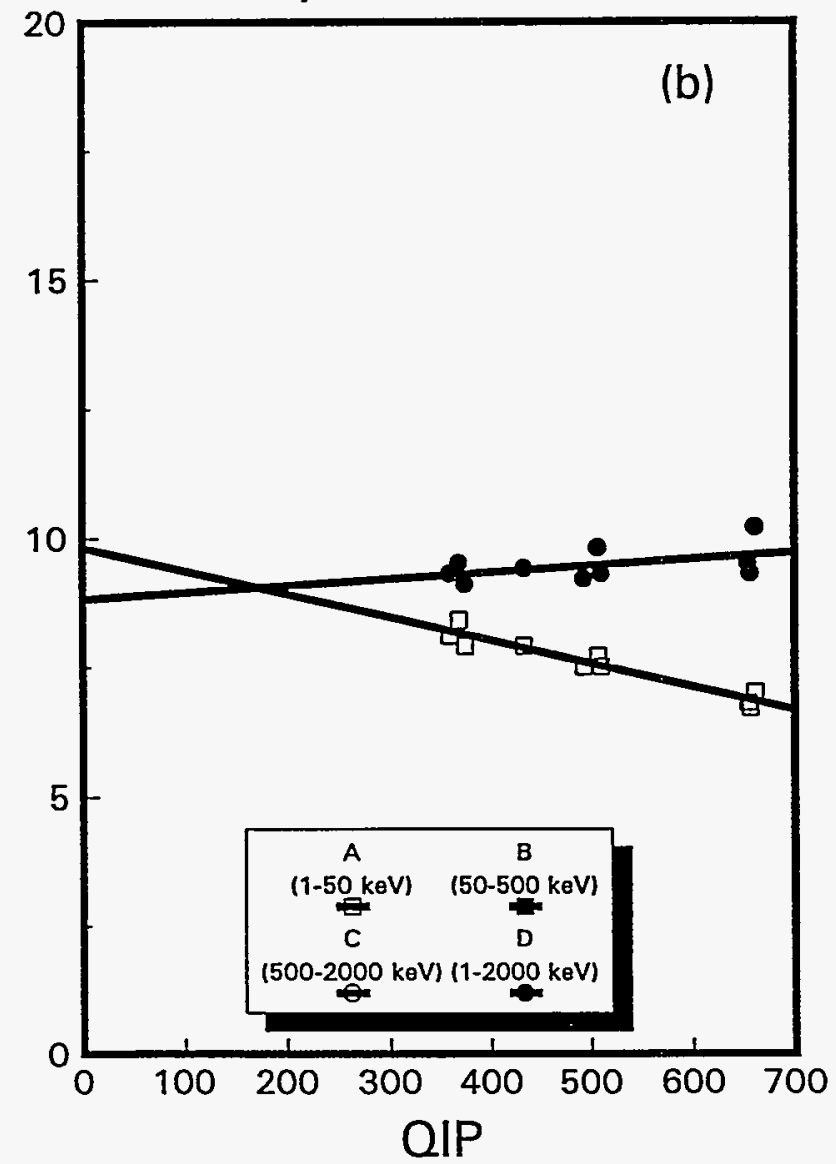

SIS

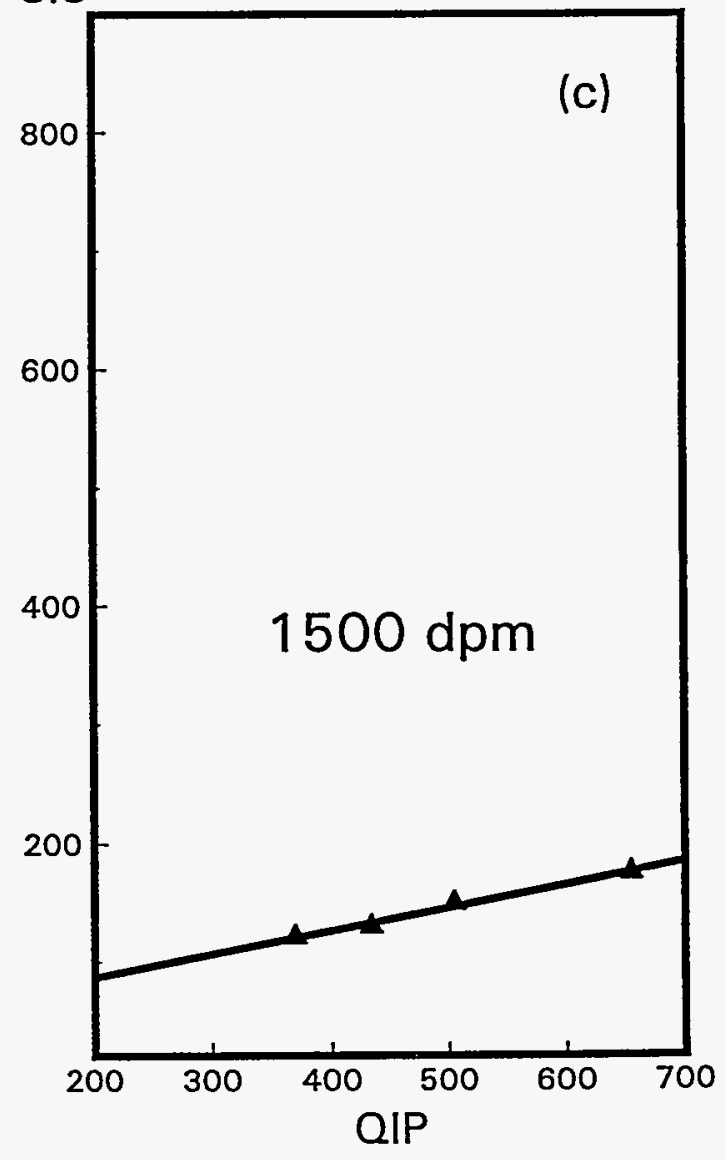

Figure B14. ${ }^{133} \mathrm{Ba}$ Nuclide Spectral Data: (a), (b), (c) same as Figure B1. 

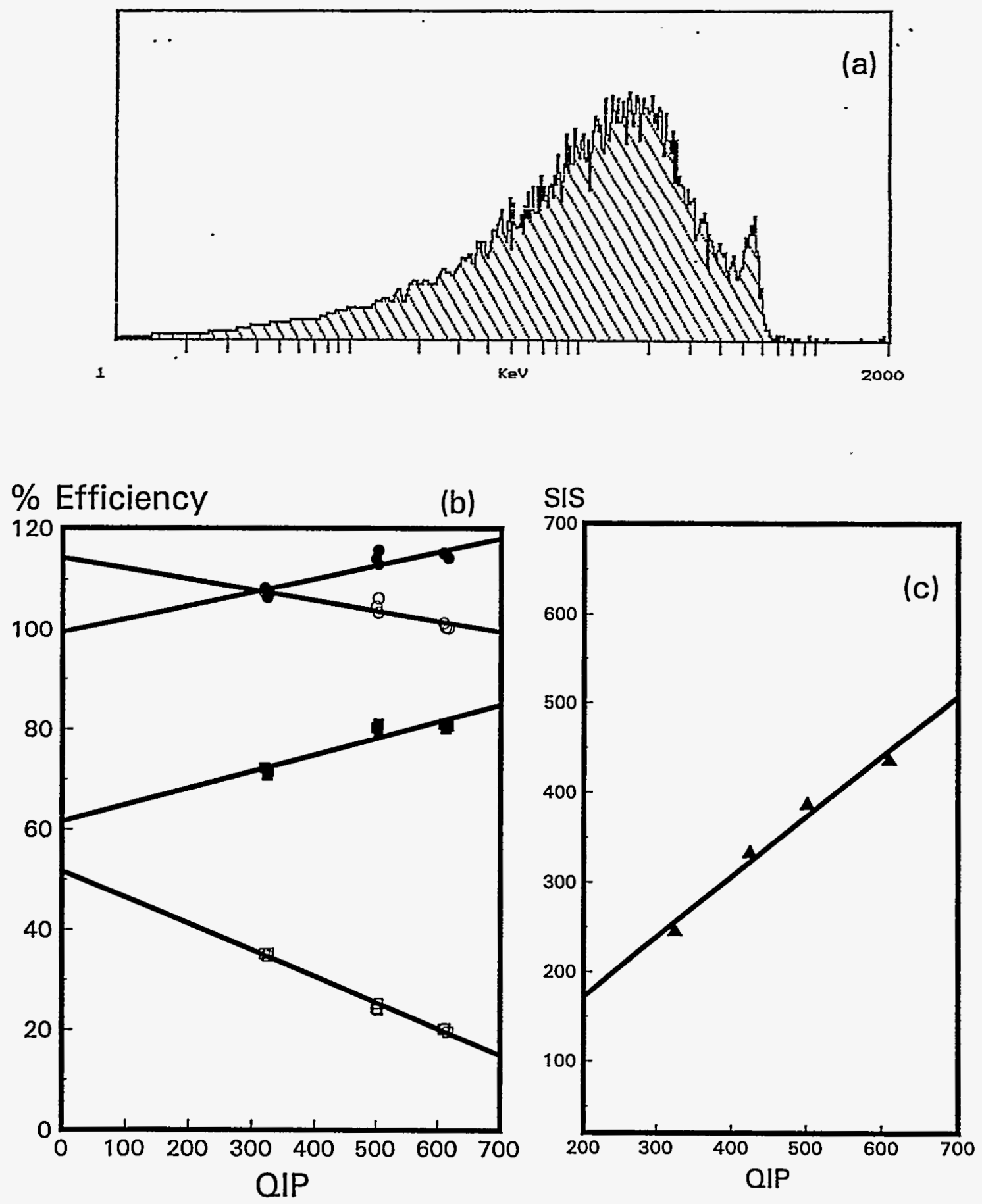

$\begin{array}{cccc}A & B & C & D \\ (1-35 \mathrm{keV}) & (35.300 \mathrm{keV}) & (1-300 \mathrm{keV}) & (1-2000 \mathrm{keV})\end{array}$

Figure B15. ${ }^{137} \mathrm{Cs} / \mathrm{Ba}$ Nuclide Spectral Data:(a), (b), (c) same as Figure B1. 

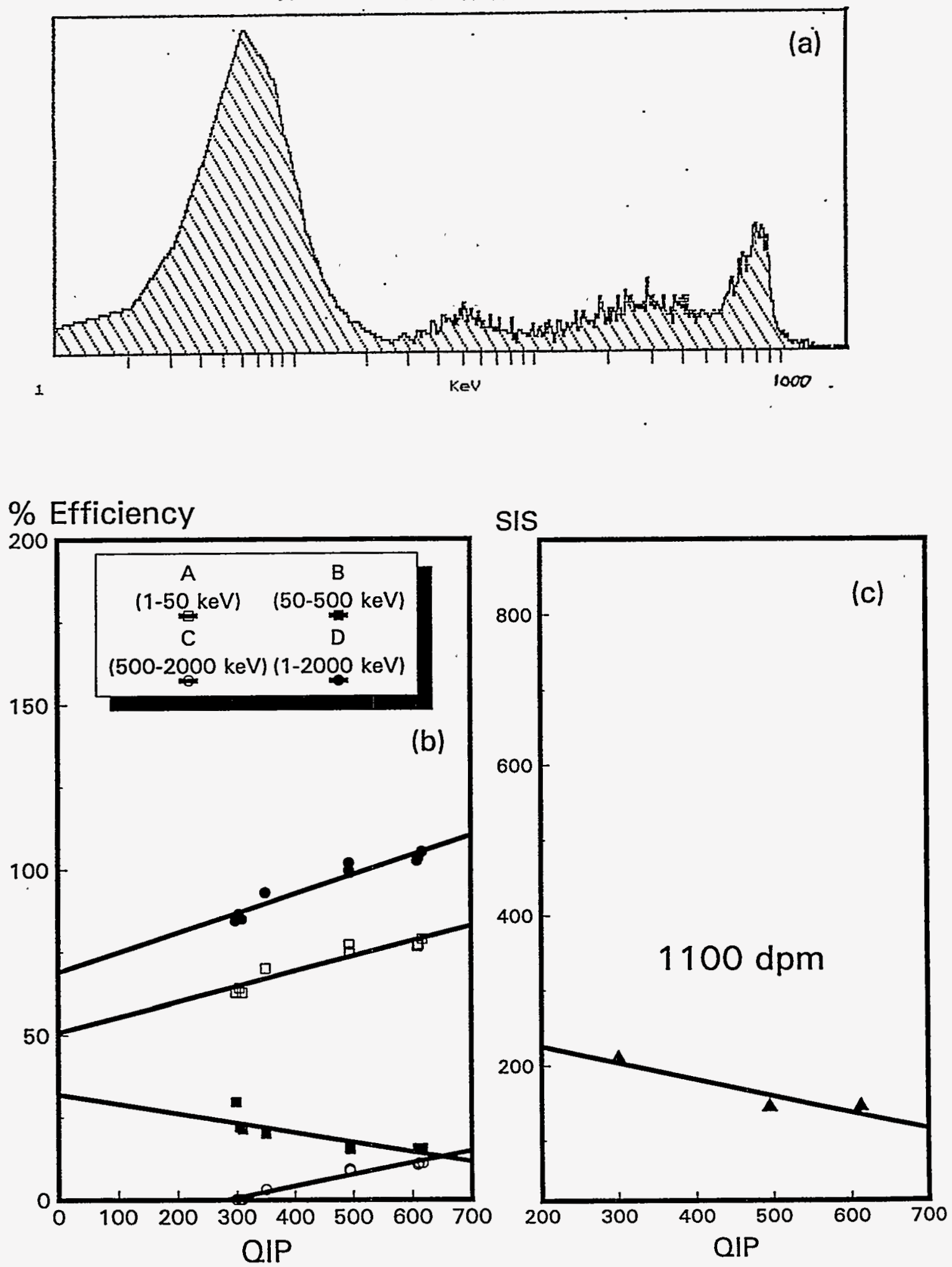

Figure B16. ${ }^{207} \mathrm{Bi}$ Nuclide Spectral Data: (a), (b), (c) same as Figure B1. 

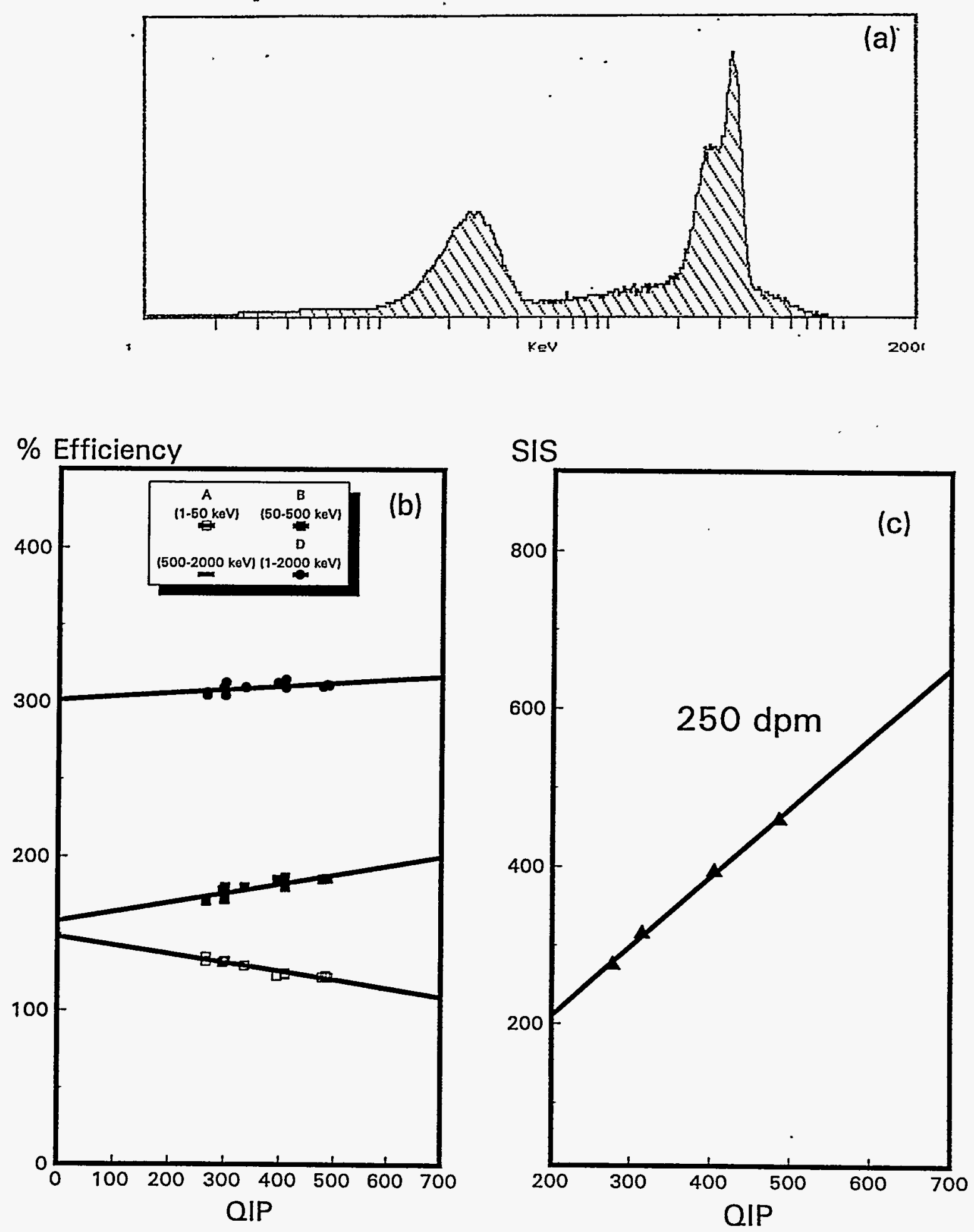

Figure B17. ${ }^{210} \mathrm{~Pb} / \mathrm{Bi} / \mathrm{Po}$ Nuclide Spectral Data:

(a), (b), (c) same as Figure B1. 

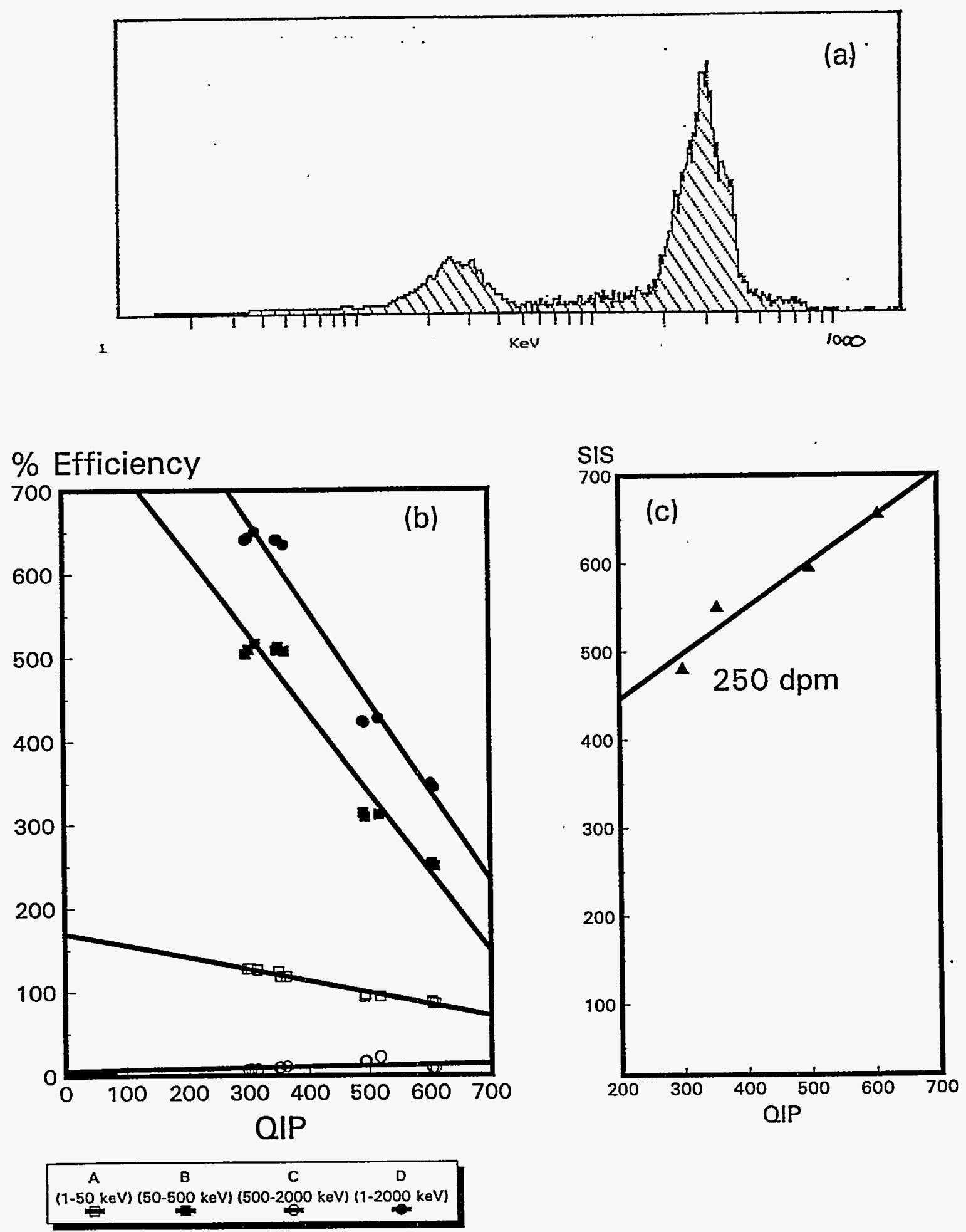

Figure B18. ${ }^{226}$ Ra/Progeny Nuclide Spectral Data:

(a), (b), (c) same as Figure B1. 

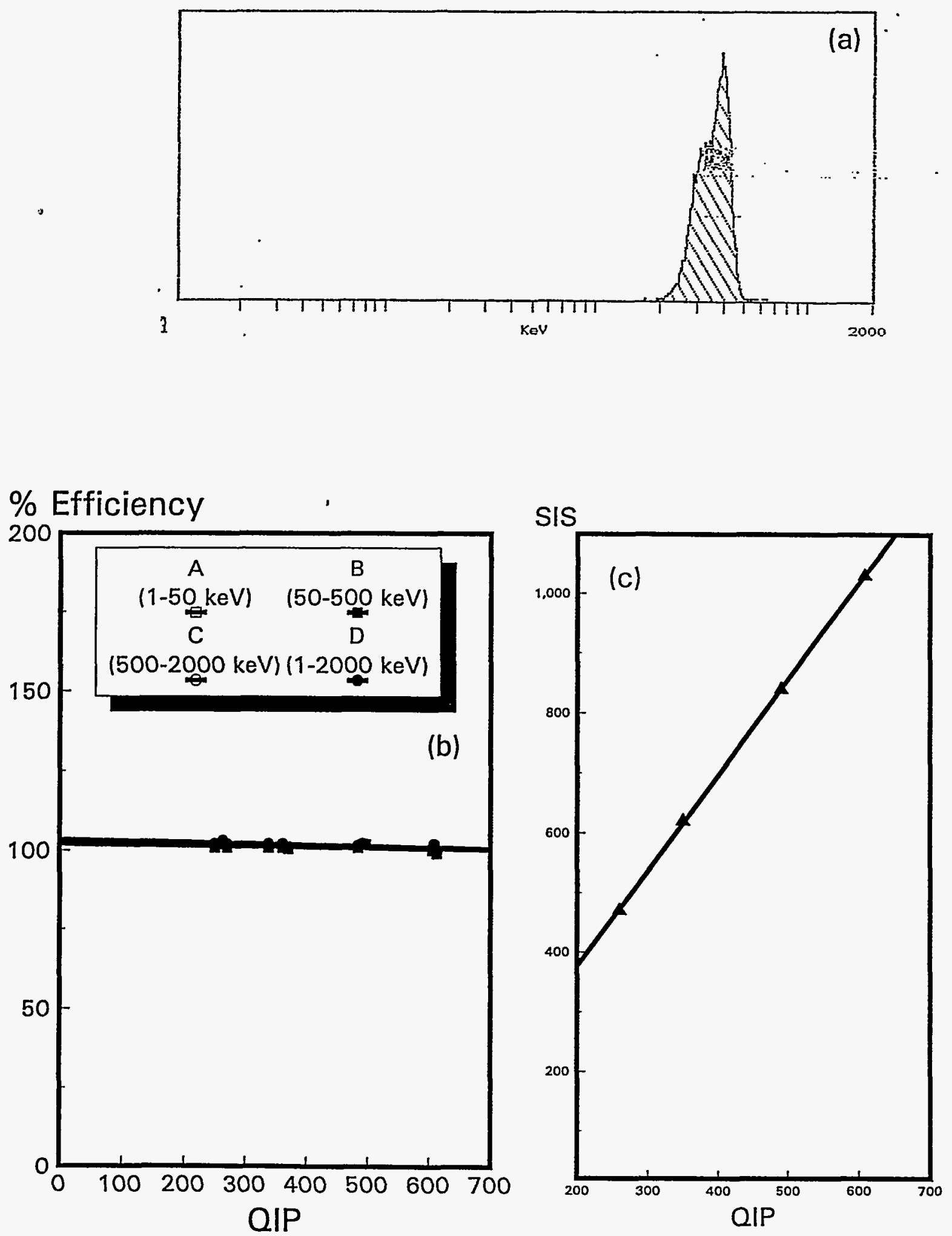

Figure B19. ${ }^{232} \mathrm{U}$ Nuclide Spectral Data: (a), (b), (c) same as Figure B1. 

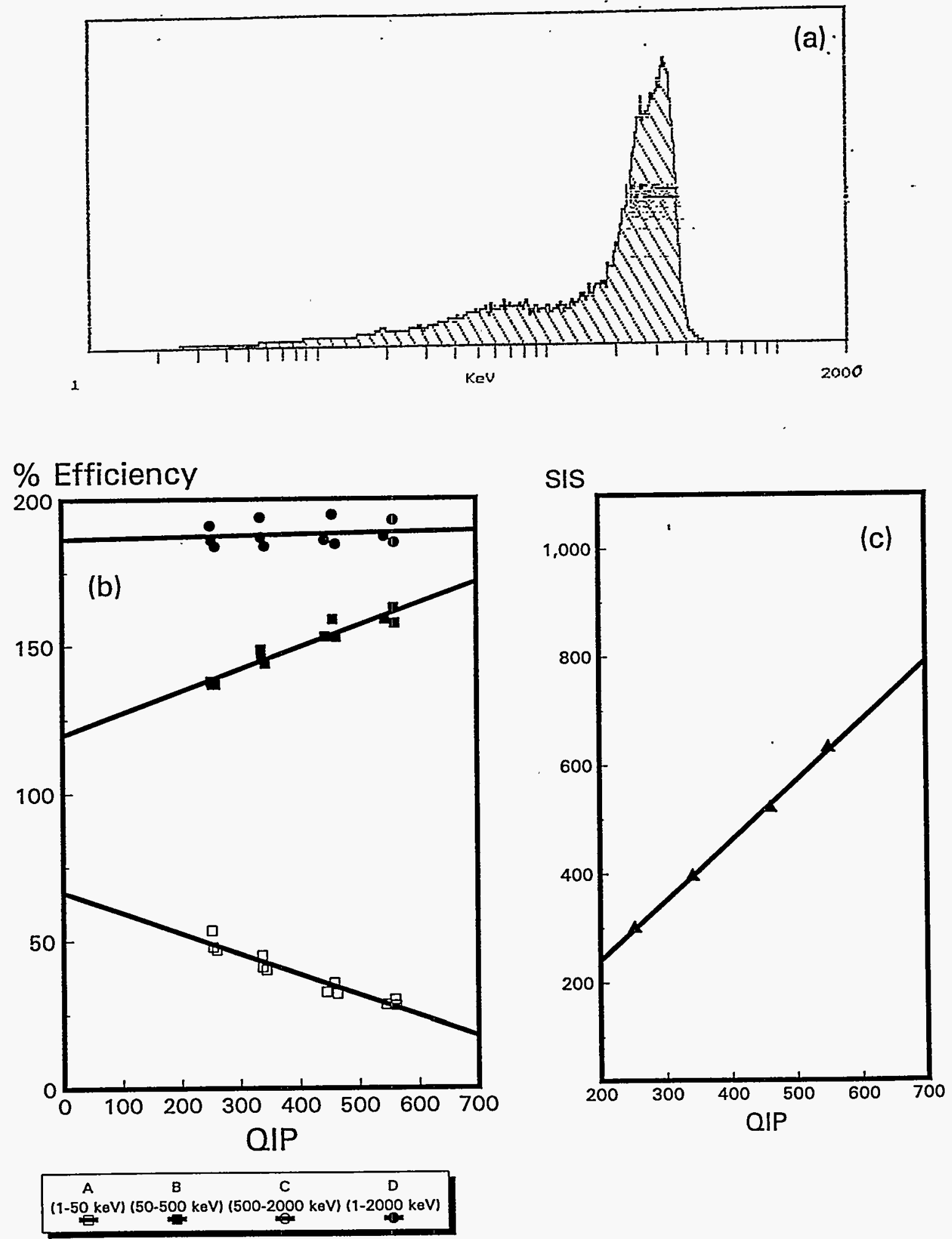

Figure B20. ${ }^{237} \mathrm{~Np}$ Nuclide Spectral Data: (a), (b), (c) same as Figure B1. 

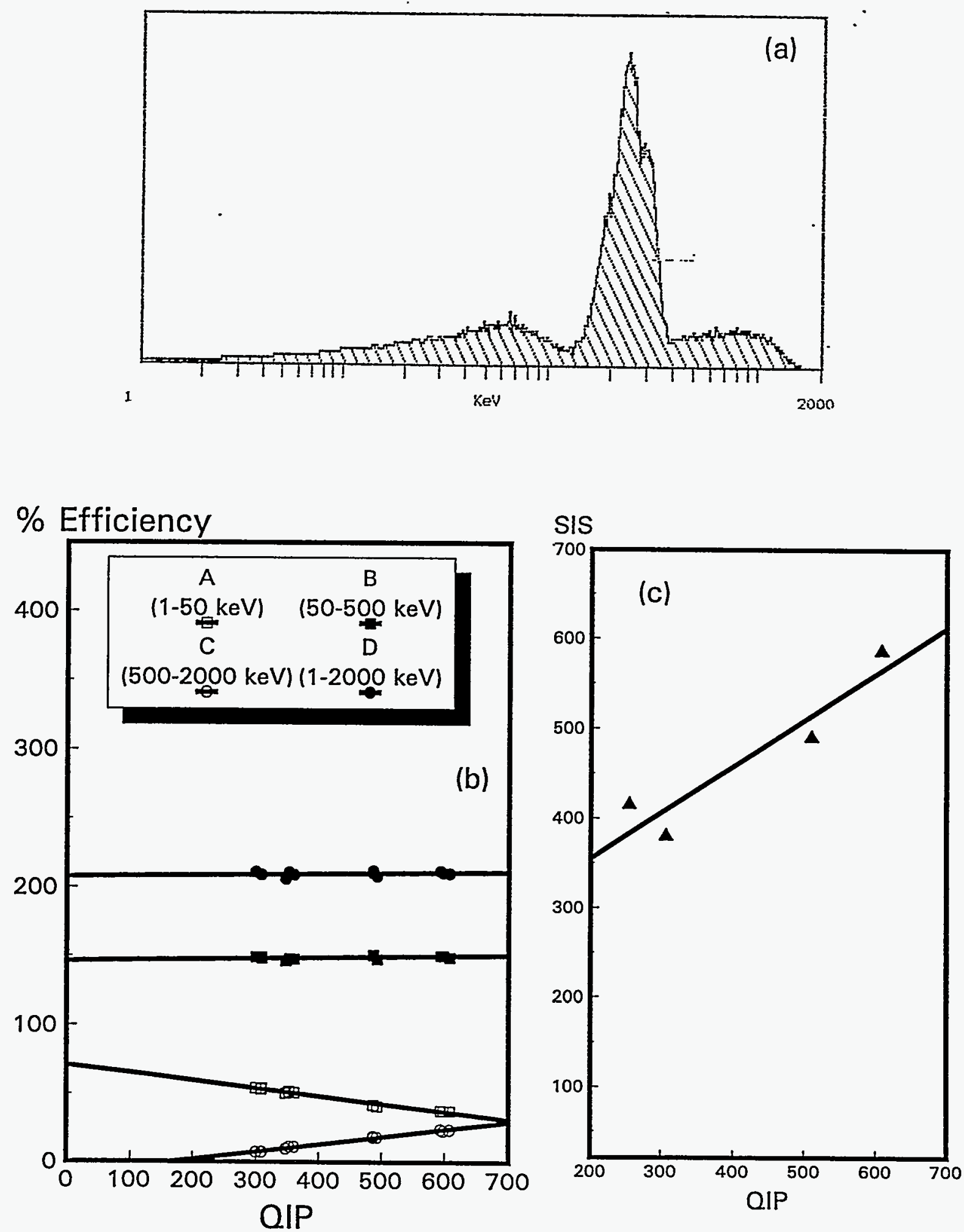

Figure B21. Nat U Nuclide Spectral Data: (a), (b), (c) same as Figure B1. (nat $U=48.2 \%{ }^{238} U+2.3 \%{ }^{235} U+49.5 \%{ }^{234} U$ ). 

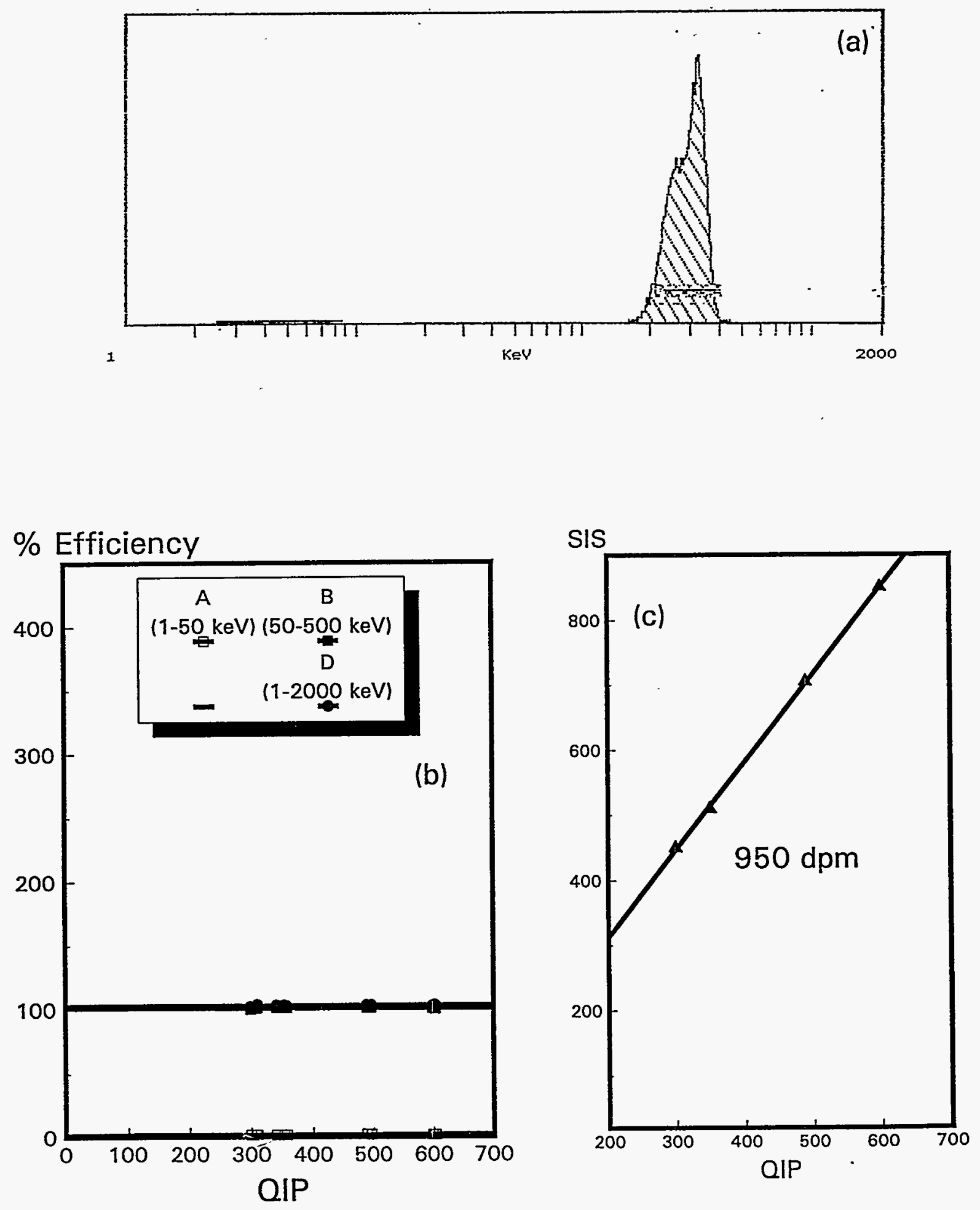

Figure B22. ${ }^{242} \mathrm{Pu}$ Nuclide Spectral Data: (a), (b), (c) same as Figure B1. 


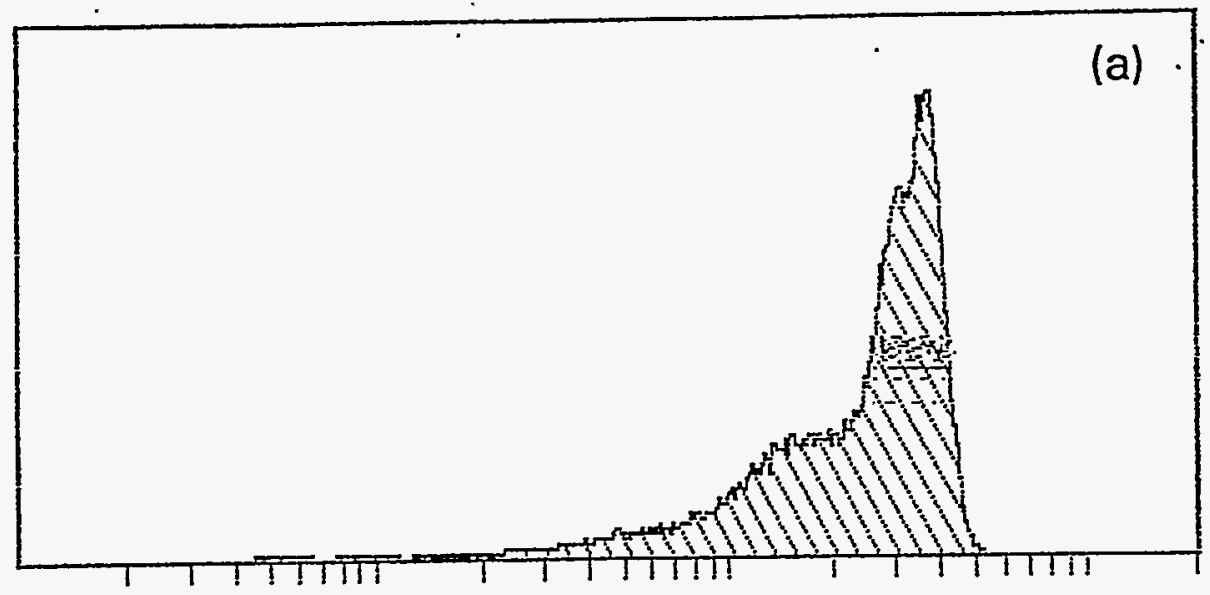

\% Efficiency

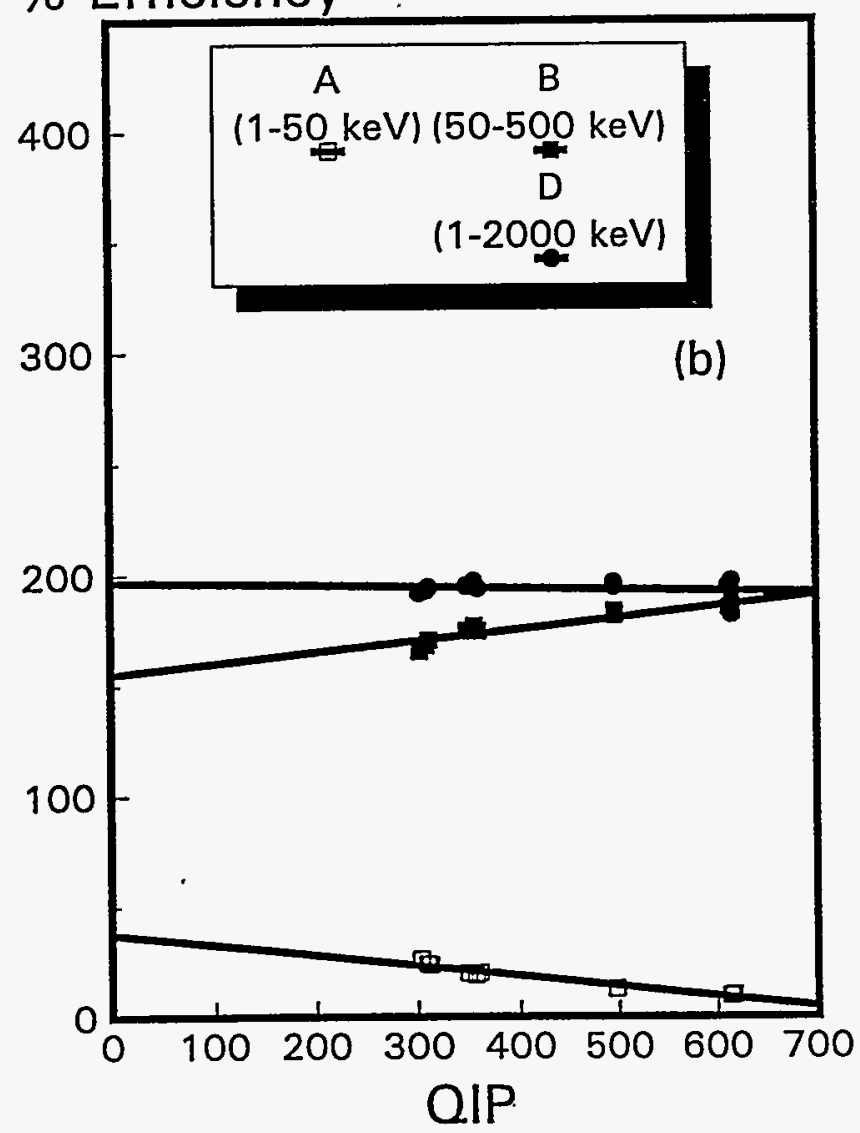

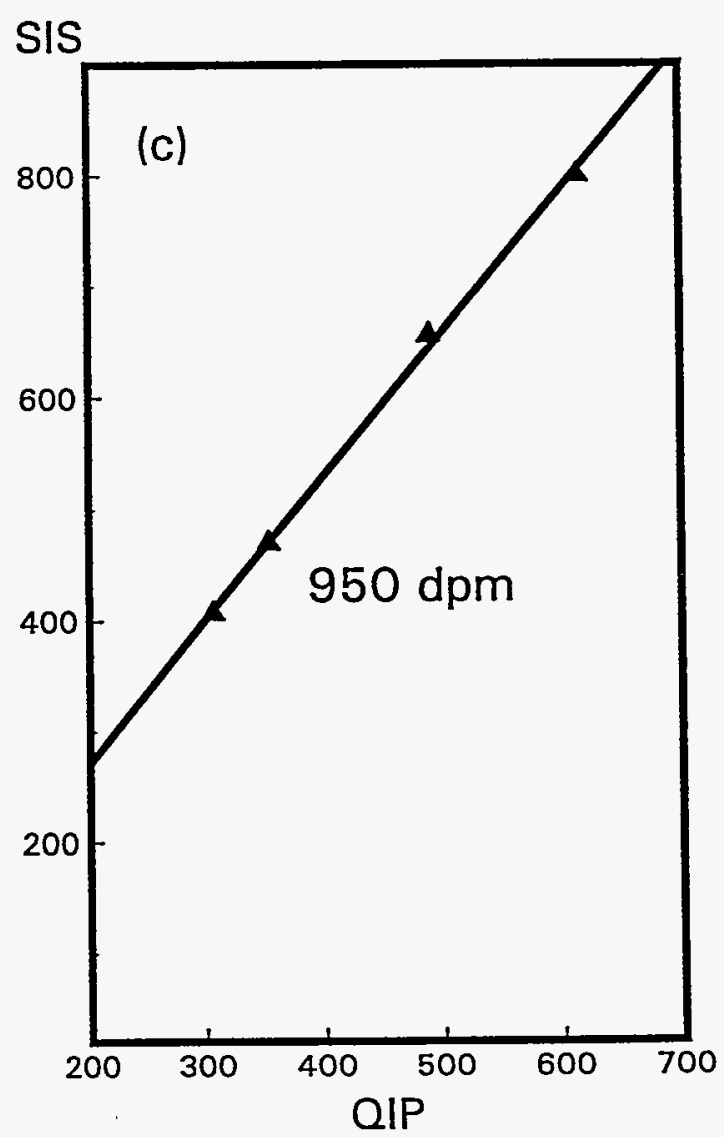

Figure B23. ${ }^{243} \mathrm{Am}$ Nuclide Spectral Data: (a), (b), (c) same as Figure B1. 


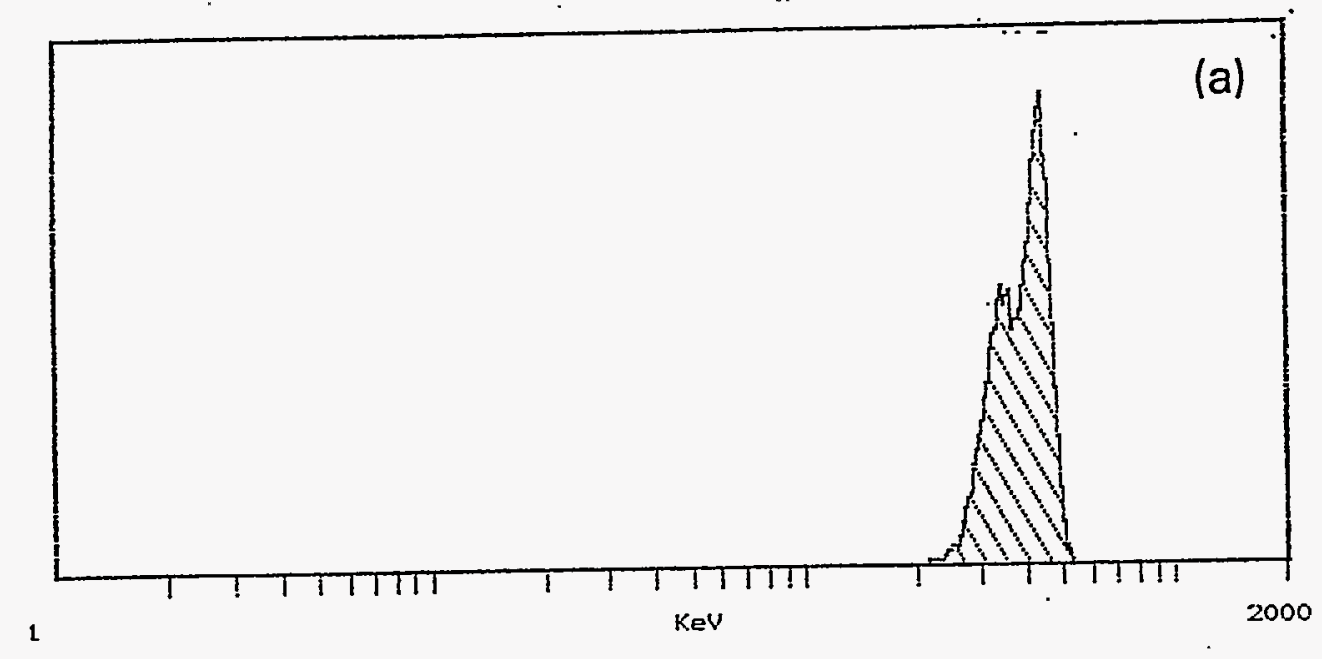

$\%$ Efficiency

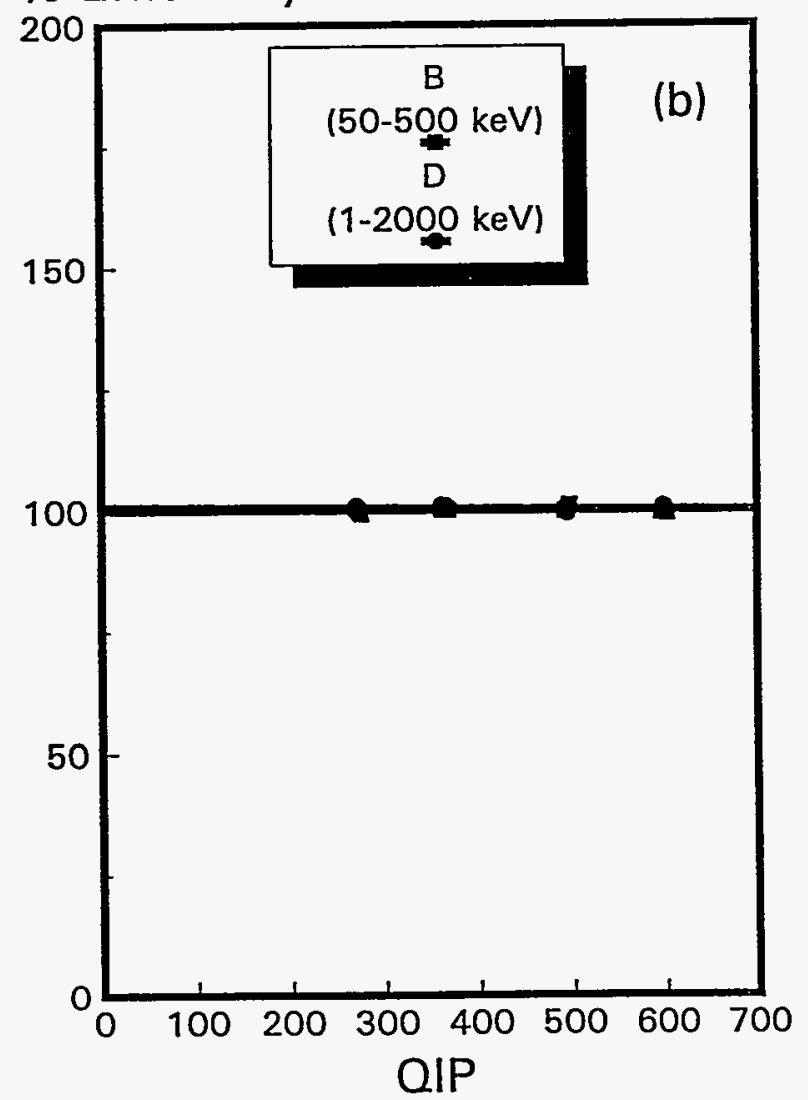

SIS

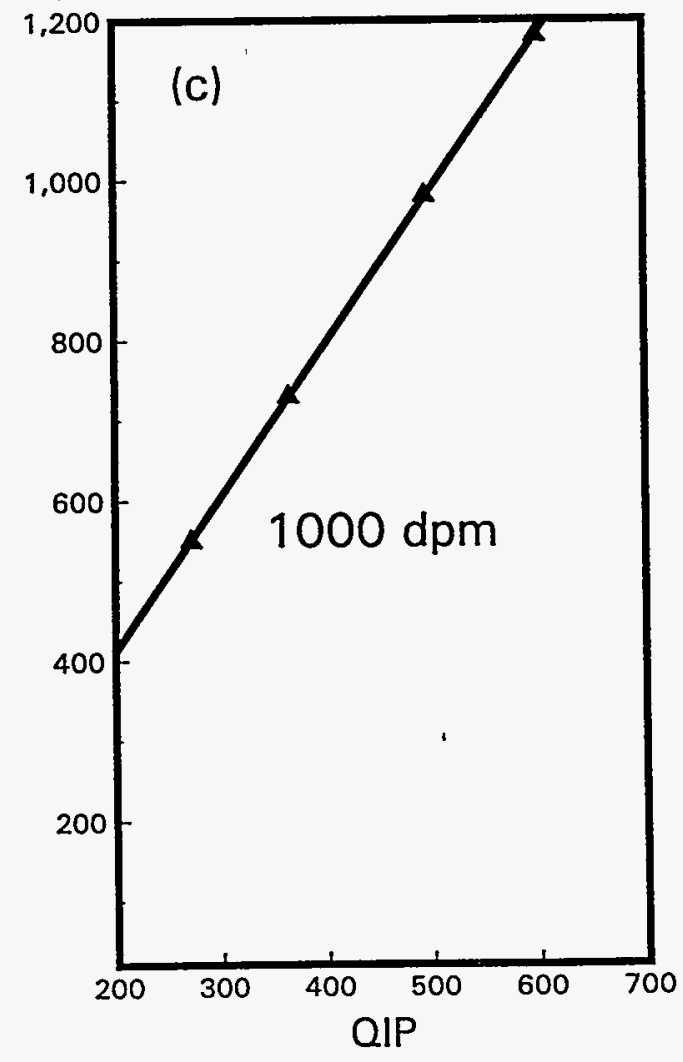

Figure B24. ${ }^{244} \mathrm{Cm}$ Nuclide Spectral Data: (a), (b), (c) same as Figure B1. 